\title{
FACEBOOK CAUSES PROTESTS
}

Leopoldo Fergusson

Carlos Molina

\section{LATIN AMERICAN AND THE CARIBBEAN ECONOMIC ASSOCIATION}

April 2021

The views expressed herein are those of the authors and do not necessarily reflect the views of the Latin American and the Caribbean Economic Association. Research published in this series may include views on policy, but LACEA takes no institutional policy positions.

LACEA working papers are circulated for discussion and comment purposes. Citation of such a paper should account for its provisional character. A revised version may be available directly from the author.

(C) 2021 by Leopoldo Fergusson and Carlos Molina. All rights reserved. Short sections of text, not to exceed two paragraphs, may be quoted without explicit permission provided that full credit, including (C) notice, is given to the source. 
LACEA WORKING PAPER SERIES No. 0041 April 2021

Facebook causes protests

Leopoldo Fergusson

Universidad de los Andes, Department of Economics

lfergusson@uniandes.edu.co

Carlos Molina

Massachusetts Institute of Technology, Department of Economics

camolina@mit.edu

\begin{abstract}
Using Facebook's release in a given language as an exogenous source of variation in access to social media where the language is spoken, we show that Facebook has had a significant and sizable positive impact on citizen protests. By exploiting variation in a large sample of countries during close to 15 years and combining both aggregate and individual-level data, we confirm the external validity of previous research documenting this effect for specific contexts along a number of dimensions: geographically, by regime type, temporally, and by the socioeconomic characteristics of both countries and social media users. We find that "coordination" effects that rest on the "social" nature of social media play an important role beyond one-way information transmission, including a "liberation effect" produced by having a direct outlet to voice opinions and share them with others. Finally, we explore the broader political consequences of increased Facebook access, helping assess the welfare consequences of the increase in protests. On the negative side, we find no effects on regime change, democratization or governance. To explain this result, we show there are no effects on other political engagements, especially during critical periods, and that social media access also helps mobilize citizens against opposition groups, especially in less democratic areas. On the positive side, we find that Facebook access decreases internal conflict, with evidence that this reflects increased visibility deterring violence and that social media and the resulting protests help voice discontents that might otherwise turn more violent.
\end{abstract}

JEL Classification: J23; J38; J88.

Keywords: Minimum Wage, Job Separations, New Hires, Worker Flows, Wage Distribution, Wage Spillover Effects, Differences-in-Differences, Employment, Ecuador.

\title{
ACKNOWLEDGEMENTS AND FINANCIAL DISCLOSURE
}

We thank Daron Acemoglu, Levi Boxell, Andreu Casas, Filipe Campante, Emilio Depetris-Chauvin, Stefano DellaVigna, Oendrila Dube, Ruben Enikolopov, Marcela Eslava, Kelley Friel, Lisa George, Victoire Girard, Philip Keefer, Rachid Lajaaj, Horacio Larreguy, Daniel Lederman, Luis Roberto Martínez, Mónica Martinez-Bravo, Maria Petrova, Pablo Querubín, James Robinson, Shanker Satyanath, Jake Shapiro, Joshua Tucker, Austin Wright, Ekaterina Zhuravskaya and seminar participants at the Harvard-MIT Positive Political Economy Seminar, Princeton University ESOC Lab Meeting, New York University, the University of Chicago, Universidad de los Andes, Universitat Pompeu Fabra, the NYC Media Seminar-Columbia University and Hunter College (CUNY), the World Bank Office of the Chief Economist for Latin America, the Households in Conflict Network 
at the Paris School of Economics, NOVA School of Business and Economics, Lacea's 2016 Annual Meeting, and the 2021 ASSA Annual Meeting. Juan Camilo Yaml'in provided excellent research assistance. 


\section{Introduction}

Has the worldwide diffusion of social media increased collective action globally? If so, what have been the broader political implications? The Arab Spring coincided with the expansion of information technologies, creating a widespread perception that social media helped bring about the popular uprisings against authoritarian regimes. The press also cites social media as a critical factor in explaining more recent protests, from the 2019 waves across diverse political regimes (Economist, 2019) to the Capitol Riots during the 2021 US presidential transition (Brewster, 2021).

While journalistic accounts may exaggerate the real impact of these technologies Aday et al., 2010; Farrell, 2012), careful academic research has confirmed the causal effect of social media on protests. Nevertheless, the best available evidence is limited to specific contexts and political junctures and, in particular, to non-democratic regimes or weak democracies. How generalizable are these impacts? When and where do protest movements respond to social media? What mechanisms might explain the influence of social media on protests?

In this paper, we contribute to our understanding of these issues by studying Facebook's impact on collective action across a broad sample of countries and regions. Moreover, we also examine the broader political implications of social movements encouraged by online networks. Indeed, early optimism about the political implications of social media waned as some of these movements failed to translate into meaningful political change. Confirming such skepticism, we document a robust effect of Facebook on protests with few other impacts on political outcomes like regime change, democracy, or governance. The sole exception is a decrease in violent conflict. In each case, we offer possible explanations and evidence for the mechanisms that may be driving these results.

Our identification strategy relies on the introduction of Facebook, the world's most common and widely used social media outlet with over 2 billion users worldwide, in different languages. Facebook's platform, launched worldwide in September 2006 in English, was gradually extended to versions in other languages. We exploit its release in a given language as an exogenous source of variation in access to social media among countries, regions, and people speaking that language. Our strategy builds on the idea that the platform's introduction in French, for example, increases Facebook use in French-speaking countries and regions, and among French-speaking people for at least two reasons. First, Internet users interpret and use the platform more efficiently in their main language. Second, even if some people can understand the platform well enough in their second language, they will likely 
use it more when their peers (friends, politicians, businesses) enjoy greater access with the language barrier gone.

We collect data from a variety of sources, and present results at the national, subnational, and individual levels that complement each other. The national-level regressions based on protest counts allow us to directly examine a key concern of our empirical strategy: that the arrival of language-specific platforms responds to an increased demand for social media in protest-prone countries. Four findings suggest that this source of reverse causality is unlikely to be a concern. First, there are no pre-existing differential trends in protest activities between countries with more or less people speaking languages available on Facebook, a finding that we also confirm with individual-level variation. Second, collective action in a country does not predict increased efforts to translate the platform into languages spoken in that country. Third, the main results are not driven by any region, country, language, or by countries that are significant in terms of their wealth, size, or level of political turmoil. Fourth and relatedly, our findings are robust to the exclusion of countries that could influence Facebook's translation into a new language.

Omitted variables are also not a likely confounder given the fine-grained variation we can use, controlling for country and even regional trends in collective action, as well as for trends parametrized as a function of initial country characteristics. Moreover, we confirm that the results are not merely driven by major episodes of collective action coinciding with Facebook's expansion into new languages. We pay particular attention to whether our results reflect a spurious coincidence between Facebook's expansion with the global financial crisis of 2007-2008 and the Arab Spring, and find no evidence that this is the case.

The national-level analysis is also useful to explore potential mechanisms by studying the heterogeneous effects of Facebook availability as a function of national socio-economic and political characteristics. At the national level we can also validate that language-specific Facebook platforms increase Facebook access using data on users and search interest in Facebook from Google Trends. Comparable data on Facebook use is incomplete at the subnational level, and measuring protest locations in smaller geographical regions may introduce more error. Despite these two drawbacks, the subnational analysis helps control for national and regional trends in collective action, which relaxes the identification assumptions.

Individual-level survey data has three main advantages. First, it allows us to examine who protests, not merely where protests take place. Second, it enriches the set of outcomes and likely mechanisms of influence that we can study. Finally, this data helps us address the concern that our findings partly reflect that Facebook increases reported protests because it 
makes them more visible, but does not change the number of demonstrations. While several robustness exercises in our national- and subnational-level regressions suggest this is very unlikely, the individual-level analysis reinforces our findings since it relies on direct reports rather than media coverage.

The magnitudes of the effects are economically meaningful. A one-standard-deviation increase in the share of people who speak a language available on Facebook (a variable that we term "Facebook Speakers") increases protest counts by 0.05 to 0.11 standard deviations. A counterfactual exercise implies that without Facebook, 14-26\% fewer protests would have taken place around the world during the study period. The magnitudes at the individual level indicate that being a Facebook Speaker increases participation by $10 \%$ on average.

To the best of our knowledge, our study is the first to offer convincing quantitative evidence of the effect of social media on protests on a global scale. Our approach improves the understanding of the effects of social media on collective action in three main ways. First, we contribute to assessing the external validity of previous research. Second, we contribute evidence that informs the mechanisms whereby social media affects protests. Third, we explore the broader political consequences of increased Facebook access, helping assess the potential welfare consequences of increased collective mobilization.

Our first contribution reflects the global scale of our approach W We are not the first to provide causal evidence of the impact of social media on collective action. Notably, Enikolopov, Makarin, and Petrova (2020) exploit exogenous variation in the expansion of VKontakte (VK), Russia's leading social network, to identify the impact of network penetration on political protests. Qin, Strömberg, and Wu (2019) use a difference-in-differences methodology to document the effect of network interactions (in particular, retweets by users in one city of blogposts from other cities) on protests and strikes in China. We show that these findings for the Russian or Chinese contexts can be generalized to other areas and settings. Moreover, we do so along several dimensions besides in the obvious "geographic" or "scale" sense. Indeed, the best evidence we have so far is for less democratic countries and, in the case of the impacts of VK, in a specific juncture of citizen discontent following electoral corruption allegations. Leveraging on our large sample of countries, we directly explore how regime type shapes the reaction to increased social media, and we use data for over 15 years which enables us to look at relevant temporal variation like electoral versus

\footnotetext{
${ }^{1}$ Examining the impact of information technologies on political outcomes, Guriev, Melnikov, and Zhuravskaya (2020) show that increased access to $3 \mathrm{G}$ networks reduced government approval in a sample of 116 countries and, in European democracies, the vote shares of anti-establishment populist parties.
} 
non-electoral periods or booms versus recessions. The nature of the variation we explore is also different. The VK study, for instance, relies on variation from early adopters, whereas we demonstrate empirically that the emergence of new Facebook platforms produces variation in social media not only among diverse countries but also among individuals with a wide range of characteristics ${ }^{2}$

Turning to our second main contribution, one important question is whether social media can, like traditional media, strengthen collective action via a one-way transmission of information, or whether its influence goes beyond this effect and includes increased "coordination". Coordination effects rely on the "social" nature of social media and its multidirectional exchange of information. Those emphasized in the literature might be grouped in three broad categories: strengthening horizontal communication among users and weakening the obstacles to tactical coordination (e.g., Little, 2016; Enikolopov et al., 2020), altering beliefs about how many others are also willing to act (e.g., Edmond, 2013; Barbera \& Jackson, 2020; González, 2020), or motivating (or deterring) participation to project one's social image (e.g., Enikolopov, Makarin, Petrova, \& Polishchuk, 2017; Cantoni, Yang, Yuchtman, \& Zhang, 2019).

We contribute to the information versus coordination debate and evidence in two main ways. First, our findings reveal the importance of coordination in explaining social media effects on collective action globally. In particular, our survey data reveals no change on a large battery of personal opinions, including government approval and views towards local institutions and democracy. To the extent that information should change individual's opinions, this result suggests that coordination effects must play an important role $3^{3}$ Second, we show that Facebook has been a "liberation technology" (Diamond, 2010) in the sense that access to the social network increases, by an appreciable $10 \%$, the chances that people report freedom of saying what they think, joining political organizations, voting and saying their political opinions. We suggest this also reflects the "social" nature of social media's information exchange, but one that goes beyond tactical coordination, concerns about social image, or the effect of beliefs about others' participation studied in the literature: that online social networks like Facebook provide an explicit outlet to voice opinions and share them

$\sqrt[2]{\text { Fujiwara, Müller, and Schwarz }(2020)}$ also exploit variation from early adopters to explore effects of social media, in this case Twitter, on US elections.

${ }^{3}$ Consistent with a limited role on access to information that might change people's opinions, we also find that protests react even with no comparable changes in people's consumption of news on other media. Finally, we find that social media has a muted effect around electoral periods, a finding that could also reflect the importance of coordination since during elections political parties and other social groups deploy organizational capacities that facilitate coordination. 
with others, likely producing this "liberation effect".

Our third main contribution comes from examining the broader political impacts of Facebook access. This is an essential ingredient for the debate on the welfare consequences of online social networks (Allcott, Braghieri, Eichmeyer, \& Gentzkow, 2020), since the positive average impact of social media on collective action does not directly translate into positive social outcomes. One could fear, like Gladwell (2010), that online social networks based on "weak ties" are unlikely to promote - and can displace - costly offline action and commitment to successful protest movements. By contrast, the potential strength of weak ties has been long recognized (Granovetter, 1973). Recent research on information diffusion through online social networks highlights the potential advantages of the very decentralized and diffuse nature of organization (Bennett \& Segerberg, 2012; Barberá et al., 2015), as well as possible complementarities between online and offline activities (Campante, Durante, \& Sobbrio, 2017; Vaccari et al., 2015).

Findings from previous studies in specific contexts and our estimations at a global scale suggest that these advantages, on average, overshadow any possible negative impacts on protests. Moreover, research on the impact of specific protest movements on broader political outcomes has uncovered meaningful impacts on other collective outcomes (e.g., Collins \& Margo, 2007; Madestam, Shoag, Veuger, \& Yanagizawa-Drott, 2013: Acemoglu, Hassan, \& Tahoun, 2017; El-Mallakh, Maurel, \& Speciale, 2018; El-Mallakh, 2017).

Yet the results from specific, and possibly particularly noteworthy protest movements, do not necessarily imply that, on average, the increase in collective action produced by Facebook has also produced other beneficial social changes. We examine this directly and find, on the negative side, no effects on regime change, democracy, or governance, suggesting that protests have been on average ineffective at producing major political transformations. With additional evidence, we suggest three possible explanations. First, in oppressive regimes where political reform is most important, the government might also use social media to identify and suppress political opponents and to mobilize citizens against opposition movements (Diamond \& Plattner, 2012; Sanovich, Stukal, Penfold-Brown, \& Tucker, 2015). Examining heterogeneous effects by levels of democracy, we document a U-shape pattern: Facebook's impact on protests is largest at either low or high levels of democracy. Using information on protest targets, however, we find that while protests against the establishment also follow the same U-shape pattern, those against the opposition are most important in the least democratic areas. Thus, this counteracting force limiting possible broader effects of protests appears to be relevant precisely where it matters most. 
A second possible reason is that traditional power structures like political parties or the traditional media may trump Facebook's effect during key critical junctures, as suggested by our finding that Facebook has a more limited impact on protests during electoral campaigns. A third and related reason is that Facebook might fail to increase political engagement in any other form besides protests. Using our survey data, we confirm that Facebook access has no comparable influence on various outcomes including voting, interest in and discussion of politics, participation in organizations, signing petitions, reaching politicians, participating in partisan activities, and identifying with parties.

On the positive side, we find that Facebook access produces a substantial decrease in violent conflict. We explore two possible reasons. First, Facebook's increase in protests provides one way to voice discontent and conflict that might otherwise turn more violent. The increase in perceived political freedom of expression is consistent with this possibility. Also, examining heterogeneous effects using the common determinants of collective action and social strife, we find that protests tend to increase more in countries with a history of protests and features that make countries more conflict-prone. Correspondingly, the decrease in internal conflict is more pronounced in countries with a history of conflict and features making them more conflict-prone. This provides some suggestive evidence that, in areas where there are more underlying reasons for conflict, Facebook's protests help voice discontent that would otherwise turn violent. Second, increased visibility could deter certain violent actions, thus decreasing conflict (Durante \& Zhuravskaya, 2018). Consistent with this mechanism, we show that the decrease in civil conflict is smaller in places with more freedom of the press, where Facebook should be less important to increase exposure.

Our paper contributes to several strands of research besides those already mentioned. We add to the literature exploring the impact of the expansion of the Internet (e.g. increased access to broadband or mobile technologies) on various political outcomes such as turnout and voting behavior (Campante et al., 2017; Larcinese \& Miner, 2017), ideological polarization (Gentzkow \& Shapiro, 2011; Barberá, 2014; Boxell, Gentzkow, \& Shapiro, 2017), and policies (Gavazza, Nardotto, \& Valletti, 2019). However, with the noteworthy exceptions mentioned before, these studies typically evaluate the overall role of Internet access, without identifying which Internet tool determines the results 4 We contribute by focusing on the impact of social media, one of the critical innovations of the Internet era, on protests - a fundamental outcome that has received considerable attention in recent studies (for a recent

\footnotetext{
${ }^{4}$ Another exception is Enikolopov, Petrova, and Sonin (2018), who study the impact of blog posts about state-controlled companies on the companies' stock returns and management turnover.
} 
survey, see Zhuravskaya, Petrova, \& Enikolopov, 2020).

Also related is the work of Manacorda and Tesei (2020) and Christensen and Garfias (2018), who evaluate the impact of cell phone access on protests in Africa and a panel of countries, respectively; both studies find a positive effect 5 Like social media, cell phones provide access to information and connect individuals (smartphones also connect to the Internet and online social networks), but their impact can also reflect broader influences.

Our results complement an extensive literature on online social networks' content and activity to evaluate the role that platforms like Twitter and Facebook play during protest events. Much of this literature focuses on explaining online behavior during protest events (Segerberg \& Bennett, 2011; Munger, Bonneau, Jost, Nagler, \& Tucker, 2016; GonzálezBailón, Borge-Holthoefer, Rivero, \& Moreno, 2011). Other studies also rely on surveys of participants to show that they learn about the protests and are encouraged to participate by information gathered through these networks, either directly or indirectly via friends. Evidence from Turkey, Ukraine, Occupy Wall Street, Chile, and Tahir Square (e.g., Jost et al., 2018; Tufekci \& Wilson, 2012; J. Tucker et al., 2015; Valenzuela, Arriagada, \& Scherman, 2012; Valenzuela, 2013) reveals that Twitter and Facebook are used to share information on key logistical issues (ranging from carpools to protest sites to advice on counteracting the effects of tear gas), to disseminate motivational appeals emphasized in social psychological theories of protest participation (shared interests, a sense of injustice or grievance, and social identification), and to publicize visuals from the demonstrations 6 Steinert-Threlkeld, Mocanu, Vespignani, and Fowler (2015) also show, for 16 countries during the Arab Spring uprising, that coordination via Twitter messages using specific hashtags correlates with increased protests the following day. Acemoglu et al. (2017) find that Twitter activity predicts the Tahrir Square protests, and Qin, Strömberg, and Wu (2017) find that the penetration of China's microblogging platform Sina Weibo is correlated with the incidence of collective action events.

While these are not necessarily causal correlations, they illuminate potential channels

5 Pierskalla and Hollenbach (2013) look at the relationship between cell phone coverage and violence in Africa. Müller and Schwarz exploit Facebook and Internet outages (Müller \& Schwarz, 2020a) and the rise of Donald Trump together with Twitter usage (Müller \& Schwarz, 2020b) to show that social media increases hate crimes in Germany and the US, respectively. Bursztyn, Egorov, Enikolopov, and Petrova (2019) also find that social media influences hate crimes in Russia.

${ }^{6}$ One paper that goes beyond documenting the uses of social networks to evaluate their impact is Larson, Nagler, Ronen, and Tucker (2019), who collect data on Twitter activity during the 2015 Charlie Hebdo protests in Paris, recording both real-world protest attendance and social network structure. They show that the protesters are significantly more connected to one another relative to comparable Twitter users. By shaping these connections, online social network structures influence offline protest participation. 
of influence that might underlie our results; that is, this research sheds light on how social media influences collective action. However, these studies are not designed to determine how much additional protest activity can be attributed to these tools. Indeed, if online social networks had not been available, protestors might have used traditional ways to coordinate and communicate. Global Positioning System (GPS) devices and applications provide a useful analogy. Do people drive more since the appearance of apps like Waze, which track their location and suggest a route? Probably. But many journeys would likely have occurred without the technology. So, while there is little doubt that people use Twitter and Facebook during protests, it is less obvious that these technologies increase the number protests, and if so, how important this effect is on average.

The rest of the paper proceeds as follows. Section 2 presents our data and empirical strategy. Section 3 presents our baseline estimates on protests using the protest counts data and individual-level surveys. This section explores the main threats to the validity of our empirical strategy including the possibility of reverse causality, omitted variables, and reporting biases. In section 4 we present additional outcomes that help interpret the mechanisms explaining our main results and draw conclusions about their broader significance. Section 5 concludes.

\section{Data sources and empirical strategy}

\section{$2.1 \quad$ Data}

To measure protests at the national and subnational levels, we use several variables from the Global Database of Events, Language and Tone (GDELT), which records six types of collective action events on a daily basis using news reports from a variety of sources. 7 The types of protest are engagement in political dissent, demonstrations or rallies, hunger strikes, strikes or boycotts, obstruction of passages or blockades, and violent protests or riots. Using this dataset, we aggregate the number of total protest events per month in each country or region. Importantly, since Facebook may facilitate information flows or news reporting, we emphasize that a protest refers to a single event record (coded with a globally unique identifier number in the dataset) even if there are multiple reports of the event. Our results are also robust to more demanding de-duplication strategies.

\footnotetext{
${ }^{7}$ This section describes the main data and variables in our analysis. Appendix Table A-1 describes all our variables.
} 
To construct our main independent variable, we coded the dates when Facebook was released in all 81 distinct languages in which it was available up until March 2016 (including beta versions) 8 Launch dates for each Facebook interface were determined through Google searches for news announcing the release. Dates for relatively uncommon languages were found in specialized blogs. In the 24 cases for which both options failed, we relied on the first crawl from the Internet Archive (https://archive.org/index.php) to identify the initial date when the corresponding webpage (e.g. https://mk-mk.facebook.com/ for Facebook in Macedonian) was created $9^{9}$

Information on the official languages spoken in each country comes from the World Language Mapping System (WLMS, version 16). This source provides the aggregate number of speakers by country and language. For the 12 countries (listed in Appendix Table A-1) without data, we complete the information using WLMS's original source, Ethnologue.

Our sample includes 240 countries and non-sovereign territories for the period January 2000 to December 2015 The subnational-level regressions rely on language polygons within countries as units of analysis (and robustness tests show similar results when using politicaladministrative divisions).

For the individual-level estimations, we collect data from three surveys reporting protest participation and the language spoken by the respondent - the World Values Survey (WVS), European Social Survey (ESS), and Afrobarometer (AB). In this analysis, protest activity is based on direct individual reports rather than media sources.

We use search interest in Facebook as calculated by Google Trends as the main measure of Facebook use. Facebook does not publicly disclose the number of users at the country-month level. However, we also combine a variety of sources, including the platform's own partial reports and figures from secondary sources, to construct an unbalanced country-month panel containing Facebook users' information for a subset of our sample. We show that, where data is available, "Facebook users" and "Facebook searches" are very strongly and significantly correlated and both respond to local-language platforms.

"Facebook searches" offer two main advantages relative to "Facebook users". First, the former is available for a larger sample of countries. Second, since some Facebook users sub-

\footnotetext{
${ }^{8}$ Facebook reported 91 different platforms, but this includes minor variations such as US vs. UK English and Spanish from Spain versus Latin America.

${ }^{9}$ Appendix Table A-2 lists all language-specific platforms and the source for coding the dates of entry.

${ }^{10}$ Some non-sovereign territories have independent data for our main dependent and independent variables. Appendix Table A-3 lists the full set of countries and non-sovereign territories in the sample. We use the term 'countries' for simplicity. Our results are similar when we restrict the analysis to sovereign territories.
} 
scribe to the platform but are either "fake" or do not actively participate 4 search interest more accurately captures interest and activity in the social network. The main disadvantage, in theory, is that some Facebook searches may have little to do with activity in the network. For instance, when people search for information on the company's stock price, or are curious about its founder, or are looking for an employment opportunity in the company, etc. However, this is a negligible problem in practice ${ }^{12}$

\subsection{Identification strategy}

There are two main empirical challenges when studying the effect of social media on various forms of collective action: omitted variables and reverse causality. The sign of the bias is not easy to determine a priori. Social media outlets such as Facebook or Twitter are available globally and thus variation in access is largely driven by Internet access rates, which confounds other country characteristics such as wealth, education or infrastructure. Areas with more social media activity may be more prosperous and democratic and experience less citizen discontent and fewer demonstrations, or people could be drawn to the Internet and social networks where social capital and collective organizations are stronger, which in turn may correlate with more citizen demonstrations. Also, some countries may restrict access to social media 13 In this case, a naive comparison of countries with high and low levels of access to social media may confound the (positive or negative) effect of state censorship on collective action with the effect of access to social media. Also, we cannot rule out the possibility that reverse causality causes a positive bias.

We propose using Facebook's release in a given language as an exogenous source of

\footnotetext{
${ }^{11}$ Facebook reports that only $65 \%$ of monthly active users are daily active users (see Facebook Reports 2019). The platform took down 2.2 billion fake accounts in the first three months of 2019, roughly equivalent to the total number of monthly active users it claims to have (see Stewart, 2019).

${ }^{12}$ Information from Google Trends shows that the top 25 "related queries" concern access to the platform. "Facebook login" is the most common search query, followed by equivalents of facebook login in other languages ("facebook entrar," "iniciar facebook," and "iniciar sesion facebook," which have 35\%, 35\% and $30 \%$ as many queries as "facebook login," respectively), and the following terms that again indicate interest in logging into Facebook or using its tools (all with 5\% as many queries as "facebook login"): "facebook español," "facebook login in facebook," "facebook login in," "facebook download," "my facebook," "entrar no facebook," "facebook com," "facebook lite," "facebook en español," "facebook sign in," "www facebook," "free facebook," "mi facebook," "facebook messenger," and "facebook log in." The final seven still relate to Facebook access, and are consulted less than 1\% as much as "facebook login": "facebook live," "facebook app," "facebook mobile," "login to facebook," "iniciar sesion en facebook," and "facebook belépés". These numbers are from a Google search query conducted on September 26, 2017.

${ }^{13}$ King, Pan, and Roberts (2013, 2014) show that in China, censorship silences information on collective action, but allows criticism of the state - likely in an effort to collect information on government performance.
} 
variation in access to social media. We estimate the following two-way fixed-effects regression for protests in a panel of countries using monthly observations:

$$
\text { Protests }_{c t}=\beta \times \text { Facebook Speakers }_{c t}+\mathbf{Z}_{c t}^{\prime} \psi+\gamma_{c} \times f(t)+\gamma_{c}+\delta_{t}+\varepsilon_{c t},
$$

where $\gamma_{c}$ are country fixed effects and $\delta_{t}$ time (month) fixed effects that partial out any global trends in collective action. We also allow linear (or quadratic) country-specific time trends $\gamma_{c} \times f(t)$ to recognize that countries may be on differential protest trends that would have been observed even without the new Facebook interfaces. $\mathbf{Z}_{c t}^{\prime}$ is a vector of additional controls that always includes initial population interacted with time dummies in order to allow for scale effects. In robustness exercises, we include additional baseline variables interacted with time dummies, to permit flexible differential trends based on country features.

Our main independent variable, Facebook Speakers ${ }_{c t}$, captures the share of each country's population that can access the platform in their first language. To compute it, we interact Facebook $_{t l}$, which indicates whether a Facebook version in language $l$ exists at time $t$, with Speakers $_{c l}$, the share of the population in country $c$ that speaks language $l$. More formally:

$$
\text { Facebook Speakers }_{c t}=\left(\sum_{l} \text { Facebook }_{t l} \times \text { Speakers }_{c l}\right) .
$$

This variable equals zero if either Facebook has not been released or if it has only been released in languages $l$ not spoken in country $c$. Once Facebook appears in a language spoken in country $c$, it equals the share of the population that speaks this language. Moreover, there is an additional "treatment" in country $c$ every time Facebook is released in the language of at least a fraction of the population.

Speakers $_{c l}$ refers to the share of people in country $c$ that speak $l$ as their first language. There may be individuals who also understand $l$ as a second or third language, but data for second languages is less complete in the WLMS. We thus focus on variation in access stemming from main language availability in our baseline regressions, but explore effects of second languages in additional exercises. Also, note that even though multilingual individuals may access the platform before it is released in their first language, they may still use it more when this occurs because they will have more peers (friends, relatives, companies, politicians) to interact with for whom the language barrier is relevant.

In short, Facebook Speakers measures the share of people that can potentially benefit 
from increased access to Facebook as the new language platforms are launched. For instance, in Canada this variable is 59.6\% when Facebook was first launched (in English), $61.4 \%$ when released in Spanish, and 83\% when launched in French.

Our identification assumption is that, absent the release of these language-specific platforms, countries with different proportions of speakers of the corresponding languages would have observed similar collective action trends. It is plausible that the timing of these releases is orthogonal to collective action episodes in countries, regions and people who speak the corresponding language. For example, the introduction of Facebook in French probably does not depend on political developments in French-speaking countries as diverse as France and Cote d'Ivoire. Also, our regression framework takes into account any time-invariant country characteristics (absorbed by the country fixed effects), plus country-specific temporal trends. Only trends that would have differentially affected places with comparably more speakers of a given language and that are not well captured by this country-specific (linear or quadratic) trend could contaminate our results. We also perform a number of robustness tests to determine whether our findings reflect the influence of omitted variables or reverse causality.

We also exploit within-country variation in regressions where, unlike the national-level regressions, we can control for a full set of country $\times$ time fixed effects. This relaxes the identification assumption and examines whether Facebook platforms in a given language increase collective action in regions where people can interpret that language compared to other areas in the same country where they cannot. For region $j$ in country $c$ at time (month) $t$, we estimate:

$$
\text { Protests }_{c j t}=\beta \times \text { Facebook Speakers }_{c j t}+\mathbf{Z}_{c j t}^{\prime} \psi+\gamma_{c} \times \delta_{t}+\omega_{j}+\varepsilon_{c j t},
$$

where $\omega_{j}$ are region fixed effects and $\gamma_{c} \times \delta_{t}$ are fixed effects for each country and month. As in equation (1), $\mathbf{Z}_{c j t}$ includes the initial population of region $j$ interacted with month fixed effects and other controls. Similar to equation (2), our main independent variable is defined as:

$$
\text { Facebook Speakers }_{c j t}=\left(\sum_{l} \text { Facebook }_{t l} \times \text { Speakers }_{c j l}\right)
$$

where Speakers $s_{c j l}$ is the share of people in region $j$ of country $c$ that speaks language $l$ 
(which is either 0 or 1 except in areas where more than one main language is reported by the WLMS).

Finally, our individual-level regressions take the following form, for individual $i$ in country $c$ responding the survey at time (year) $t$ :

$$
\text { Protest }_{c i t}=\beta \times \text { Facebook Speaker }_{c i t}+\mathbf{Z}_{c i t}^{\prime} \psi+\gamma_{c} \times \delta_{t}+\gamma_{c} \times \ell_{i}+\varepsilon_{c i t}
$$

where protest is now a dummy variable that equals 1 if the individual reports participating

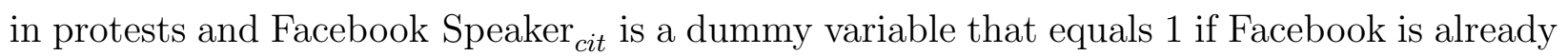
available in individual $i$ 's main language. Also, in addition to country-specific flexible time trends, this specification includes language fixed effects $\left(\ell_{i}\right)$ and their interaction with country fixed effects, to allow for potential differential participation in collective action activities by individuals with specific linguistic backgrounds within a polity. Finally, $\mathbf{Z}_{\text {cit }}$ now denotes individual controls.

In our benchmark specification, we use two-way clustered standard errors at the country and month (year, in the case of individual data) levels to account for potential temporal and spatial correlation (Bertrand, Duflo, \& Mullainathan, 2004), but we also show results under alternative clustering approaches. We focus on linear estimators because they are consistent under comparably weaker assumptions and more flexibly admit fixed effects and clustering of the standard errors (Cameron \& Trivedi, 2015).

\subsection{Sources of variation and event-study estimates}

To illustrate the variation in our dataset Panel A of Figure 1 shows (on the left-hand vertical axis) the number of Facebook language-specific platforms that have been launched since the English version was made available in 2006. From 2007 to 2011, Facebook accumulated 62 additional versions. The number of versions remained relatively stable from 2012 to 2014, and 16 new platforms were launched from 2014 to 2015. The right-hand vertical axis measures the average country-level value of Facebook Speakers. Panel B displays the share of Facebook Speakers in our individual-level data, by survey wave. The share of speakers increases as new versions arrive, and the languages launched earlier have, on average, a stronger impact on the number of speakers than those launched later. Nevertheless, even later languages create meaningful variation because in some regions within countries, and in some waves and places in the survey data, a significant share of the population speaks those languages. 
Figure 2 illustrates one major advantage of this global approach with widespread variation: that it exploits changes in Facebook access across countries and individuals with many different characteristics. In Panel A, we use Google Trends data on Facebook Searches as the dependent variable in our baseline regression equation (1). The first row shows average Facebook Searches for the full sample as a bar on the left and the effect of Facebook Speakers on these searches (with 95\% confidence intervals) on the right. This verifies that increases in Facebook Speakers augment Facebook use, a robust finding as we document below. The remaining rows repeat the exercise, but breaking the sample in two equally-sized subgroups (below and above the median) according to several available predetermined countries characteristics (total population, age distributions, urbanization and urban growth, sex ratios, fertility rates, income per capita, education, linguistic fragmentation or polarization, share of English-speaking population, and measures of religiosity). Consistently, we find that our strategy of relying on Facebook platforms' languages as a barrier to access produces meaningful variation in Facebook use for countries with different characteristics.

In Panel B, we turn to our survey data and rely on one round of the AB survey inquiring for social media use (Facebook or Twitter ${ }^{14}$ ) to conduct a similar exercise. The first row shows average use and the positive impact of being a Facebook Speaker for the full sample: having a Facebook version in one's language increases the likelihood of reporting using Facebook or Twitter by 11 percentage points, from a mean incidence of $21 \%$. This strong effect further validates our proposed source of variation to study the impact of Facebook. The remaining rows reveal that this effect is present for individuals with diverging characteristics in terms of age, sex, education and wealth.

With this individual-level survey data we can further present a complier analysis following Abadie (2003), as in Panel C. This panel reports the fraction of respondents with a given characteristic (again, in terms of age, sex, education and wealth) both among all respondents and among the subset of compliers. On the right, we report that the difference is typically small and not statistically significant, revealing that the set of compliers is not only very diverse but also very similar to the average person, at least as captured by these observable features.

Before turning to our main results and examining how robust they are, our final piece of graphical analysis is an event-study exercise that illustrates the effect on protests once a new platform appears and helps validate our approach by revealing no variation in collective

\footnotetext{
${ }^{14}$ Unfortunately, a separate question for Facebook is not available, and the remaining surveys do not inquire about Facebook use.
} 
action before this. We keep observations that experience an increase in Facebook Speakers and a study window of eight 6-month periods around this increase or "event." We then run a regression for the $(\log$ of) protests on unit and period (semester) $\times$ country fixed effects (excluding the period just before the hike in the number of Speakers).

Figure 3 shows the coefficients on period dummies; negative numbers on the horizontal axis indicate periods before the increase, and positive numbers those following the event. The figure reveals no change in protests before the increase in Speakers caused by a new language-specific platform (confirming this, a test for statistical significance of any coefficient associated to the control period has a p-value of 0.3 ). Two periods after the event, the change in protests is already positive and statistically significant; the effect increases gradually and levels out at around 0.3 (approximately a 30\% change) five periods after the increase. This magnitude is roughly in line with the full approach using specifications (1), (3) and (5) presented below.

\section{Baseline Estimates}

The first part of this section presents our main results using aggregate national and subnational measures of collective action. In the benchmark case, the dependent variable is the natural logarithm of the number of protests plus one, to allow for zero values 15 This transformation reduces the skewness when protests are measured in levels, which is 21.8 at the country level with a standard deviation around 6 times as large as the mean. The second part of the section focuses on individual protest participation as the main outcome. Descriptive statistics for the main variables are in Table 1. There are protests in $68 \%$ of our country-months; demonstrations are the most frequent types of protest, on average, and hunger strikes the least common.

\footnotetext{
${ }^{15}$ We report robustness below using the inverse hyperbolic sine (or arcsinh) transformation which also retains zero values and approximates the natural logarithm of the variable. Both transformations allow to interpret coefficients as semi-elasticities, but this interpretation is only valid when $y$ is large enough. Bellemare and Wichman (2020) suggest directly deriving elasticities analytically for each regression specification and their standard errors (using the delta method) to calculate exact values. In our application, the coefficients have similar magnitudes to those using the exact formula, and regressions with $\log (1+y)$ or $\operatorname{arcsinh}(y)$ are very similar to each other. Nevertheless, when presenting the main results, we show the implied exact magnitudes as well for reference.
} 


\subsection{The effect of Facebook Speakers on Protest Counts and Face- book use}

\subsubsection{National variation}

Table 2 reports our baseline estimation of equation (11) for protests at the country-month level. All panels in this table follow the same structure. Column 1 includes only country and time (month) fixed effects as well as initial population interacted with time fixed effects. Column 2 includes linear country-specific trends and column 3 instead uses a quadratic polynomial. Column 4 runs the same specification as in column 3, but restricts attention to the sample of countries for which we have complete data on a set of predetermined covariates. This facilitates comparison with column 5, which interacts time fixed effects with these controls, allowing for fully flexible temporal patterns in collective action as a function of these characteristics 16

Our key estimates for the effect of Facebook Speakers on protests are in Panel A. The coefficient for Facebook Speakers is very robust and stable across specifications (and always significant at more than the $99 \%$ level). Only column 1, which ignores potential countrylevel temporal trends, produces a relatively larger value of 0.36 than the remaining columns, with values ranging from 0.22 to 0.27 . The stability of the effect across these specifications suggests that Facebook Speakers is responsible for increasing protests, and that other omitted factors are not creating differential trends $[7$

Since allowing for country-specific temporal trends appears important, we use column 3 (the most demanding one with the full available sample) as our benchmark specification. The size of the coefficient in this column (0.221) implies a nearly $22 \%$ increase in protests when Facebook Speakers increases from 0 to 100\%. This approximation is almost identical to the implied magnitude with the exact formula (see footnote 15), which is also reported in the lower row of the panel. Such a large increase in Facebook Speakers at the country level is uncommon; a one-standard-deviation increase (0.34) implies roughly a $7.5 \%$ increase.

\footnotetext{
${ }^{16}$ Covariates included are: GDP, share of GDP in manufacturing, share of population aged 15-24, Internet users and linguistic polarization.

${ }^{17}$ In this panel, we also report robustness to different choices for clustering of standard errors, including: errors with two-way clustering at the month and country levels (shown in parenthesis), two-way clustering at the month and (main) language levels (in square brackets), and randomization-inference standard errors drawing the timing of Facebook expansion across languages (in curly brackets). Appendix Figure B-1 depicts the randomization inference exercise graphically for the estimate in column 3, and reveals that the estimated parameter is a clear outlier in the distribution of these placebo estimates. Our inference is robust to any of these alternatives.
} 
To further illustrate the magnitude of this impact, Panel A in Figure 4 plots the observed total number of protests together with the corresponding quantity implied by our estimates assuming no version of Facebook had ever been launched (that is, imposing zero Facebook Speakers throughout). The figure also plots the cumulative difference since Facebook's launch in September 2006 between protests with and without Facebook (expressed as the percent of total cumulative protests without Facebook up to each time period). The calculations imply that, had it not been for Facebook, there would have been close to $14 \%$ fewer protests around the world during our study period.

These estimates presume that Facebook availability in local languages increases collective action via an increase in Facebook use. To confirm this, Panel B of Table 2 explores the robustness of the estimates in Panel A of Figure 2 which revealed a positive effect of Facebook Speakers on Facebook use. This panel runs the same specifications as in Panel A with Facebook Searches as the dependent variable. The results show a clear increase in Google searches for Facebook when Facebook Speakers increase. The coefficient for Facebook Speakers ranges from 0.06 to 0.09 and is precisely estimated, significant at more than the $99 \%$ level. These estimations demonstrate the relevance of the proposed mechanism: Facebook availability in a local language strongly increases platform use.

For further confirmation of this conclusion and validation of the Facebook Searches variable, Panels C and D use the (unbalanced) panel of Facebook users that we compiled using various sources (see Appendix Table A-1) 18 Panel C presents the regressions of Facebook Searches on Facebook Users, confirming that Facebook search interest strongly correlates with the number of users. Panel D examines whether Facebook Speakers increases Facebook Users, and again finds a robust positive and significant correlation in every specification (even if the magnitude of the coefficient of Facebook Speakers is somewhat more sensitive with this more limited sample than in Panel B).

Appendix Table B-1 presents two-stage least-squares estimates of the effect of Facebook Searches on protests, instrumenting searches with Facebook Speakers (the first stage is column 3 of Panel B in Table 2, with an F-statistic of 15.52). The coefficient on Facebook Searches (2.65 with standard error 1.08) is positive and significant at the $95 \%$ confidence level. A one-standard-deviation increase in Facebook use as captured by searches implies close to one-third of a standard deviation increase in protests $(2.65 \times 0.24 / 1.88=0.33) .{ }^{19}$

\footnotetext{
${ }^{18}$ In these panels with a more limited sample, there is no difference between columns 3 and 4 since we have covariates for all countries with Facebook user data.

19 For reference, comparing the magnitudes of our findings with those in Enikolopov et al. (2020) suggests smaller impacts on protests than in their setting, while our speakers variable is at least as relevant for
} 
For comparison, the table also shows the corresponding ordinary least squares (OLS) relationship between protests and Facebook searches, which is also positive and statistically significant, but appreciably smaller (coefficient 0.53, standard error 0.14). This could mean that the sources of negative bias in OLS estimations discussed above are empirically more important than those leading to a positive bias. Probably more important, although Facebook Searches captures Facebook interest and use, it measures with some error the amount of time and intensity of interactions by users in the platform. Thus, attenuation bias likely also explains part of the gap between the OLS and IV estimates.

We focus on the "reduced-form" relationship between protests and Facebook Speakers in what follows both for simplicity and, more importantly, because we can run comparable regressions at the subnational and individual levels (where we have no good proxy for Facebook use).

Table 3 leverages on our global approach and examines the heterogeneous effects of particular country characteristics to better understand which country features increase Facebook's impact on collective action and some additional implications of our findings. We start with a simple reality check in column 1: Facebook's release in a language spoken by a significant share of people in a country has larger impacts in countries with more initial Internet users. ${ }^{20}$ A one-standard-deviation increase in Internet users increases the baseline effect by around $7 \%$.

Facebook may matter because it motivates collective mobilizations in countries where protests have traditionally been scarce, or because it increases protest activity in polities with a tradition to mobilize. In column 2, we interact Facebook Speakers with historical protests and find that countries with traditionally more protests react comparably more: a one-standard deviation increase in historical protests nearly duplicates the baseline effect.

Columns 3 to 9 examine some common determinants of collective action and social strife.

Facebook use as their instrument is for VK use. Since treatment and outcome variables are measured differently, for comparison consider the implied standardized effects or " $\beta$-coefficients". Our estimate of 0.22 for Facebook Speakers in column 3 of Panel A in Table 2 implies a standardized effect of $0.04((0.22 \times$ 0.34)/1.88), which is smaller than the 0.096 standardized effect of Enikolopov et al.'s instrument on (log of one plus) protesters in Russia (coefficient 0.259, column 6, Table 2). Also, our instrumental variable (IV) estimates in Appendix Table B-1 for the effect of Facebook Searches on protests is 0.33, while Enikolopov et al. (2020) find that a one-standard-deviation increase in VK users increases (log of one plus) protesters by 1.2 standard deviations (coefficient 1.787 in column 2 of Table 3). The first-stage relation between their instrument and VK has a standardized effect of 0.08 , while a one-standard-deviation increase in Facebook Speakers increases Facebook Searches by 0.11 standard deviations (using column 3 of Panel B in Table 2 $(0.083 \times 0.34) / 0.24)$.

${ }^{20}$ As with other interactions with variables that Facebook might influence, we measure Internet users before Facebook appeared in order to avoid a "bad control" bias (Angrist \& Pischke, 2008). 
A vast literature has documented a positive relationship between education and various forms of political participation, including protests (see, e.g. Campante \& Chor, 2012, 2014). Column 3 interacts with average initial years of schooling (for those over age 15), and finds that increased Facebook access has a larger effect in more educated countries.

Ethnic, religious and linguistic diversity has been linked both theoretically and empirically to collective action, social capital, and conflict (see, among others, Esteban \& Ray, 1994; Alesina, Baqir, \& Easterly, 1999; Montalvo \& Reynal-Querol, 2005b, 2005a; Esteban \& Ray, 2008). In columns 4 and 5, we interact Facebook Speakers with linguistic diversity, examining both fragmentation and polarization given disputes regarding which is the relevant measure of diversity for particular outcomes. We focus on linguistic diversity since we can measure it directly with WLMS for our full sample, and find no evidence that either index exacerbates the impact of Facebook Speakers.

Together with ethnic tensions, natural resources also stand out as a salient potential determinant of conflict (for a review, see M. L. Ross, 2004). In columns 6 to 8, we focus on diamond production per capita and oil reserves (from Humphreys, 2005) and oil and gas rents per capita (from M. Ross, 2008) ${ }^{21}$ In this case, we find consistent evidence that Facebook Speakers increase protests more in countries with more resource rents. A onestandard-deviation increase in diamond production, oil reserves, or oil and gas rents per capita increases the baseline effect of Facebook Speakers by 47\%, 15\%, and 68\%, respectively.

Finally, there is a long-standing debate on whether denser urban populations contribute to more social unrest, as mobilization is both easier to coordinate and potentially more effective at bringing about change in urban areas (e.g. Weiner, 1967; Traugott, 1995; DiPasquale \& Glaeser, 1998; Nash, 2009; Glaeser \& Steinberg, 2017; Campante, Do, \& Guimaraes, 2019). In column 9 we observe that initial urban population increases the impact of Facebook Speakers (coefficient 0.17, standard error 0.09).

\subsubsection{Subnational variation}

Table 4 presents the results for the subnational-level regressions described in equation (3). In column 1 we look at total protests as the dependent variable. The coefficient for Facebook Speakers is, as with the national-level regressions, positive and precisely estimated (0.51 with standard error 0.08). The standardized effect implied by this coefficient is $0.11((0.51 \times$

\footnotetext{
${ }^{21}$ Though the share of natural resource exports is commonly used as a measure of resource abundance, it is a poor measure of relevant rents when there is high local consumption, when extraction costs vary, and if countries have endogenously low non-resource exports (see M. Ross, 2006; Acemoglu, Fergusson, \& Johnson, 2020).
} 
0.12)/0.54), which is larger than the 0.04 increase we find in the national-level regressions. To further compare the magnitudes, in Panel B of Figure 4 we replicate the counterfactual exercise we conducted using the national-level estimates. Again, we plot total observed protests and protests assuming Facebook was never launched (i.e., imposing zero Facebook Speakers throughout), and the resulting cumulative difference. These calculations imply that Facebook accounts for close to $26 \%$ additional protests over our sample period, compared to $14 \%$ national-level estimates. This suggests national-level regressions may attenuate the effect by averaging regions that are heavily treated with those that are not when Facebook appears in a new local language.

In columns 2 to 7, we examine the impact on different types of protests (Schrodt, 2012): political dissent, demonstrations or rallies, hunger strikes, strikes or boycotts, obstruction of passages or blockades and violent protests or riots. Facebook Speakers significantly increases all types of protests. Thus, the subnational-level analysis reaffirms the very robust, positive, and generalized effect of Facebook access on protests. Moreover, since we are including fully flexible country-level temporal trends, these specifications relax our identification assumption and rely on more fine-grained variation than country-level regressions. ${ }^{22}$

\subsection{Identification, measurement, the language barrier and other robustness}

Having presented our main results based on protest counts, we next analyze a set of independent results validating the causal interpretation of our findings, as well as ruling out potential measurement biases. We also examine the relevance of the language barrier and present robustness results along several other dimensions. We relegate tables and figures in this section, and a more detailed discussion of the findings, to the Appendix.

We conduct three sets of exercises to assess the possibility of reverse causality. First, we show there are no differential trends in collective action in countries with and without increased Facebook access in their languages before these language-specific platforms are launched. Second, by exploiting the way in which Facebook platforms are launched, building from user-provided translations, we show that the "demand" for Facebook is unlikely to

\footnotetext{
${ }^{22}$ For the subnational analysis we rely on WLMS's polygons within countries where each language is spoken. Using the the intersection of administrative divisions (the first level of administrative division, equivalent to US states) with language polygons as the unit of analysis, Appendix Table B-2 shows that our results are robust to incorporating month $\times$ state fixed effects, thus flexibly controlling even for subnational trends in collective action.
} 
be driven by social unrest. To do so, we collect data on translator's location and use the frequency of both translations and translators from each country and language to capture the "eagerness" to have Facebook. We find no evidence that collective action trends before Facebook predicts increased translation efforts. Third, even though the latter two analyses suggest that reverse causality is unlikely, we further explore the concern that social changes, turmoil, modernization, increased openness, and other trends can drive a society to "demand" Facebook local platforms and simultaneously be more prone to protest by dropping plausibly influential countries or regions from the sample.

We also explore the potential role that the 2008 crisis plays in our analysis since a considerable number of platforms were launched around this period. Parallel trends and the lack of apparent demand effects suggest it is unlikely that the crisis raised the demand for Facebook on local platforms to coordinate protests. Nevertheless, we explore the issue directly in five additional ways. First, we show that the effects are not limited to crisis years, and in fact, are larger much later on. Second, we find no evidence that periods of recession predict translation activity. Third, we show that determinants of the spread of the crisis are not correlated with changes in Facebook Speakers. Fourth, we allow for differential trends capturing the potential influence of the crisis. Fifth and finally, we explore the broader relationship between the economic cycle and the magnitude of the main effect of Facebook Speakers. Like Manacorda and Tesei (2020), and consistent with poor economic conditions likely triggering discontent and reducing the opportunity cost of protesting, we find a stronger effect during sharp recessions. At the same time and unlike Manacorda and Tesei (2020), protests respond to Facebook even during growth episodes, suggesting an effect not confined to the crisis.

We also carefully investigate the possibility of reporting bias because Facebook makes protests more visible (e.g., by creating spillovers on protest reporting), and therefore that Facebook increases not actual protests, but reported protests in GDELT (Weidmann, 2016, Cagé, Hervé, \& Mazoyer, 2020). We show that the effect is relevant for many types of protests, including those that are more newsworthy and therefore likely to be reported on in any case. We also find no evidence for changes in reporting by studying effects on the distribution of number of outlets reporting events and on the time elapsed between protest and report. We also examine whether the media sources fail to successfully de-duplicate protests that are reported on more than once, which might affect our estimates if Facebook directly influences this success rate. However, our results are robust to stringent de-duplication strategies at the geographic and temporal levels. Also, we find similar and even stronger 
effects for Africa using the Armed Conflict Location \& Event Data Project (ACLED), also media-based as GDELT but complemented with reports from nongovernmental organizations and "hand checked." These checks all reinforce the idea that the Facebook Speakers variable matters because it increases Facebook access, thus enabling collective action, not because it improves protest recording. However, we further confirm this and explore additional implications by relying on individual reports on protest participation, which are independent of media reports. We turn to these results in Section 3.3. ${ }^{23}$

Finally, we also examine the language barrier in more detail. Our finding that having more Facebook Speakers in a given country increases Facebook use confirms that not having the platform in a local language is an important barrier to accessing the technology. But some individuals may overcome this barrier with a second language. We find that the second language increases Facebook use and that the coefficient on protests, though positive, is not significant and does not change the significance or magnitude of the main Facebook Speakers effect. Also the first language has about twice the effect on access as the second language. We suggest this reflects that even individuals who are fluent in a second language that enables them to access Facebook may still respond to a local language arriving on Facebook since this enriches their network of interactions (with friends, politicians, businesses, etc. that enter the platform then). Confirming this intuition that access in the first language complements rather than displaces Facebook use for those who can access in a second language, we find a positive interaction between access in the first and second language 24 On the other hand, we find that the writing systems are important: in general, the first language to appear on a given writing system has a larger effect than subsequent languages on that system.

\subsection{Results from individual-level protest participation}

Turning to our individual-level regressions, we first verify parallel trends between respondents before one becomes a Facebook Speaker. Panel C of Appendix Figure B-2 shows a similar exercise as in the protest-count data (at the yearly level since we do not have complete monthof-interview information to perform this exercise monthly). Again, years before a Facebook platform becomes available in a respondent's language, we see no difference in collective action. Placebo treatments for anticipation effects one, two, three and up to 6 years are

\footnotetext{
${ }^{23}$ Other robustness tests in the Appendix include: verifying that our results are not driven by outliers; exploring alternative transformations of the dependent variable; estimating dynamic panel data models, models for the extensive margin and nonlinear models (quantile, negative binomial and a zero-inflated negative binomial, logit and probit); and transforming the independent variable

${ }^{24}$ We also test, but fail to find, possible spillover effects between similar languages.
} 
consistently not statistically significant and smaller in magnitude than the treatment effect.

Table 5 shows the results from the individual-level regressions as in equation (5). In Panel A we pool all surveys, and regress the indicator variable for individual participation in protests on the Facebook Speaker dummy, with fixed effects controlling flexibly for heterogeneity at the country, time, and survey wave levels. We also control for age group and sex, since these are clearly predetermined individual characteristics. Moreover, we allow each language in each survey to have differential patterns of protests, since some groups may have more grievances and/or social capital than others. In case this varies by country, column 2 adds the full set of country $\times$ language and survey fixed effects. This specification is particularly flexible, allowing for differential participation in collective action activities by individuals who share specific linguistic backgrounds within a polity. Column 3 adds the individual-level controls education and wealth (which probably do not react quickly to Facebook access, but which we include separately since an argument could be made that these are "bad" controls). We also study each of the surveys separately, in Panels B-D.

This table demonstrates a very robust relationship between speaking a language that is already available in Facebook and protest participation. The average effect using the coefficients in Panel A implies that being a Facebook Speaker increases protest participation by about 2.5 percentage points, from a mean participation of $26 \%$, roughly a $10 \%$ increase. This masks variation by survey, where the corresponding increases in the most demanding specification are: roughly 7 percentage points in the WVS from a mean incidence of 0.48 (close to a $15 \%$ average increase), 1.9 percentage points in the ESS from a mean incidence of 0.07 (a low absolute change but comparably larger $27 \%$ increase given the low base level), and 9.5 percentage points in the $\mathrm{AB}$ (nearing $25 \%$ from a base average of $38 \%$ ) ${ }^{25}$

In Table 6, we examine who responds more to Facebook access. This table breaks down the reported average effects by age group, sex, level of education, and income level. The effect of speaking a language available on Facebook is very widespread. It is present and often similar for many types of individuals, with some exceptions (p-values for equality of the coefficients on Facebook Speakers by group are reported in each panel). The response is smaller for older cohorts (over 55), though these differences are smaller in the ESS than

\footnotetext{
${ }^{25}$ We note that the higher protest participation rate in the WVS and AB than in the ESS partly reflects the lower incidence of protests in European countries. However, it is also due to differences in the survey instruments since the ESS identifies effective participation whereas the WVS and AB explore effective and intended participation. In the Appendix, we argue that using either expression of protest activity, when available, allows us to capture Facebook's full effect on collective action. But we also show that the effects reflect a change both in effective and intended participation in the WVS and AB samples.
} 
in the WVS and AB samples and the very young (under 25) also appear to respond less in the WVS sample. There are no large differences by gender, except in the AB samples where there is a stronger response for females (a point estimate of 0.13 compared to 0.06 for males). There are no consistent differences by levels of education across the samples, and the most notable feature is the non-response of those with secondary education in the ESS sample. This sample is also the only one featuring statistically significant differences by wealth, with a stronger reaction for individuals in the middle tercile (a 3 percentage point impact relative to 1 and 1.8 for the highest and lowest tercile, respectively). The point estimate is larger for the lowest tercile of income in the AB sample (0.13 compared to 0.05 and 0.09 for the middle and highest tercile, respectively), but the p-value for equality of coefficients between wealth terciles is 0.364 .

In short, Facebook impacts protest participation among many types of individuals, other than a smaller reaction by older people. On the latter, while we have no measure of social media for all samples, note that the results from Panel B in Figure 2 for the AB sample suggest this does not reflect a lower take-up of social media use by older people when the language barrier disappears. At least in this sample, therefore, this muted impact on older individuals possibly reflects a lower propensity to participate in protests and respond to incentives to do so (note in Panel A of Table 6 that, indeed, average protest participation decreases with age).

\section{Mechanisms and broader implications}

In this section, we use our approach's richness to shed light on the possible channels through which the information that individuals receive or exchange via social media influences protests. Social media can strengthen collective action by providing information on issues motivating the protest, thus changing individuals' priors (operating similar to conventional media). But information received and exchanged via social media can also influence protests by strengthening horizontal communication and easing tactical coordination, altering beliefs about how many others are also willing to act, and motivating (or deterring) participation to project one's social image. The literature sometimes refers to the first set of mechanisms as "information" and to the second set as "coordination". One could alternatively refer to them as "non-social" versus "social" mechanisms since, ultimately, the effects on coordination also 
depend on receiving or exchanging information ${ }^{26}$ We use the terms information/non-social versus coordination/social to differentiate these two broad sets of influences.

We also examine the broader political implications of our findings, to help inform the debate on the possible welfare effects of social media. To do this, we examine results across different types of political regimes and evaluate impacts on other political outcomes.

\subsection{Social media and freedom}

Social media has often been considered a "liberation technology", since it may empower individuals to freely express their political opinions, report news, expose wrongdoings and ultimately deepen their political participation and widen the public sphere. Our effects on political mobilization may result from this "liberation".

Table 7 relies on the Afrobarometer sample to show that, along with increased protest participation (reproduced in column 1), Facebook Speakers are more likely to report freedom along several dimensions. The Facebook Speaker effect is close to $10 \%$ of the sample mean for a freedom index that averages reported freedom of saying what one thinks, joining political organizations, voting and saying one's political opinions (column 2). Every component of the index responds, with sizes ranging from about $6 \%$ (freedom to vote) to $57 \%$ (freedom to voicing one's political opinion) of the mean (columns 3 to 6). Speakers fear of facing political intimidation also diminishes, by nearly $18 \%$ of the mean (column 7 ).

Such political empowerment may reflect the traditional information channels of influence of social media to the extent that views and information obtained through Facebook changes individuals' beliefs about their freedom of expressing their political opinions and mobilizing. This seems however unlikely in our context since, as we show below, other personal views on topics that feature even more prominently in the news do not change with social m.dia access.

It is instead quite likely that social media has a particularly important impact on this dimension because it provides an explicit outlet to voice opinions and share them with others. Therefore, this liberation effect is most plausibly connected with the social channels of social media. Notice however that this influence goes beyond tactical coordination, concerns about social image, or the effect of beliefs about others' participation studied in the economics and

\footnotetext{
${ }^{26}$ Of course, these terms are not perfect either since even pure information distributed on a traditional newspaper implies a "social" effect, for example because readers know that others are accessing the information too.
} 
political science literature ${ }^{27}$

\subsection{Social media and information}

One way to explore whether the information/non-social or coordination/social channels explain the impact of social media on protests is by studying the effects on personal views. We now do so, using a broad range of measures from our survey data.

Table 8 estimates the effects on trust in institutions and satisfaction with the government (Panels A1-A3), satisfaction with the degree of democracy in the country (Panels B1-B3), and measures for support for democracy (Panels C1-C2). Since we look at multiple outcomes, we explore the effect on a normalized average of all available measures in each category. We find no evidence that Facebook deteriorates perceptions about institutions or the government, a view that one would expect to change if inherent information about the protests' motives drives the results. In the WVS sample, in fact, we actually observe an average increase in trust on institutions. In all other cases, our point estimates not only fail to be statistically significant but are also small in magnitude (well below $5 \%$ of the mean).

That Facebook access changes protests but has limited effects on political views suggests that the coordination/social channels play a potentially more important role than information in explaining the effects on collective action. Pointing in this same direction, Panels B1-C2 show that Facebook access does not change satisfaction with the degree of democracy in the country or measures of support for democratic institutions.

Consistent with a limited impact on individuals' access to news and other information that might shape their views, we also find that Facebook access does not consistently crowd out traditional media in our sample. However, we find some interesting differences by surveys and type and purpose of the media. In Panel A of Table 9, we report the Facebook Speaker coefficient in regressions for relying on Radio, TV, or Newspapers as sources of information. For the WVS sample (Panel A1), the point estimates are close to a decrease in 5 percentage points (from an average use of $90 \%$ for Radio or TV and $55 \%$ for Newspapers). While these are not negligible sizes, especially for newspapers where they would imply close to a $10 \%$ decrease, the estimates are imprecise and not statistically different from zero at conventional confidence levels. Panel A2 for the ESS sample reflects a positive coefficient for Radio and

\footnotetext{
${ }^{27}$ The results connect, however, to a debate among media and communication scholars on whether social media might exacerbate or attenuate the "spiral of silence", or the tendency of people not to speak up about policy issues when they believe their own point of view is not widely shared. Our results suggest that, on average, Facebook might help people feel more willing to speak up their political opinions.
} 
a negative one for TV and Newspapers, yet in this case the magnitudes of the coefficient are very small (of under one percentage point), suggesting no meaningful crowding out (or crowding in) of traditional media. In Panel A3 for the AB sample, all coefficients are positive and, in the case of Radio, a statistically significant 3.7 percentage point increase from a baseline use frequency of $73.8 \%$, suggesting some crowding in. Finally, Panel B uses the ESS to examine the impact on total media use (that is, for entertainment and other purposes and not simply to get news) and finds a negative impact on Radio (a point estimate of -0.03 with standard error of 0.01 , from an average mean of $78 \%$ for non-speakers) and on TV (point estimate of -0.013 with standard error of 0.006 and average mean of $96 \%$ for non-speakers).

We have two main takeaways from the findings of traditional media use. First, they contradict the fears voiced in the literature that online social networks simply displace traditional sources of information. Second, the effects are nuanced and depend on media type and context. While there is some (imprecise) evidence of displacement in the WVS sample especially for newspaper 28 , for other media and samples we find no such displacement and we even find that Facebook might increase traditional media use, in particular Radio in the African sample. One possibility is that, especially in developing country contexts, users directly access radio programs via Facebook, or share Radio content through the platform. Finally, using the available data from the ESS survey we find suggestive evidence that Facebook might crowd out traditional media for entertainment more than it crowds it out for news. Again, this could reflect users are consulting traditional media outlets or sharing their content through the platform.

\subsection{Social media and democracy}

The best available evidence about the causal effect of social media on protests comes from contexts of non-democratic regimes or weak democracies. Social media could be less important for protests in more democratic environments if it disproportionally facilitates tactical coordination (coordination/social channel) or discloses otherwise unavailable antigovernment news or information (information/non-social channel) in repressive regimes. On the other hand, there is evidence that governments in more authoritarian regimes can heavily influence not only traditional media but also social media. Therefore repressive regimes may block and even reverse each of these channels, controlling tactical coordination or the set of available information more efficiently using social media. In short, how the degree of democratization

\footnotetext{
${ }^{28}$ Consistent with the findings in Gavazza et al. (2019) for the UK and in Bhuller, Havnes, McCauley, and Mogstad (2020) for Norway.
} 
shapes the effect of social media on collective action is ultimately an empirical question.

In this section, we show a U-shape relationship between levels of democracy and governance and Facebook's effect on protests. With complementary evidence on protests' targets, we interpret the large effect in strong democracies as reflecting a relative political freedom to mobilize, despite probably fewer grievances. Instead, the strong effect in more autocratic areas occurs in spite of direct efforts to control collective action, thus likely reflecting that grievances dominate the additional risks of protesting in oppressive regimes.

In Figure 5, we explore differential effects of Facebook Speakers on protests using the more commonly employed indicators of democratic accountability and governance. The figure plots the effect of Facebook Speakers on protests at different levels of these indicators measured before the introduction of Facebook 29

Panels A to C consistently show that Facebook has been an important driver of protests especially in very autocratic or very democratic countries. Panels D to F show a similar picture when we interact the effect with indicators of voice and accountability, regulatory quality, and the rule of law. Only with control of corruption in Panel G there is a negative monotonic relationship.

We then explore specific characteristics of democracy directly related to the mechanisms. In Panel $\mathrm{H}$ and I, we divide the Freedom House index into its two components: Political Rights (measuring political pluralism, quality of the electoral process, and functioning of the government) and Civil Liberties (capturing freedom of expression and belief, associational and organizational rights, the rule of law, and personal autonomy and individual rights). In Panels $\mathrm{J}$ to $\mathrm{L}$ we look at Freedom of Opposition (measuring the allowed level of oppositional activity outside the ranks of the ruling party), Freedom of Assembly and Association (measuring the extent to which citizens are allowed by the government to join, form, and participate in political parties, protest or publicly criticize government decisions and actions), and the Freedom of the Press index (combining press pluralism, media independence, censorship, legislative framework, transparency, infrastructure, and abuses against

\footnotetext{
${ }^{29}$ We use the Freedom House indices (Panels A, H and I), Polity IV's democracy index (Panel B), V-Dem's democracy index (Panel C); the World Bank's governance indicators (Panels D, E, F and G), Freedom of Opposition (Panel J), Freedom of Assembly and Association (Panel K) and the Freedom of the Press index (Panel L). When the indices are constructed on a point scale, we interact dummy variables for each level with Facebook Speakers and plot the coefficients. For all other indices, we divide the scales into three equal parts (low, intermediate and high) and plot the coefficients for these interactions. We use the levels of the indices (rather than dividing the sample by quantiles, for example) because they build on the conceptual framework used in each case to determine whether a country scores low or high in democracy and governance, irrespective of whether few or many countries perform well.
} 
journalists).

The figure shows two consistent patterns. First and most important, Facebook has driven protests not only in places where the freedom of organization and expression has been very limited, presumably acting (at least partially) as a substitute to controlled media and offering a tool to coordinate, but also in places where the media is independent and where there are less associational barriers. Second, the effect of Facebook Speakers on collective action is more limited in places with intermediate levels of grievances, thus usually forming a U-shape pattern.

To help interpret these results, in Table 10 we further explore the nature of the protests that Facebook boosts by looking at the different protest targets. Since target data is incomplete (close to half of the sample has missing values), in column 1 of Panel A we run our baseline regression for an indicator variable on whether the protest target is known. Facebook Speakers has a negligible and not significant impact on reporting protest targets. In column 2, we restrict our sample to the $48.5 \%$ of protests with a known target and run our baseline specification, finding a coefficient very similar to our baseline. In columns 3-9 we run regressions where the dependent variable is protests against specific targets (in each column title under the protest target, we report how common each type is, expressed as a share of total protests with known targets) B0 Protests against most actors respond to Facebook Speakers, even though magnitudes vary somewhat as measured by the beta coefficients in the bottom of the panel.

Finally, we explore a potential connection between the U-shape pattern of the effects by levels of democracy and protest targets in Panel B of Table 10. In column 1, we group protests against the "establishment" (the army, government and legislature) as a single category and find a positive average impact of Facebook Speakers on these forms of collective action. In columns 2 to 4 , we break down this effect by low, middle, and high levels of democracy as measured by Freedom House, Polity and V-Dem. All columns confirm the U-shape pattern reported for protests as a whole: complaints against the government react most at either low or high levels of democracy. Column 5 then shows that the average effect of Facebook Speakers on protests against the opposition, while positive, is smaller and not significant at

\footnotetext{
${ }^{30}$ Protests against the government are the most common category (25.4\%), followed by armed forces $(16.2 \%)$. Other protests against regime actors, like the legislature $(3.2 \%)$, are less common. Protests against the opposition are also relatively rare (6.9\%). Protests against business, labor, and the media (which is defined broadly to include journalists, newspapers, television stations, as well as providers of Internet services and other forms of mass information dissemination and therefore akin to businesses or public sector providers) also react to Facebook Speakers, even though they are relatively infrequent (less than $4 \%$ of protests with known targets in each case).
} 
conventional levels. Nevertheless, when we explore the effects by levels of democracy using each of the three key indices in columns 6 to 8, the effect of Facebook on protests against the opposition are most important in the least democratic areas.

Thus, while results showing increased opposition to the government, the army, or the legislature are consistent with the notion that Facebook is mostly promoting citizen empowerment against the government, the findings related to protests against the political opposition in less democratic areas suggest that Facebook can also enhance the government's ability to organize rallies to attack the opposition. Taken together, these results suggest the following interpretation about the U-shape pattern in overall protests. Facebook's effect is large in consolidated democracies because despite probably fewer grievances there is little effort from the government to counteract these influences, including supporting protests against the opposition. Instead, the effect is strong in autocracies because despite efforts to counteract collective mobilization against the establishment (including aiding mobilization against the opposition), they are insufficient to overcome the increased opportunity for coordination and availability of new information in contexts where social and political grievances are likely meaningful.

\subsection{Social media and elections}

We now study the role of social media around prominent political events by exploiting the timing of elections. This is interesting not only given the potential critical impact that successful mobilizations may have when societies are electing their leaders, but also because it may shed some light on how social media interacts with the overall information environment.

The information/non-social influence of social media might play a more limited role since political information abounds in the traditional media during these episodes. Therefore, if traditional and social media are substitutes during elections, then the marginal contribution of social media is likely smaller. Of course, if there is sufficient complementarity, then access to social media could have larger effects on protests during elections.

As for the coordination/social channels, these may also be more or less prominent during elections depending on how social media interacts with traditional media. Traditional media possibly provides comparably more information than in "normal" times about the time, location and (expected) turnout of political rallies. This would ameliorate the impact of social media on protests if it substitutes its influence over tactical coordination and over beliefs about others' involvement, but would exacerbate it if it is complementary. Similarly, 
people are likely more politically mobilized and coordinated during elections and political parties deploy their organizational capacity for electoral campaigning. This might again make the marginal contribution of social media smaller if substitution dominates, but increase the role of social media if complementarity is more important.

We therefore extend our baseline regression by interacting Facebook Speakers with quarterly dummy variables around elections ${ }^{31}$ Figure 6 plots the results. Panel A plots the coefficients of the quarter dummies, and reveals that political mobilizations are indeed much more common during campaigning (one to two quarters before the election) and during the election's quarter. Panel B looks instead at the impact of Facebook Speakers during each period (that is, it plots the coefficient for the interaction of Facebook Speakers with the quarter dummies). The pattern is exactly opposite that of Panel A: Facebook's impact decreases one to two quarters before the election and during the election's quarter (when it is in fact small and not distinguishable from zero). Instead, the impact increases right after the election and is comparable to Facebook's effect during off-election quarters.

These results suggest that, during elections, traditional media presence and party organization might substitute the otherwise significant influence that Facebook has on protests via the social and/or non-social channels. Notice that this substitution refers to the role that social media plays in different time periods, not to a potential substitution away from social media use and into traditional media. Indeed, our estimates with individual data from Table 9 discussed in the previous section suggest no such substitution in our sample, since Facebook Speakers do not appear to consume less of other media sources. Moreover, Panel C of Figure 6 verifies that this conclusion also holds during quarters around the election. Also in this Panel, we find that Facebook use, as captured by our Facebook Searches variable, does not exhibit any cycle around elections.

Finally, Panels D to F of Figure 6 show no discernible cycle around elections for three key personal views (trust in institutions, satisfaction with government and satisfaction with democracy). In particular, these views have no noticeable change in off-election periods when we observe Facebook's strongest impact on protests, reaffirming the conclusion of the preceding section that social media's coordination/social channels are likely more important than information/non-social ones to influence collective mobilization.

From this we conclude that the main reason for the limited effects of social media during elections is that the organizational capacity deployed by political parties and other social

\footnotetext{
${ }^{31}$ We exclude countries without any election during the period of analysis, though results are similar if these are included.
} 
organizations trumps Facebook's coordination role. Facebook might be used during elections intensively, including to organize collective action, but such action would still have occurred without Facebook.

\subsection{Other political outcomes}

One fundamental question to discuss the possible welfare effects of Facebook's impact on collective action is whether it has been effective at changing other outcomes beyond protests. Table 11 looks at effects on regime change, democracy, governance, and conflict. Since most of these outcomes are measured annually, column 1 first verifies that at the yearly level we are still able to detect the positive impact of Facebook Speakers on protests. We then examine measures of regime change in columns 2 and $32^{32}$ of democracy in columns 4 to $73^{33}$ and of quality of governance indicators in columns 8 to 12 The Thenght this table using various dependent variables with different scales we report beta coefficients to facilitate assessing the magnitudes of the impacts. In Panel A, we find no significant effects on any of the outcomes. Moreover, the size of the standardized coefficients are typically small, of under one-percent with a few exceptions, implying precisely measured non-effects.

There are several possible reasons for the findings of Panel A. First, as we discussed when exploring effects by levels of democracy and protest targets, our own analysis reveals that there is an active effort to use this same tools to offset the effects on social media on collective action where protests might seek changing oppressive political regimes.

A second possible reason is that traditional power structures like political parties or the traditional media may trump Facebook's effect during key critical junctures, as suggested by our finding that Facebook has a more limited impact on protests during electoral campaigns. To the extent that significant governance or institutional change is more likely to occur during such windows of opportunity, this could be another reason why Facebook impacts protests

\footnotetext{
${ }^{32}$ Number of successful, attempted, plotted, or alleged coup d'état events (a forceful seizure of executive authority and office that results in a change in the executive leadership and policies of the prior regime, column 2), the number of irregular removals from office (when the executive leader was removed in contravention of explicit rules and established conventions, column 3).

${ }^{33}$ Composite index of institutionalized democracy on a 0 (less democratic) to 10 (more democratic) scale (column 4), composite index of institutionalized autocracy on a 0 (less autocratic) to 10 (more autocratic) scale (column 5), combined freedom rating, average of Political Rights and Civil Liberties indices, on a 1 to 7 scale (column 6), continuous index of institutionalized democracy on a 0 (less democratic) to 1 (more democratic) scale (column 7).

${ }^{34} \mathrm{On}$ a scale of 0 (lowest rank) to 100 (highest rank): voice and accountability (column 8), government effectiveness (column 9), regulatory quality (column 10), rule of law (column 11), and control of corruption (column 12).
} 
but with few other effects on broader political outcomes.

We investigate a third reason, closely related to the second, in Panels C1-C3 of Table 9 . whether Facebook fails to increase political engagement in any other form besides protests. Indeed, Facebook's impact on protests and freedom of expression might reflect a corresponding increase in other forms of political participation or interest. Alternatively, as some have warned, Facebook could crowd out political engagement in the "real" world. We use questions for political engagement from our surveys including voting, interest in and discussion of politics, participation in organizations, signing petitions and other forms of engagement like reaching politicians or participating in partisan activities and identifying with parties. We also report the effect on a normalized average of all available measures in each survey. For the composite index, being a Facebook Speaker does not change other forms of political participation and interest. Moreover, relative to the average (0.33, 0.25 and 0.52 in WVS, EES and $A B$, respectively), the Speaker effect is in each case a precisely measured zero (effects are merely $-0.037,0.003,0.0018$, respectively). The effect in some individual components is both statistically significant and the magnitudes not negligible 55 However, because there is no consistent direction of other effects, and most coefficients are both relatively small and not statistically significant, we conclude that there is no compelling evidence that Facebook crowds in (or crowds out) other forms of political participation and interest. This might also explain why we see few changes in democratization or governance 36

Panel B of Table 11 turns to Facebook's impact on conflict in columns 1 to $33^{37}$ Interestingly, in this case we do find a substantial decrease with standardized effects of close to $5 \%$ for all types of conflict (column 1), as well as when we break the effect for minor internal conflict (column 2) or more intense civil war (column 3).

We explore two possible reasons. First, the increase in collective action facilitated by Facebook provides one way to voice discontent and conflict that might otherwise turn more violent. That people feel politically "liberated" as we showed in Table 7 is consistent with

\footnotetext{
${ }^{35}$ Most importantly, interest in politics in the WVS and ESS increases, as does working with a political party in the ESS. In contrast, the coefficient for being a member of an association is large and negative in the WVS sample.

${ }^{36} \mathrm{~A}$ final possibility is that most of these variables tend to react more slowly and our strategy is best suited to capturing effects on variables that might react quickly to greater Facebook access. Nevertheless, recall that this are yearly-level regressions. Coupled with the precision of our estimates, this table offers compelling evidence that increased Facebook access has been unable to increase governance, regime change or democratization.

${ }^{37}$ Number of violent internal conflicts of any intensity (column 1), number of minor internal conflicts producing between 25 and 1,000 battle-related deaths in a given year (column 2), number of internal civil conflicts or war producing over 1,000 battle-related deaths in a given year (column 3).
} 
this possibility. Also, in columns 4 to 11 we examine heterogeneous effects using the common determinants of collective action and social strife (as we did in Table 3 for protests). The decrease is much larger for countries with historical conflict, where the effect is twice as large for a one-standard deviation increase in historical conflict. In the remaining columns the interactions with factors that might make countries more conflict-prone is also negative, albeit with smaller coefficients (the sole exception is column 11 where we interact with the share of urban population, where the interaction is positive and very close to zero). This provides some suggestive evidence that areas where there are more underlying reasons for conflict Facebook's protests help voice discontent that would otherwise turn violent.

A second possibility builds on the idea that the media environment constraints behavior in conflict settings (Seethaler, Karmasin, Melischek, \& Wöhlert, 2013). Specifically, and as shown by Durante and Zhuravskaya (2018), increased visibility could deter certain violent actions, thus decreasing conflict. Suggestive evidence of the importance of this mechanism appears in column 12, where we show that the decrease in civil conflict is smaller in places that enjoy more freedom of the press, where we would expect this effect to be smaller. A one-standard deviation increase in the freedom of the press index decreases the impact of Facebook Speaker on reduced conflict by roughly one half.

\section{Conclusion}

We study Facebook's effect on collective action on a global scale. We find robust evidence that it increases collective action. The effect appears when exploiting different levels of variation, including when we focus simply on within-country changes in Facebook access areas with different languages, as well as when we rely on media-based or individual reports of protest participation.

Collecting data for various countries and over an extended period, we therefore confirm the external validity of previous research documenting this effect for specific contexts along a number of dimensions: geographically, by regime type, temporally, and by the socioeconomic characteristics of both countries and social media users.

Informing the mechanisms that drive these effects, we find that the "social" nature of social media plays an important role beyond one-way information transmission. Also, we argue that these "coordination" or social mechanisms reflect a "liberation effect" produced by having a direct outlet to voice opinions and share them with others. The intrinsic effect of having such access to a platform of social expression goes beyond tactical coordination, 
concerns about social image, or the effect of beliefs about others' participation studied in the literature.

Finally, we explore the broader political consequences of increased Facebook access, helping to assess the welfare consequences of the increase in protests. A long tradition going back to at least Olson (1965) emphasizes the importance of collective action to bring about "good" social outcomes. Along these lines, theories and evidence on democratization give protests a key role (Acemoglu \& Robinson, 2006; Aidt \& Franck, 2015; Aidt \& Leon, 2016). Therefore, the finding that Facebook causes protests raises key questions to gauge the broader welfare implications, including whether these protests have discernible additional aggregate effects.

Some of our results, like the stronger impacts on undemocratic areas and places with limited press freedom, the effects on anti-government protests, as well as the increased freedom of political expression reported by individuals, align with this tradition by suggesting that Facebook is empowering people and unsettling traditional elites in contexts of weak accountability (Farrell, 2012). These results could counteract fears that the Internet, and social media in particular, could facilitate control and propaganda by authoritarian regimes, empower a small set of elites (Hindman, 2009), facilitate control of citizen collective action (Morozov, 2012, 2014; King et al., 2013), spread misinformation (Silverman, 2016; Silverman \& Singer-Vine, 2016; Allcott \& Gentzkow, 2017; Munger, Egan, Nagler, Ronen, \& Tucker, 2020; Allcott, Gentzkow, \& Yu, 2019), or facilitate foreign influence (Martin \& Shapiro, 2019).

However, it would be overstating to conclude that social media is unambiguously a "liberation" technology. As with any general-purpose technology, it has many other applications, so the broader (and changing) implications as different players adapt are still up for debate (J. A. Tucker, Theocharis, Roberts, \& Barberá, 2017). Our findings suggest that protests against the opposition also increase, and that some additional mobilizations are violent results that may have negative welfare consequences. More substantially, we show that the increase in Facebook access has produced no broader changes in the political equilibrium in the form of regime change, improvements in indices of democracy, and measures of governance. To explain this result, we document a failure to spur other political engagements, especially during critical periods, and that social media is also used to mobilize against opposition groups, especially in less democratic areas. On the positive side, we find that Facebook access decreases internal conflict, with evidence that this reflects increased visibility deterring violence and that social media and the resulting protests help voice discontents and conflicts that might otherwise turn more violent. 


\section{References}

Abadie, A. (2003). Semiparametric instrumental variable estimation of treatment response models. Journal of Econometrics, 113(2), 231-263.

Acemoglu, D., Fergusson, L., \& Johnson, S. (2020). Population and conflict. The Review of Economic Studies, 87(4), 1565-1604.

Acemoglu, D., Hassan, T. A., \& Tahoun, A. (2017). The power of the street: Evidence from Egypt's Arab Spring. The Review of Financial Studies, 31(1), 1-42.

Acemoglu, D., \& Robinson, J. A. (2006). Economic origins of dictatorship and democracy. New York, NY: Cambridge University Press.

Aday, S., Farrell, H., Lynch, M., Sides, J., Kelly, J., \& Zuckerman, E. (2010). Blogs and bullets: New media in contentious politics. Washington, DC: United States Institute of Peace.

Aidt, T. S., \& Franck, R. (2015). Democratization under the threat of revolution: Evidence from the Great Reform Act of 1832. Econometrica, 83(2), 505-547.

Aidt, T. S., \& Leon, G. (2016). The democratic window of opportunity: Evidence from riots in Sub-Saharan Africa. Journal of Conflict Resolution, 60(4), 694-717.

Alesina, A., Baqir, R., \& Easterly, W. (1999). Public goods and ethnic divisions. The Quarterly Journal of Economics, 114(4), 1243-1284.

Allcott, H., Braghieri, L., Eichmeyer, S., \& Gentzkow, M. (2020). The welfare effects of social media. American Economic Review, 110(3), 629-76.

Allcott, H., \& Gentzkow, M. (2017). Social media and fake news in the 2016 election. Journal of Economic Perspectives, 31(2), 211-36.

Allcott, H., Gentzkow, M., \& Yu, C. (2019). Trends in the diffusion of misinformation on social media. Research \& Politics, 6(2), 1-8.

Angrist, J. D., \& Pischke, J.-S. (2008). Mostly harmless econometrics: An empiricist's companion. Princeton: PUP.

Arellano, M., \& Bond, S. (1991). Some tests of specification for panel data: Monte Carlo evidence and an application to employment equations. The Review of Economic Studies, $58(2), 277-297$.

Barberá, P. (2014). How social media reduces mass political polarization: Evidence from Germany, Spain, and the US. Job Market Paper, New York University, 46 .

Barberá, P., Wang, N., Bonneau, R., Jost, J. T., Nagler, J., Tucker, J., \& González-Bailón, S. (2015). The critical periphery in the growth of social protests. PloS one, 10(11), 
$\mathrm{e} 0143611$.

Barbera, S., \& Jackson, M. O. (2020). A model of protests, revolution, and information. Quarterly Journal of Political Science, 15(1), 297-335.

Bellemare, M. F., \& Wichman, C. J. (2020). Elasticities and the inverse hyperbolic sine transformation. Oxford Bulletin of Economics and Statistics, 82(1), 50-61.

Bennett, W. L., \& Segerberg, A. (2012). The logic of connective action: Digital media and the personalization of contentious politics. Information, Communication $\&$ Society, 15(5), 739-768.

Bertrand, M., Duflo, E., \& Mullainathan, S. (2004). How much should we trust differencesin-differences estimates? Quarterly Journal of Economics, 119(1), 249-275.

Bhuller, M., Havnes, T., Leuven, E., \& Mogstad, M. (2013). Broadband internet: An information superhighway to sex crime? Review of Economic Studies, 80(4), 12371266.

Bhuller, M., Havnes, T., McCauley, J., \& Mogstad, M. (2020). How the internet changed the market for print media. Unpublished.

Boxell, L., Gentzkow, M., \& Shapiro, J. M. (2017). Greater internet use is not associated with faster growth in political polarization among US demographic groups. Proceedings of the National Academy of Sciences, 114(40), 10612-10617.

Brewster, T. (2021). Sheryl sandberg downplayed facebook's role in the capitol hill siege-justice department files tell a very different story. Retrieved from https://www.forbes.com/sites/thomasbrewster/2021/02/07/ sheryl-sandberg-downplayed-facebooks-role-in-the-capitol-hill-siege -justice-department-files-tell-a-very-different-story/ (Accessed: 202003-19)

Bursztyn, L., Egorov, G., Enikolopov, R., \& Petrova, M. (2019). Social media and xenophobia: Evidence from Russia. National Bureau of Economic Research, NBER Working Paper No. 26567.

Cagé, J., Hervé, N., \& Mazoyer, B. (2020). Social media and newsroom production decisions. Available at SSRN 3663899.

Cameron, C., \& Trivedi, P. (2015). Count panel data. In B. H. Baltagi (Ed.), Oxford handbook of panel data econometrics (chap. 8). Oxford: Oxford University Press.

Campante, F., \& Chor, D. (2012). Why was the Arab World poised for revolution? Schooling, economic opportunities, and the Arab Spring. Journal of Economic Perspectives, $26(2), 167-88$. 
Campante, F., \& Chor, D. (2014). "The people want the fall of the regime": Schooling, political protest, and the economy. Journal of Comparative Economics, 42(3), 495517.

Campante, F., Do, Q.-A., \& Guimaraes, B. (2019). Capital cities, conflict, and misgovernance. American Economic Journal: Applied Economics, 11 (3), 298-337.

Campante, F., Durante, R., \& Sobbrio, F. (2017). Politics 2.0: The multifaceted effect of broadband internet on political participation. Journal of the European Economic Association, 16(4), 1094-1136.

Cantoni, D., Yang, D. Y., Yuchtman, N., \& Zhang, Y. J. (2019). Protests as strategic games: Experimental evidence from Hong Kong's antiauthoritarian movement. The Quarterly Journal of Economics, 134(2), 1021-1077.

Caren, N. (2014). It is time to get rid of the E in GDELT. Retrieved from http:// badhessian.org/2014/05/it-is-time-to-get-rid-of-the-e-in-gdelt/ (Accessed: 2020-03-19)

Christensen, D., \& Garfias, F. (2018). Can you hear me now? How communication technology affects protest and repression. Quarterly Journal of Political Science, 13(1), 89-117.

Collins, W. J., \& Margo, R. A. (2007). The economic aftermath of the 1960s riots in American cities: Evidence from property values. The Journal of Economic History, $67(04), 849-883$.

Cook, R. D. (1977). Detection of influential observation in linear regression. Technometrics, $19(1), 15-18$.

Diamond, L. (2010). Liberation technology. Journal of Democracy, 21, 69.

Diamond, L., \& Plattner, M. F. (Eds.). (2012). Liberation technology: Social media and the struggle for democracy. Baltimore, MD: Johns Hopkins University Press.

DiPasquale, D., \& Glaeser, E. L. (1998). The Los Angeles riot and the economics of urban unrest. Journal of Urban Economics, 43(1), 52-78.

Durante, R., \& Zhuravskaya, E. (2018). Attack when the world is not watching? US news and the Israeli-Palestinian conflict. Journal of Political Economy, 126(3), 1085-1133.

Economist, T. (2019). Something in the air: Why are so many countries witnessing mass protests? Retrieved from https://www.economist.com/international/2019/11/ 04/why-are-so-many-countries-witnessing-mass-protests (Accessed: 2020-0319)

Edmond, C. (2013). Information manipulation, coordination, and regime change. Review of 
Economic Studies, 80(4), 1422-1458.

El-Mallakh, N. (2017). Did the Egyptian protests lead to change? Evidence from Egypt's first free presidential elections. Documents de Travail du Centre d'Economie de la Sorbonne.

El-Mallakh, N., Maurel, M., \& Speciale, B. (2018). Arab spring protests and women's labor market outcomes: Evidence from the egyptian revolution. Journal of Comparative Economics, 46(2), 656-682.

Enikolopov, R., Makarin, A., \& Petrova, M. (2020). Social media and protest participation: Evidence from Russia. Econometrica, 88(4), 1479-1514.

Enikolopov, R., Makarin, A., Petrova, M., \& Polishchuk, L. (2017). Social image, networks, and protest participation. dx.doi.org/10.2139/ssrn.2940171.

Enikolopov, R., Petrova, M., \& Sonin, K. (2018). Social media and corruption. American Economic Journal: Applied Economics, 10(1), 150-74.

Esteban, J., \& Ray, D. (1994). On the measurement of polarization. Econometrica, 62(4), $819-51$.

Esteban, J., \& Ray, D. (2008). Polarization, fractionalization and conflict. Journal of Peace Research, 45(2), 163-182.

Facebook Reports. (2019). Facebook reports first quarter 2019 results. Retrieved from https://investor.fb.com/investor-news/press-release-details/ 2019/Facebook-Reports-First-Quarter-2019-Results/default.aspx (Accessed: 2020-03-19)

Farrell, H. (2012). The consequences of the internet for politics. Annual Review of Political Science, 15(1), 35-52.

Frost, R. D., \& Strauss, J. (2016). E-marketing. Routledge.

Fujiwara, T., Müller, K., \& Schwarz, C. (2020). The effect of social media on elections: Evidence from the United States. Available at SSRN.

Gavazza, A., Nardotto, M., \& Valletti, T. (2019). Internet and politics: Evidence from U.K. local elections and local government policies. The Review of Economic Studies, 86(5), 2092-2135.

Gentzkow, M., \& Shapiro, J. M. (2011). Ideological segregation online and offline. The Quarterly Journal of Economics, 126(4), 1799-1839.

Gladwell, M. (2010). Small change. The New Yorker, 4(2010), 42-49.

Glaeser, E. L., \& Steinberg, B. M. (2017). Transforming cities: Does urbanization promote democratic change? Regional Studies, 51(1), 58-68. 
González, F. (2020). Collective action in networks: Evidence from the Chilean Student Movement. Journal of Public Economics, 188, 104220.

González-Bailón, S., Borge-Holthoefer, J., Rivero, A., \& Moreno, Y. (2011). The dynamics of protest recruitment through an online network. Scientific reports, 1, 197.

Granovetter, M. S. (1973). The strength of weak ties. American Journal of Sociology, 78(6), 1360-1380.

Guriev, S., Melnikov, N., \& Zhuravskaya, E. (2020). 3G internet and confidence in government. The Quarterly Journal of Economics, forthcoming.

Hindman, M. (2009). The myth of digital democracy. Princeton, NJ: PUP.

Holman, E. (2014). Programs for calculating ASJP distance matrices. (version 2.2).

Humphreys, M. (2005). Natural resources, conflict, and conflict resolution. Journal of Conflict Resolution, 49(4), 508-537.

Jost, J. T., Barberá, P., Bonneau, R., Langer, M., Metzger, M., Nagler, J., .. Tucker, J. A. (2018). How social media facilitates political protest: Information, motivation, and social networks. Political Psychology, 39, 85-118.

King, G., Pan, J., \& Roberts, M. (2013). How censorship in China allows government criticism but silences collective expression. American Political Science Review, 107(2), $1-18$.

King, G., Pan, J., \& Roberts, M. E. (2014). Reverse-engineering censorship in China: Randomized experimentation and participant observation. Science, 345(6199), 1251722.

Larcinese, V., \& Miner, L. (2017). The political impact of the internet on US presidential elections. Unpublished manuscript.

Larson, J. M., Nagler, J., Ronen, J., \& Tucker, J. A. (2019). Social networks and protest participation: Evidence from 130 million Twitter users. American Journal of Political Science, 63(3), 690-705.

Little, A. T. (2016). Communication technology and protest. The Journal of Politics, 78(1), $152-166$.

Madestam, A., Shoag, D., Veuger, S., \& Yanagizawa-Drott, D. (2013). Do political protests matter? Evidence from the Tea Party Movement. The Quarterly Journal of Economics, 128(4), 1633. doi: 10.1093/qje/qjt021

Manacorda, M., \& Tesei, A. (2020). Liberation technology: Mobile phones and political mobilization in Africa. Econometrica, 88(2), 533-567.

Martin, D. A., \& Shapiro, J. N. (2019). Trends in online foreign influence efforts. ESOC Publications. 
Montalvo, J. G., \& Reynal-Querol, M. (2005a). Ethnic diversity and economic development. Journal of Development Economics, 76 (2), 293-323.

Montalvo, J. G., \& Reynal-Querol, M. (2005b). Ethnic polarization, potential conflict, and civil wars. American Economic Review, 95(3), 796-816.

Morozov, E. (2012). The net delusion: The dark side of internet freedom. PublicAffairs.

Morozov, E. (2014). To save everything, click here: The folly of technological solutionism. PublicAffairs.

Müller, K., \& Schwarz, C. (2020a). Fanning the flames of hate: Social media and hate crime. Journal of the European Economic Association, 00(0), 1-37.

Müller, K., \& Schwarz, C. (2020b). From hashtag to hate crime: Twitter and anti-minority sentiment. http://dx.doi.org/10.2139/ssrn.3149103.

Munger, K., Bonneau, R., Jost, J. T., Nagler, J., \& Tucker, J. A. (2016). Elites tweet to get feet off the streets: Measuring regime social media strategies during protest. $N Y U$ SMaPP Lab.

Munger, K., Egan, P., Nagler, J., Ronen, J., \& Tucker, J. A. (2020). Political knowledge and misinformation in the era of social media: Evidence from the 2015 UK election. British Journal of Political Science.

Nash, G. (2009). The urban crucible: The northern seaports and the origins of the american revolution. Cambridge, MA: Harvard University Press.

Olson, M. (1965). Logic of collective action public goods and the theory of groups. Cambridge, MA: Harvard University Press.

Pierskalla, J. H., \& Hollenbach, F. M. (2013). Technology and collective action: The effect of cell phone coverage on political violence in Africa. American Political Science Review, $107(2), 207-224$.

Qin, B., Strömberg, D., \& Wu, Y. (2017). Why does China allow freer social media? Protests versus surveillance and propaganda. Journal of Economic Perspectives, 31 (1), 117-40.

Qin, B., Strömberg, D., \& Wu, Y. (2019). Social media, information networks, and protests in China. (Unpublished manuscript)

Rose, A. K., \& Spiegel, M. M. (2011). Cross-country causes and consequences of the crisis: An update. European Economic Review, 55(3), 309-324.

Ross, M. (2006). A closer look at oil, diamonds, and civil war. Annual Review of Political Science, 9, 265-300.

Ross, M. (2008). Oil, Islam, and women. American Political Science Review, 102(1), $107-123$. 
Ross, M. L. (2004). What do we know about natural resources and civil war? Journal of Peace Research, 41(3), 337-356.

Sanovich, S., Stukal, D., Penfold-Brown, D., \& Tucker, J. (2015). Turning the virtual tables: Government strategies for addressing online opposition with an application to Russia. In Annual conference of the international society of new institutional economics.

Schrodt, P. A. (2012). Cameo: Conflict and mediation event observations event and actor codebook. Pennsylvania State University.

Seethaler, J., Karmasin, M., Melischek, G., \& Wöhlert, R. (2013). Selling war: The role of the mass media in hostile conflicts from world war $i$ to the "war on terror". Intellect Books.

Segerberg, A., \& Bennett, W. L. (2011). Social media and the organization of collective action: Using Twitter to explore the ecologies of two climate change protests. The Communication Review, $14(3)$, 197-215.

Silverman, C. (2016). This analysis shows how fake election news stories outperformed real news on facebook. Retrieved from https://www.buzzfeed.com/craigsilverman/ viral-fake-election-news-outperformed-real-news-on-facebook

Silverman, C., \& Singer-Vine, J. (2016). Most americans who see fake news believe it, new survey says. Retrieved from https://www.buzzfeed.com/craigsilverman/fake -news-survey

Steinert-Threlkeld, Z. C., Mocanu, D., Vespignani, A., \& Fowler, J. (2015). Online social networks and offline protest. EPJ Data Science, 4(1), 19.

Stewart, E. (2019). Facebook has taken down billions of fake accounts, but the problem is still getting worse. Retrieved from https://www.vox.com/recode/2019/5/23/18637596/ facebook-fake-accounts-transparency-mark-zuckerberg-report (Accessed: 2020-03-19)

Strezhnev, A. (2014). How bad are duplication problems in GDELT events data? Very! Retrieved from http://causalloop.blogspot.com/2014/05/how-bad-are -duplication-problems-in.html (Accessed: 2020-03-19)

Traugott, M. (1995). Capital cities and revolution. Social Science History, 19(1), 147-168.

Tucker, J., Metzger, M., Penfold-Brown, D., Bonneau, R., Jost, J., \& Nagler, J. (2015). Protest in the age of social media. Medium.com.

Tucker, J. A., Theocharis, Y., Roberts, M. E., \& Barberá, P. (2017). From liberation to turmoil: social media and democracy. Journal of Democracy, 28(4), 46-59.

Tufekci, Z., \& Wilson, C. (2012). Social media and the decision to participate in political 
protest: Observations from Tahrir Square. Journal of Communication, 62(2), 363379.

Vaccari, C., Valeriani, A., Barberá, P., Bonneau, R., Jost, J. T., Nagler, J., \& Tucker, J. A. (2015). Political expression and action on social media: Exploring the relationship between lower-and higher-threshold political activities among Twitter users in Italy. Journal of Computer-Mediated Communication, 20(2), 221-239.

Valenzuela, S. (2013). Unpacking the use of social media for protest behavior: The roles of information, opinion expression, and activism. American Behavioral Scientist, 57(7), 920-942.

Valenzuela, S., Arriagada, A., \& Scherman, A. (2012). The social media basis of youth protest behavior: The case of Chile. Journal of Communication, 62(2), 299-314.

Wang, W., Kennedy, R., Lazer, D., \& Ramakrishnan, N. (2016). Growing pains for global monitoring of societal events. Science, 353(6307), 1502-1503.

Weidmann, N. B. (2016). A closer look at reporting bias in conflict event data. American Journal of Political Science, 60(1), 206-218.

Weiner, M. (1967). Urbanization and political protest/urbanisation et agitation politique. Civilisations, 44-52.

Wichmann, S., Holman, E., \& Brown, C. (2016). The ASJP database. (data retrieved from the Automated Similarity Judgment Program, http://asjp.clld.org/)

Zhuravskaya, E., Petrova, M., \& Enikolopov, R. (2020). Political effects of the internet and social media. Annual Review of Economics, 12, 415-438. 
Table 1: Summary Statistics

\begin{tabular}{|c|c|c|c|c|c|c|}
\hline & \multicolumn{6}{|c|}{ Descriptive Statistics } \\
\hline & Observations & Mean & Median & SD & Min & Max \\
\hline \multicolumn{7}{|c|}{ Panel A. Main variables country analysis, 2000.1-2015.12 (240 countries) } \\
\hline Protests & 46,080 & 63.36 & 5.00 & 364.06 & 0.00 & $16,951.00$ \\
\hline $\log (1+$ Protests $)$ & 46,080 & 2.04 & 1.79 & 1.88 & 0.00 & 9.74 \\
\hline Facebook Speakers & 46,080 & 0.18 & 0.00 & 0.34 & 0.00 & 1.00 \\
\hline Facebook Second-Language Speakers & 46,080 & 0.17 & 0.00 & 0.32 & 0.00 & 2.00 \\
\hline Facebook Searches & 45,120 & 0.19 & 0.01 & 0.24 & 0.00 & 0.69 \\
\hline Facebook Users & 10,359 & 1.30 & 0.00 & 4.18 & 0.00 & 18.87 \\
\hline \multicolumn{7}{|c|}{ Panel B. Controls, Pre-2004 } \\
\hline Population (millions) & 240 & 24.63 & 3.75 & 107.27 & 0.00 & $1,258.37$ \\
\hline GDP (USD billions) & 214 & 226.11 & 12.32 & 963.40 & 0.03 & $11,966.75$ \\
\hline Internet users (millions) & 214 & 3.15 & 0.11 & 13.65 & 0.00 & 169.01 \\
\hline Linguistic polarization & 214 & 0.47 & 0.50 & 0.27 & 0.00 & 1.00 \\
\hline Share of population aged $15-24$ & 214 & 17.51 & 18.71 & 6.57 & 0.00 & 81.63 \\
\hline Share of GDP in manufacturing & 214 & 0.23 & 0.12 & 1.54 & 0.00 & 22.60 \\
\hline \multicolumn{7}{|c|}{ Panel C: Main variables subnational analysis (4,777 jurisdictions) } \\
\hline Protests & $1,441,728$ & 1.43 & 0.00 & 33.95 & 0.00 & $9,027.00$ \\
\hline $\log (1+$ Protests $)$ & $1,441,728$ & 0.11 & 0.00 & 0.54 & 0.00 & 9.11 \\
\hline Facebook Speakers & $1,441,728$ & 0.01 & 0.00 & 0.12 & 0.00 & 1.00 \\
\hline $\log (1+$ Political Protests $)$ & $1,441,728$ & 0.02 & 0.00 & 0.22 & 0.00 & 6.65 \\
\hline $\log (1+$ Demonstrations $)$ & $1,441,728$ & 0.09 & 0.00 & 0.49 & 0.00 & 8.82 \\
\hline $\log (1+$ Hunger Strikes $)$ & $1,441,728$ & 0.01 & 0.00 & 0.13 & 0.00 & 6.56 \\
\hline $\log (1+$ Strikes or boycotts $)$ & $1,441,728$ & 0.02 & 0.00 & 0.19 & 0.00 & 5.86 \\
\hline $\log (1+$ Blocks $)$ & $1,441,728$ & 0.01 & 0.00 & 0.11 & 0.00 & 6.67 \\
\hline $\log (1+$ Violent Protests $)$ & $1,441,728$ & 0.03 & 0.00 & 0.23 & 0.00 & 7.01 \\
\hline \multicolumn{7}{|l|}{ Only Africa... } \\
\hline $\log (1+$ Protests $)$, GDELT & 469,056 & 0.08 & 0.00 & 0.42 & 0.00 & 8.55 \\
\hline $\log (1+$ Protests $)$, ACLED & 469,056 & 0.02 & 0.00 & 0.17 & 0.00 & 5.26 \\
\hline Facebook Speakers & 469,056 & 0.00 & 0.00 & 0.04 & 0.00 & 1.00 \\
\hline \multicolumn{7}{|c|}{ Panel D. Main variables individual analysis } \\
\hline Protest (All surveys) & 708,936 & 0.26 & 0.00 & 0.44 & 0.00 & 1.00 \\
\hline Facebook Speaker (All surveys) & 708,936 & 0.29 & 0.00 & 0.45 & 0.00 & 1.00 \\
\hline Protest (World Value Survey) & 239,114 & 0.48 & 0.00 & 0.50 & 0.00 & 1.00 \\
\hline Facebook Speaker (World Value Survey) & 239,114 & 0.20 & 0.00 & 0.40 & 0.00 & 1.00 \\
\hline Protest (European Social Survey) & 340,562 & 0.07 & 0.00 & 0.25 & 0.00 & 1.00 \\
\hline Facebook Speaker (European Social Survey) & 340,562 & 0.41 & 0.00 & 0.49 & 0.00 & 1.00 \\
\hline Protest (Afrobarometer) & 129,260 & 0.38 & 0.00 & 0.49 & 0.00 & 1.00 \\
\hline Facebook Speaker (Afrobarometer) & 129,260 & 0.13 & 0.00 & 0.34 & 0.00 & 1.00 \\
\hline
\end{tabular}

Notes: The units of observation are as follows: Panel A, country-month; Panel B, country; Panel C, a region within a country and month; Panel D, an individual in a survey wave. Facebook Speakers is the proportion of people speaking (as a first language) a language available in Facebook, Facebook Second-Language Speakers is the proportion speaking (as a second language) a language available in Facebook (note that people may speak more than one second language, so this proportion may exceed 1), and Facebook Speaker is an indicator variable for whether the respondent's language is available in Facebook. Facebook Searches is the Google Trends index for the intensity of searches for the word "Facebook" in each country-month. Facebook Users are expressed in logarithms (we take the log of one plus users to allow for zero values). For all variable definitions and sources, see Appendix Table A-1 


\section{Table 2: Effect of Facebook Speakers on Protests and Facebook Use}

\begin{tabular}{lccccc}
\hline \hline \multicolumn{7}{c}{} & $(1)$ & $(2)$ & $(3)$ & $(4)$ & $(5)$ \\
\hline $\begin{array}{l}\text { Panel A. The effect of Facebook Speakers on protests } \\
\text { Dependent variable is log }(1+\text { protests) }\end{array}$ & & & & & \\
& & & & & \\
Facebook Speakers & 0.3578 & 0.2649 & 0.2213 & 0.2350 & 0.2699 \\
& $(0.1082)$ & $(0.0764)$ & $(0.0788)$ & $(0.0839)$ & $(0.0868)$ \\
& {$[0.0772]$} & {$[0.0757]$} & {$[0.0872]$} & {$[0.0847]$} & {$[0.0847]$} \\
& $\{0.0593\}$ & $\{0.0716\}$ & $\{0.0825\}$ & $\{0.0894\}$ & $\{0.0898\}$ \\
Semi-elasticity (exact formula) & 0.3633 & 0.2690 & 0.2248 & 0.2386 & 0.2741 \\
& $(0.1099)$ & $(0.0776)$ & $(0.0800)$ & $(0.0852)$ & $(0.0881)$
\end{tabular}

\begin{tabular}{|c|c|c|c|c|c|}
\hline \multicolumn{6}{|c|}{$\begin{array}{l}\text { Panel B. The effect of Facebook Speakers on Facebook Searches } \\
\text { Dependent variable is Facebook Searches }\end{array}$} \\
\hline Facebook Speakers & $\begin{array}{c}0.0618 \\
(0.0153)\end{array}$ & $\begin{array}{c}0.0931 \\
(0.0185)\end{array}$ & $\begin{array}{c}0.0834 \\
(0.0212)\end{array}$ & $\begin{array}{c}0.0787 \\
(0.0225)\end{array}$ & $\begin{array}{c}0.0655 \\
(0.0229)\end{array}$ \\
\hline Observations (Panels A-B) & 44,928 & 44,928 & 40,896 & 40,896 & 40,896 \\
\hline Countries (Panels A-B) & 234 & 234 & 213 & 213 & 213 \\
\hline \multicolumn{6}{|c|}{$\begin{array}{l}\text { Panel C. Correlation of Facebook searches and Facebook users } \\
\text { Dependent variable is Facebook Searches }\end{array}$} \\
\hline Facebook Users & $\begin{array}{c}0.0553 \\
(0.0056)\end{array}$ & $\begin{array}{c}0.0563 \\
(0.0060)\end{array}$ & $\begin{array}{c}0.0603 \\
(0.0089)\end{array}$ & $\begin{array}{c}0.0603 \\
(0.0089)\end{array}$ & $\begin{array}{c}0.0552 \\
(0.0088)\end{array}$ \\
\hline
\end{tabular}

Panel D. Validating Facebook Speakers with users data

Dependent variable is Facebook Users

$\begin{array}{cccccc}\text { Facebook Speakers } & 1.2695 & 1.3326 & 1.0552 & 1.0552 & 0.6736 \\ & (0.3421) & (0.3455) & (0.2898) & (0.2898) & (0.2510)\end{array}$

\begin{tabular}{lccccc}
\hline Observations (Panels C-D) & 10,357 & 10,357 & 10,357 & 10,357 & 10,357 \\
Countries (Panels C-D) & 115 & 115 & 115 & 115 & 115 \\
\hline Country fixed effects $\times$ linear trend & & $\checkmark$ & $\checkmark$ & $\checkmark$ & $\checkmark$ \\
Country fixed effects $\times$ quadratic trend & & & $\checkmark$ & $\checkmark$ & $\checkmark$ \\
Controls $\times$ month fixed effects & & & & $\checkmark$ \\
\hline \hline
\end{tabular}

Notes: Estimates of the effect of Facebook Speakers on the log of one plus protests (Panel A), Facebook Searches (Panel B) and Facebook Users (Panel D) as well as the correlation between Facebook Users and Facebook Searches (Panel C). Country-level regressions with monthly data from January 2000 to December 2015. Facebook Speakers is the proportion of people speaking (as a first language) a language available in Facebook in each country and month. Facebook Searches is the log of an index of search interest for the term "Facebook" from Google Trends. Facebook Users, available for a subset of country-months, is the number of registered Facebook users (expressed in logs, taking $\log$ of one plus users to allow for zero values). Controls, measured in the pre-treatment period, include GDP, share of GDP in manufacturing, share of population aged 15 - 24, Internet users, and linguistic polarization. For all variable definitions and sources, see Appendix Table A-1 Semi-elasticity (exact formula) is the percent increase in the dependent variable caused by a change from $0 \%$ to $100 \%$ in Facebook Speakers. All regressions include country fixed effects, month fixed effects as well as initial population interacted with time fixed effects. Two-way clustering of standard errors at the month and country levels reported in parenthesis. Two-way clustering of standard errors at the month and (main) language levels reported in square brackets. Standard errors from randomized inference drawing the timing of Facebook expansion in curly brackets. 
Table 3: Effect of Facebook Speakers on Protests

Heterogenous effects with determinants of protests and other country characteristics

\begin{tabular}{|c|c|c|c|c|c|c|c|c|c|}
\hline & 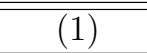 & $(2)$ & (3) & (4) & $(5)$ & (6) & (7) & (8) & 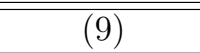 \\
\hline \multicolumn{10}{|c|}{ Dependent variable is $\log (1+$ protests $)$} \\
\hline & \multicolumn{9}{|c|}{ Facebook Speakers $\times \ldots$} \\
\hline & $\begin{array}{c}\text { Internet } \\
\text { users }\end{array}$ & $\begin{array}{c}\text { Historical } \\
\text { protests }\end{array}$ & $\begin{array}{c}\text { Years of } \\
\text { schooling }\end{array}$ & $\begin{array}{c}\text { Linguistic } \\
\text { fragmentation }\end{array}$ & $\begin{array}{c}\text { Linguistic } \\
\text { polarization }\end{array}$ & $\begin{array}{c}\text { Diamond } \\
\text { production }\end{array}$ & $\begin{array}{c}\text { Oil } \\
\text { reserves }\end{array}$ & $\begin{array}{c}\text { Oils and gas } \\
\text { rents }\end{array}$ & $\begin{array}{c}\text { Share urban } \\
\text { population }\end{array}$ \\
\hline \multirow[t]{2}{*}{ Facebook Speakers } & 0.2118 & 0.1754 & 0.1119 & 0.1645 & 0.2032 & 0.2353 & 0.2282 & 0.1857 & 0.1566 \\
\hline & $(0.0812)$ & $(0.0781)$ & $(0.0927)$ & $(0.0944)$ & $(0.0793)$ & $(0.0894)$ & $(0.0914)$ & $(0.0872)$ & $(0.0855)$ \\
\hline \multirow[t]{2}{*}{ Facebook Speakers $\times \ldots$} & 0.0696 & 0.1451 & 0.1532 & -0.0957 & -0.0632 & 0.1103 & 0.0352 & 0.1258 & 0.1662 \\
\hline & $(0.0243)$ & $(0.0579)$ & $(0.0757)$ & $(0.0836)$ & $(0.0597)$ & $(0.0293)$ & $(0.0181)$ & $(0.0571)$ & $(0.0884)$ \\
\hline Observations & 42,048 & 46,080 & 36,672 & 46,080 & 46,080 & 28,992 & 28,992 & 32,832 & 41,472 \\
\hline Countries & 219 & 240 & 191 & 240 & 240 & 151 & 151 & 171 & 216 \\
\hline
\end{tabular}

Notes: Estimates of the effect of Facebook Speakers, and its interaction with country-level characteristics, on the log of one plus protests. Country-level regressions with monthly data from January 2000 to December 2015. Facebook Speakers is the proportion of people speaking (as a first language) a language available in Facebook in each country and month. For all variable definitions and sources, see Appendix Table A-1 All regressions include country fixed effects, month fixed effects, initial population interacted with time fixed effects, and country-specific quadratic trends. Column 1 additionally includes the interaction of Facebook Speakers with population as an additional control. All variables used in the interactions are standardized. Two-way clustering of standard errors is at the month and country levels. 
Table 4: Subnational Estimates of the Effect of Facebook Speakers on Protests

\begin{tabular}{|c|c|c|c|c|c|c|c|c|c|}
\hline & (1) & (2) & (3) & (4) & (5) & (6) & (7) & (8) & (9) \\
\hline \multicolumn{10}{|c|}{ A. Dependent variable is $\log (1+$ protests $)$} \\
\hline & All & $\begin{array}{c}\text { Political } \\
\text { engagement }\end{array}$ & $\begin{array}{l}\text { Demons- } \\
\text { trations }\end{array}$ & $\begin{array}{l}\text { Hunger } \\
\text { strikes }\end{array}$ & $\begin{array}{l}\text { Strikes or } \\
\text { boycotts }\end{array}$ & Blockades & $\begin{array}{l}\text { Violent } \\
\text { protests }\end{array}$ & $\begin{array}{l}\text { ACLED } \\
\text { (Africa) }\end{array}$ & $\begin{array}{l}\text { GDELT } \\
\text { (Africa) }\end{array}$ \\
\hline Facebook Speakers & $\begin{array}{c}0.5106 \\
(0.0846)\end{array}$ & $\begin{array}{c}0.2574 \\
(0.0478)\end{array}$ & $\begin{array}{c}0.5131 \\
(0.0828)\end{array}$ & $\begin{array}{c}0.1198 \\
(0.0294)\end{array}$ & $\begin{array}{c}0.2255 \\
(0.0433)\end{array}$ & $\begin{array}{c}0.1118 \\
(0.0296)\end{array}$ & $\begin{array}{c}0.2150 \\
(0.0430)\end{array}$ & $\begin{array}{c}0.2412 \\
(0.1374)\end{array}$ & $\begin{array}{c}0.1830 \\
(0.0969)\end{array}$ \\
\hline Observations & $1,430,400$ & $1,430,400$ & $1,430,400$ & $1,430,400$ & $1,430,400$ & $1,430,400$ & $1,430,400$ & 467,520 & 467,520 \\
\hline Polygons & 7,450 & 7,450 & 7,450 & 7,450 & 7,450 & 7,450 & 7,450 & 2,435 & 2,435 \\
\hline Beta-coefficient & {$[0.110]$} & {$[0.138]$} & {$[0.122]$} & {$[0.105]$} & {$[0.141]$} & {$[0.114]$} & {$[0.111]$} & {$[0.163]$} & {$[0.051]$} \\
\hline More than one source (\%) & 9.891 & 10.909 & 9.437 & 9.216 & 9.784 & 10.599 & 12.590 & & \\
\hline
\end{tabular}

Notes: Estimates of the effect of Facebook Speakers on (the log of one plus) protests (column 1) different types of protests (columns 2 to 6) and protests in Africa for different sources (columns 8 and 9). Unit of analysis is a language polygon (region) within a country, with data from January 2000 to December 2015. Facebook Speakers is the share of the population in each region within a country speaking (as a first language) a language already available in Facebook. For all variable definitions and sources, see Appendix Table A-1 More than one source (\%), in the lower row, represents the proportion of protests in each category that are reported by more than one source (computed before Facebook's introduction). All regressions include fixed effects for each country and month, region fixed effects, and initial regional population interacted with month fixed effects. Two-way clustering of standard errors is at the month and country levels. 


\section{Table 5: Individual-level estimates of the Effect of Facebook Speaker on Protest Participation}

\begin{tabular}{|c|c|c|c|}
\hline \multirow{2}{*}{\multicolumn{4}{|c|}{ Dependent variable is indicator variable for protest participation }} \\
\hline & & & \\
\hline \multicolumn{4}{|l|}{ Panel A. All surveys } \\
\hline Facebook Speaker & $\begin{array}{c}0.0256 \\
(0.0059)\end{array}$ & $\begin{array}{c}0.0264 \\
(0.0061)\end{array}$ & $\begin{array}{c}0.0239 \\
(0.0063)\end{array}$ \\
\hline Observations & 707,853 & 707,468 & 706,500 \\
\hline Countries & 123 & 123 & 123 \\
\hline Age group + Sex & $\checkmark$ & $\checkmark$ & $\checkmark$ \\
\hline Country $\times$ Year $\times$ Survey fixed effects & $\checkmark$ & $\checkmark$ & $\checkmark$ \\
\hline Language $\times$ Survey fixed effects & & & \\
\hline Country $\times$ Language fixed effects $\times$ Survey & & $\checkmark$ & $\checkmark$ \\
\hline Education + Wealth & & & $\checkmark$ \\
\hline \multicolumn{4}{|l|}{ Panel B. World Value Survey } \\
\hline Facebook Speaker & $\begin{array}{c}0.0498 \\
(0.0174)\end{array}$ & $\begin{array}{c}0.0545 \\
(0.0193)\end{array}$ & $\begin{array}{c}0.0700 \\
(0.0219)\end{array}$ \\
\hline Observations & 239,084 & 239,004 & 239,004 \\
\hline Countries & 90 & 90 & 90 \\
\hline \multicolumn{4}{|l|}{ Panel C. European Social Survey } \\
\hline Facebook Speaker & $\begin{array}{c}0.0201 \\
(0.0057)\end{array}$ & $\begin{array}{c}0.0209 \\
(0.0061)\end{array}$ & $\begin{array}{c}0.0186 \\
(0.0055)\end{array}$ \\
\hline Observations & 340,509 & 340,218 & 340,218 \\
\hline Countries & 36 & 36 & 36 \\
\hline \multicolumn{4}{|l|}{ Panel D. Afrobarometer } \\
\hline Facebook Speaker & $\begin{array}{c}0.0981 \\
(0.0109)\end{array}$ & $\begin{array}{c}0.0955 \\
(0.0148)\end{array}$ & $\begin{array}{c}0.0948 \\
(0.0170)\end{array}$ \\
\hline Observations & 128,260 & 128,246 & 127,278 \\
\hline Countries & 36 & 36 & 36 \\
\hline \multicolumn{4}{|l|}{ Panels B-D: } \\
\hline Age group + Sex & $\checkmark$ & $\checkmark$ & $\checkmark$ \\
\hline Country $\times$ Year fixed effects & $\checkmark$ & $\checkmark$ & $\checkmark$ \\
\hline Language fixed effects & $\checkmark$ & & \\
\hline Country $\times$ Language fixed effects & & $\checkmark$ & $\checkmark$ \\
\hline Education +Wealth & & & $\checkmark$ \\
\hline
\end{tabular}

Notes: Individual-level estimates of the effect of Facebook Speaker on protests participation. Data from several rounds of surveys, see list in Figure 1 In Panel B, Protest equals 1 if respondent answers "Have done" or "Might do" to the question "I'm going to read out some forms of political action that people can take, and I'd like you to tell me ... whether you have ... attend peaceful demonstrations." In Panel C, Protest equals 1 if respondent answers "Yes" to the question "Have you ... taken part in lawful public demonstration last 12 months?" In Panel D, Protest equals 1 if respondent answers "No, but would do if had the chance," "Yes, once or twice," "Yes, several times," or "Yes, often" to the question, "Please tell me whether you, personally, have done any of these things during the past year. If not, would you do this if you had the chance: Participated in a demonstration or protest march." In Panel A these definitions are used to define Protest when pooling all surveys. Facebook Speaker is a dummy that equals 1 if Facebook has been released in the respondent's language. For all variable definitions and sources, see Appendix Table A-1 Two-way clustering of standard errors is at the year and country levels. 


\section{Table 6: Individual-level estimates of the Effect of Facebook Speaker on Protest Participation by Age, Sex, Education, and Income}

\begin{tabular}{|c|c|c|c|c|c|c|}
\hline & (1) & (2) & (3) & (4) & (5) & (6) \\
\hline & World Valu & es Survey & European $S c$ & cial Survey & Afrobc & meter \\
\hline Dependent variable is $\mathrm{P}$ & otest & & & & & \\
\hline Group & $\begin{array}{c}\text { Mean non- } \\
\text { speakers }\end{array}$ & $\begin{array}{c}\text { Speakers } \\
\text { effect }\end{array}$ & $\begin{array}{c}\text { Mean non- } \\
\text { speakers }\end{array}$ & $\begin{array}{c}\text { Speakers } \\
\text { effect }\end{array}$ & $\begin{array}{l}\text { Mean non- } \\
\text { speakers }\end{array}$ & $\begin{array}{c}\text { Speakers } \\
\text { effect }\end{array}$ \\
\hline Panel A: By Age group & & & & & & \\
\hline$\leq 25$ & $\begin{array}{c}0.5195 \\
(0.0025)\end{array}$ & $\begin{array}{c}0.0208 \\
(0.0328)\end{array}$ & $\begin{array}{c}0.1035 \\
(0.0018)\end{array}$ & $\begin{array}{c}0.0259 \\
(0.0096)\end{array}$ & $\begin{array}{c}0.4218 \\
(0.0030)\end{array}$ & $\begin{array}{c}0.0854 \\
(0.0224)\end{array}$ \\
\hline$(25,40]$ & 0.5102 & 0.0661 & 0.0746 & 0.0249 & 0.3967 & 0.1543 \\
\hline & $(0.0019)$ & $(0.0220)$ & $(0.0012)$ & $(0.0080)$ & $(0.0023)$ & $(0.0279)$ \\
\hline$(41,55]$ & 0.5033 & 0.0807 & 0.0770 & 0.0209 & 0.3711 & 0.1119 \\
\hline & $(0.0023)$ & $(0.0368)$ & $(0.0012)$ & $(0.0061)$ & $(0.0032)$ & $(0.0288)$ \\
\hline$>55$ & 0.4029 & 0.0088 & 0.0452 & 0.0117 & 0.2996 & -0.0395 \\
\hline & $(0.0026)$ & $(0.0462)$ & $(0.0008)$ & $(0.0063)$ & $(0.0039)$ & $(0.0225)$ \\
\hline P-value: No difference & & 0.072 & & 0.259 & & 0.004 \\
\hline Panel B: By Sex & & & & & & \\
\hline Female & $\begin{array}{c}0.4405 \\
(0.0016)\end{array}$ & $\begin{array}{c}0.0500 \\
(0.0287)\end{array}$ & $\begin{array}{c}0.0610 \\
(0.0007)\end{array}$ & $\begin{array}{c}0.0225 \\
(0.0055)\end{array}$ & $\begin{array}{c}0.3649 \\
(0.0020)\end{array}$ & $\begin{array}{c}0.1301 \\
(0.0000)\end{array}$ \\
\hline Male & $\begin{array}{c}0.5415 \\
(0.0016)\end{array}$ & $\begin{array}{c}0.0646 \\
(0.0179)\end{array}$ & $\begin{array}{c}0.0783 \\
(0.0009)\end{array}$ & $\begin{array}{c}0.0176 \\
(0.0076)\end{array}$ & $\begin{array}{c}0.4053 \\
(0.0021)\end{array}$ & $\begin{array}{c}0.0600 \\
(0.0237)\end{array}$ \\
\hline P-value: No difference & & 0.586 & & 0.250 & & 0.007 \\
\hline Panel C: By Education & & & & & & \\
\hline Primary & $\begin{array}{c}0.3900 \\
(0.0019)\end{array}$ & $\begin{array}{c}0.1011 \\
(0.0306)\end{array}$ & $\begin{array}{c}0.0493 \\
(0.0007)\end{array}$ & $\begin{array}{c}0.0134 \\
(0.0054)\end{array}$ & $\begin{array}{c}0.3792 \\
(0.0017)\end{array}$ & $\begin{array}{c}0.1060 \\
(0.0214)\end{array}$ \\
\hline Secondary & $\begin{array}{c}0.5065 \\
(0.0017)\end{array}$ & $\begin{array}{c}0.1060 \\
(0.0214)\end{array}$ & $\begin{array}{c}0.0706 \\
(0.0012)\end{array}$ & $\begin{array}{l}-0.0040 \\
(0.0097)\end{array}$ & $\begin{array}{c}0.3903 \\
(0.0038)\end{array}$ & $\begin{array}{c}0.0858 \\
(0.0093)\end{array}$ \\
\hline Tertiary & $\begin{array}{c}0.6235 \\
(0.0024)\end{array}$ & $\begin{array}{c}0.0451 \\
(0.0391)\end{array}$ & $\begin{array}{c}0.1059 \\
(0.0013)\end{array}$ & $\begin{array}{c}0.0299 \\
(0.0055)\end{array}$ & $\begin{array}{c}0.4158 \\
(0.0043)\end{array}$ & $\begin{array}{c}0.0865 \\
(0.0490)\end{array}$ \\
\hline P-value: No difference & & 0.190 & & 0.001 & & 0.686 \\
\hline Panel D: By Wealth & & & & & & \\
\hline Lowest & $\begin{array}{c}0.4486 \\
(0.0019)\end{array}$ & $\begin{array}{c}0.0536 \\
(0.0386)\end{array}$ & $\begin{array}{c}0.0508 \\
(0.0010)\end{array}$ & $\begin{array}{c}0.0180 \\
(0.0083)\end{array}$ & $\begin{array}{c}0.3987 \\
(0.0025)\end{array}$ & $\begin{array}{c}0.1327 \\
(0.0642)\end{array}$ \\
\hline Middle & $\begin{array}{c}0.5066 \\
(0.0017)\end{array}$ & $\begin{array}{c}0.0627 \\
(0.0380)\end{array}$ & $\begin{array}{c}0.0728 \\
(0.0010)\end{array}$ & $\begin{array}{c}0.0320 \\
(0.0094)\end{array}$ & $\begin{array}{c}0.3859 \\
(0.0025)\end{array}$ & $\begin{array}{c}0.0476 \\
(0.0404)\end{array}$ \\
\hline High & $\begin{array}{c}0.5594 \\
(0.0033)\end{array}$ & $\begin{array}{c}0.0418 \\
(0.0503)\end{array}$ & $\begin{array}{c}0.0875 \\
(0.0014)\end{array}$ & $\begin{array}{c}0.0100 \\
(0.0038)\end{array}$ & $\begin{array}{c}0.3699 \\
(0.0025)\end{array}$ & $\begin{array}{c}0.0946 \\
(0.0000)\end{array}$ \\
\hline P-value: No difference & & 0.419 & & 0.000 & & 0.364 \\
\hline
\end{tabular}

Notes: Individual-level estimates of the effect of Facebook Speaker on protests participation, across different demographic characteristics. Data from several rounds of surveys, see list in Figure 1 Protest is defined as in the note under Table 5 Facebook Speaker is a dummy that equals 1 if Facebook has been released in the respondent's language. For all variable definitions and sources, see Appendix Table A-1 Odd-numbered columns report, for each subgroup, the average protest incidence (and its standard error) for non-Facebook Speakers. Even-numbered columns report, for each subgroup, Facebook Speaker's effect on protests in regressions that include fixed effects for each country and year, country and language, each subgroup, age group and sex. Twoway clustering of standard errors is at the year and country levels. 


\section{Table 7: Individual-level estimates of the Effect of Facebook Speaker on Freedom of Expression}

\begin{tabular}{lccccccc}
\hline \hline & $(1)$ & $(2)$ & $(3)$ & $(4)$ & $(5)$ & $(6)$ & $(7)$ \\
& & \multicolumn{5}{c}{ Free to... } \\
& Protest & $\begin{array}{c}\text { Freedom } \\
\text { index }\end{array}$ & $\begin{array}{c}\text { Say what } \\
\text { you think }\end{array}$ & $\begin{array}{c}\text { Join political } \\
\text { organization }\end{array}$ & Vote & $\begin{array}{c}\text { Say political } \\
\text { opinion }\end{array}$ & $\begin{array}{c}\text { Fearless of } \\
\text { political } \\
\text { intimidation }\end{array}$ \\
\hline Facebook Speaker & 0.0955 & 0.0504 & 0.0383 & 0.0288 & 0.0483 & 0.0899 & 0.0891 \\
& $(0.0148)$ & $(0.0105)$ & $(0.0179)$ & $(0.0081)$ & $(0.0176)$ & $(0.0232)$ & $(0.0467)$ \\
Observations & & & & & & & 129,389 \\
Countries & 128,246 & 123,321 & 129,650 & 127,462 & 129,313 & 128,204 & 129,389 \\
Mean Dep. & 36 & 36 & 36 & 36 & 36 & 36 & 36 \\
\hline \hline
\end{tabular}

Notes: Individual-level estimates of the effect of Facebook Speaker on protests participation (column 1) and freedom (columns 2 to 7). Data from several rounds of the Afrobarometer, see list in Figure 1 Protest is defined as in the note under Table 5 Facebook Speaker is a dummy that equals 1 if Facebook has been released in the respondent's language. For all variable definitions and sources, see Appendix Table A-1 The Freedom Index in column 2 is the average of the outcomes in columns 3 to 6 . The last raw of the table reports the mean of the dependent variable among Facebook non-Speakers. All regressions include fixed effects for each country and year, country and language, age group and sex. Two-way clustering of standard errors is at the year and country levels. 


\section{Table 8: Individual-level estimates of the Effect of Facebook Speaker on Trust and Satisfaction with the Government and Democracy}

\begin{tabular}{|c|c|c|c|c|c|}
\hline Variable & $\begin{array}{c}(1) \\
\text { Mean non } \\
\text { speakers }\end{array}$ & $\begin{array}{c}(2) \\
\begin{array}{c}\text { Speakers } \\
\text { effect }\end{array} \\
\end{array}$ & Variable & $\begin{array}{c}\text { Mean non } \\
\text { speakers }\end{array}$ & $\begin{array}{c}(4) \\
\begin{array}{c}\text { Speakers } \\
\text { effect }\end{array}\end{array}$ \\
\hline \multicolumn{3}{|c|}{ A1. Trust/Satisfaction with government (WVS) } & \multirow[t]{2}{*}{ Average $A 3$} & \multirow{2}{*}{$\begin{array}{c}0.5535 \\
(0.0009)\end{array}$} & \multirow{2}{*}{$\begin{array}{c}-0.0070 \\
(0.0117)\end{array}$} \\
\hline Trust parliament & $\begin{array}{c}0.4150 \\
(0.0012)\end{array}$ & $\begin{array}{c}0.1583 \\
(0.0595)\end{array}$ & & & \\
\hline \multirow[t]{2}{*}{ Trust courts } & 0.3728 & 0.0307 & \multicolumn{3}{|c|}{ B1. Satisfied degree of democracy in country (WVS) } \\
\hline & $(0.0012)$ & $(0.0229)$ & \multirow[t]{2}{*}{ Satisfied democracy } & 0.6054 & 0.0169 \\
\hline Trust police & $\begin{array}{c}0.5333 \\
(0.0012)\end{array}$ & $\begin{array}{c}0.0598 \\
(0.0348)\end{array}$ & & $(0.0010)$ & $(0.0261)$ \\
\hline \multirow[t]{2}{*}{ Trust government } & 0.4666 & 0.1167 & \multicolumn{3}{|c|}{ B2. Satisfied degree of democracy in country (ESS) } \\
\hline & $(0.0012)$ & $(0.0628)$ & \multirow[t]{2}{*}{ Satisfied democracy } & 0.5318 & 0.0098 \\
\hline Trust military & $\begin{array}{c}0.6329 \\
(0.0011)\end{array}$ & $\begin{array}{c}0.0894 \\
(0.0170)\end{array}$ & & $(0.0006)$ & $(0.0068)$ \\
\hline Trust civil service & 0.4708 & 0.0751 & \multicolumn{3}{|c|}{ B3. Satisfied degree of democracy in country (AB) } \\
\hline \multirow[t]{2}{*}{ Average A1 } & $\begin{array}{c}(0.0012) \\
0.4847 \\
(0.0008)\end{array}$ & $\begin{array}{c}(0.0255) \\
0.0917 \\
(0.0264)\end{array}$ & Satisfied democracy & $\begin{array}{c}0.5155 \\
(0.0015)\end{array}$ & $\begin{array}{c}-0.0102 \\
(0.0369)\end{array}$ \\
\hline & & & \multicolumn{3}{|c|}{ C1. Support for democracy (WVS) } \\
\hline \multicolumn{3}{|c|}{ A2. Trust/Satisfaction with government (ESS) } & \multirow[t]{2}{*}{ Rejects one-man rule } & 0.6031 & 0.0241 \\
\hline \multirow[t]{2}{*}{ Trust parliament } & 0.4528 & 0.0042 & & $(0.0012)$ & $(0.0677)$ \\
\hline & $(0.0006)$ & $(0.0060)$ & Rejects experts making decisions & 0.3991 & -0.0062 \\
\hline \multirow[t]{2}{*}{ Trust police } & 0.5979 & -0.0034 & & $(0.0012)$ & $(0.0591)$ \\
\hline & $(0.0006)$ & $(0.0025)$ & Rejects military rule & 0.7608 & 0.0278 \\
\hline Trust courts & 0.5204 & 0.0079 & & $(0.0010)$ & $(0.0450)$ \\
\hline & $(0.0006)$ & $(0.0041)$ & In favor of a democratic system & 0.8985 & 0.0182 \\
\hline Trust politicians & 0.3640 & 0.0013 & & $(0.0007)$ & $(0.0136)$ \\
\hline & $(0.0005)$ & $(0.0053)$ & Average $C 1$ & 0.6683 & 0.0222 \\
\hline Trust political parties & $\begin{array}{c}0.3576 \\
(0.0006)\end{array}$ & $\begin{array}{l}-0.0014 \\
(0.0068)\end{array}$ & & $(0.0006)$ & $(0.0346)$ \\
\hline Satisfied government & 0.4295 & 0.0006 & C2. Support for & ocracy (AB & \\
\hline & $(0.0006)$ & $(0.0071)$ & Rejects one-party rule & 0.7837 & -0.0492 \\
\hline Average A2 & 0.4590 & 0.0005 & & $(0.0012)$ & $(0.0156)$ \\
\hline & $(0.0004)$ & $(0.0046)$ & Rejects military rule & $\begin{array}{c}0.7872 \\
(0.0012)\end{array}$ & $\begin{array}{l}-0.0378 \\
(0.0410)\end{array}$ \\
\hline A3. Trust/Satisfacti & vith governn & $(\mathrm{AB})$ & Rejects one-man rule & 0.8529 & -0.0275 \\
\hline Trust parliament & 0.5557 & 0.0062 & & $(0.0011)$ & $(0.0240)$ \\
\hline & $(0.0015)$ & $(0.0220)$ & Support for democracy & 0.7641 & 0.0136 \\
\hline Trust courts & 0.6033 & 0.0084 & & $(0.0013)$ & $(0.0348)$ \\
\hline & $(0.0015)$ & $(0.0296)$ & Choosing leaders in elections & 0.8251 & 0.0093 \\
\hline Trust police & 0.5220 & -0.0113 & & $(0.0011)$ & $(0.0148)$ \\
\hline & $(0.0015)$ & $(0.0224)$ & Checks parliament & 0.6565 & 0.0901 \\
\hline Trust electoral commission & 0.5504 & -0.0074 & & $(0.0014)$ & $(0.0706)$ \\
\hline & $(0.0015)$ & $(0.0291)$ & Checks opposition & 0.3241 & 0.0075 \\
\hline Trust president & 0.6167 & 0.0373 & & $(0.0014)$ & $(0.0214)$ \\
\hline & $(0.0015)$ & $(0.0255)$ & Checks media & 0.7229 & 0.0089 \\
\hline Trust ruling party & 0.5236 & -0.0192 & & $(0.0013)$ & $(0.0225)$ \\
\hline & $(0.0015)$ & $(0.0216)$ & Parliament law making & 0.7047 & 0.0613 \\
\hline Trust opposition & 0.3980 & -0.0050 & & $(0.0014)$ & $(0.0300)$ \\
\hline & $(0.0015)$ & $(0.0447)$ & Checks court & 0.7057 & -0.0192 \\
\hline Performance president & 0.6612 & -0.0237 & & $(0.0014)$ & $(0.0552)$ \\
\hline & $(0.0014)$ & $(0.0216)$ & Average C2 & 0.7098 & 0.0055 \\
\hline Performance aseembly & $\begin{array}{c}0.5192 \\
(0.0016)\end{array}$ & $\begin{array}{l}-0.0419 \\
(0.0164)\end{array}$ & & $(0.0006)$ & $(0.0280)$ \\
\hline Performance local councilor & $\begin{array}{c}0.5519 \\
(0.0016)\end{array}$ & $\begin{array}{l}-0.0028 \\
(0.0000)\end{array}$ & & & \\
\hline
\end{tabular}

Notes: Individual-level estimates of the effect of Facebook Speaker on different channels specified in the rows labels. Data from several rounds of the World Values Survey (WVS) European Social Survey (ESS) and Afrobarometer (AB), see list in Figure 1 Facebook Speaker is a dummy that equals 1 if Facebook has been released in the respondent's language. For all variable definitions and sources, see Appendix Table A-1 Odd-numbered columns report the average for each outcome listed in the rows (and its standard error) for non-Facebook Speakers. Even-numbered columns report the coefficient for Facebook Speaker in regressions that include fixed effects for each country and year, country and language, age group and sex. Two-way clustering of standard errors is at the year and country levels. 


\section{Table 9: Individual-level estimates of the Effect of Facebook Speaker on Traditional media use and Political Engagement}

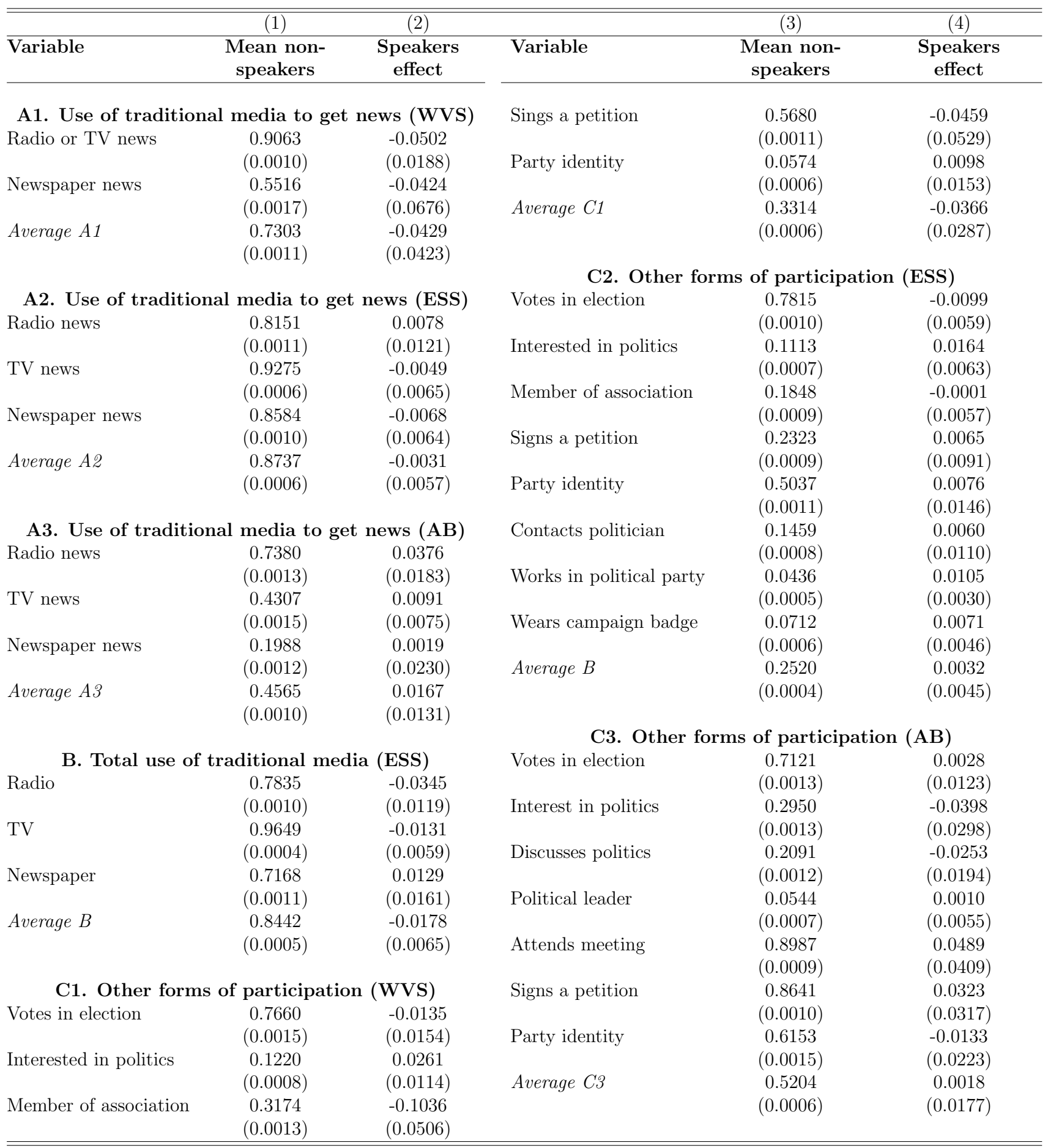

Notes: Individual-level estimates of the effect of Facebook Speaker on different channels specified in the rows labels. Data from several rounds of the World Values Survey (WVS) European Social Survey (ESS) and Afrobarometer (AB), see list in Figure 1 Facebook Speaker is a dummy that equals 1 if Facebook has been released in the respondent's language. For all variable definitions and sources, see Appendix Table A-1. Odd-numbered columns report the average for each outcome listed in the rows (and its standard error) for non-Facebook Speakers. Even-numbered columns report the coefficient for Facebook Speaker in regressions that include fixed effects for each country and year, country and language, age group and sex. Two-way clustering of standard errors is at the year and country levels. 
Table 10: Effect of Facebook Speakers on Protests by Target

\begin{tabular}{|c|c|c|c|c|c|c|c|c|c|}
\hline & (1) & (2) & (3) & (4) & (5) & (6) & $\overline{(7)}$ & (8) & $(9)$ \\
\hline & \multirow{2}{*}{$\begin{array}{l}\text { Protest share } \\
\text { with known } \\
\text { target }\end{array}$} & \multicolumn{8}{|c|}{ Dependent variable is the log of one plus the number of protests against each target... } \\
\hline & & $\begin{array}{c}\text { Known } \\
\text { target } \\
(48.5 \%)\end{array}$ & $\begin{array}{c}\text { Armed } \\
\text { forces } \\
(16.2 \%)\end{array}$ & $\begin{array}{c}\text { Legislature } \\
(3.2 \%)\end{array}$ & $\begin{array}{c}\text { Government } \\
(25.4 \%)\end{array}$ & $\begin{array}{c}\text { Education } \\
(4.7 \%)\end{array}$ & $\begin{array}{l}\text { Media } \\
(3.6 \%) \\
\end{array}$ & $\begin{array}{c}\text { Business } \\
(3.3 \%)\end{array}$ & $\begin{array}{l}\text { Labor } \\
(2.4 \%)\end{array}$ \\
\hline Facebook Speakers & $\begin{array}{c}0.0184 \\
(0.0125)\end{array}$ & $\begin{array}{c}0.2197 \\
(0.0769)\end{array}$ & $\begin{array}{c}0.0633 \\
(0.0489)\end{array}$ & $\begin{array}{c}0.0704 \\
(0.0326)\end{array}$ & $\begin{array}{c}0.1546 \\
(0.0608)\end{array}$ & $\begin{array}{c}0.0570 \\
(0.0347)\end{array}$ & $\begin{array}{c}0.0794 \\
(0.0349)\end{array}$ & $\begin{array}{c}0.0940 \\
(0.0355)\end{array}$ & $\begin{array}{c}0.1123 \\
(0.0325)\end{array}$ \\
\hline Observations & 32,121 & 46,080 & 46,080 & 46,080 & 46,080 & 46,080 & 46,080 & 46,080 & 46,080 \\
\hline Countries & 237 & 240 & 240 & 240 & 240 & 240 & 240 & 240 & 240 \\
\hline Beta-coefficient & {$[0.024]$} & {$[0.045]$} & {$[0.021]$} & {$[0.038]$} & {$[0.043]$} & {$[0.029]$} & {$[0.041]$} & {$[0.050]$} & {$[0.070]$} \\
\hline
\end{tabular}

Panel B. Dependent variable is the log of one plus the number of protests against each target...

\begin{tabular}{|c|c|c|c|c|c|c|c|c|}
\hline & \multicolumn{4}{|c|}{ Establishment (44.8\%) } & \multicolumn{4}{|c|}{ Political opposition $(6.9 \%)$} \\
\hline & \multirow[b]{3}{*}{$\begin{array}{c}0.1658 \\
(0.0667)\end{array}$} & \multicolumn{3}{|c|}{ Facebook Speakers $\times$} & \multicolumn{4}{|c|}{ Facebook Speakers $\times$} \\
\hline & & Freedom House & Polity IV & V-Dem & \multirow[b]{2}{*}{$\begin{array}{c}0.0484 \\
(0.0387)\end{array}$} & Freedom House & Polity IV & V-Dem \\
\hline Facebook Speakers & & & & & & & & \\
\hline Facebook Speakers $\times$ Low... & & $\begin{array}{c}0.5440 \\
(0.2060)\end{array}$ & $\begin{array}{c}0.3738 \\
(0.1509)\end{array}$ & $\begin{array}{c}0.4896 \\
(0.1950)\end{array}$ & & $\begin{array}{c}0.4711 \\
(0.1362)\end{array}$ & $\begin{array}{c}0.1943 \\
(0.1291)\end{array}$ & $\begin{array}{c}0.2309 \\
(0.1133)\end{array}$ \\
\hline Facebook Speakers $\times$ Intermediate... & & $\begin{array}{c}0.1026 \\
(0.0922)\end{array}$ & $\begin{array}{c}-0.3051 \\
(0.3052)\end{array}$ & $\begin{array}{c}-0.0164 \\
(0.1024)\end{array}$ & & $\begin{array}{c}-0.0382 \\
(0.0634)\end{array}$ & $\begin{array}{c}0.4398 \\
(0.5590)\end{array}$ & $\begin{array}{c}-0.0798 \\
(0.0763)\end{array}$ \\
\hline Facebook Speakers $\times$ High... & & $\begin{array}{c}0.2169 \\
(0.1010)\end{array}$ & $\begin{array}{c}0.1484 \\
(0.0838)\end{array}$ & $\begin{array}{c}0.2079 \\
(0.0994)\end{array}$ & & $\begin{array}{c}0.0772 \\
(0.0562)\end{array}$ & $\begin{array}{c}0.0089 \\
(0.0508)\end{array}$ & $\begin{array}{c}0.0895 \\
(0.0581)\end{array}$ \\
\hline Observations & 46,080 & 37,056 & 31,680 & 33,024 & 46,080 & 37,056 & 31,680 & 33,024 \\
\hline Countries & 240 & 193 & 165 & 172 & 240 & 193 & 165 & 172 \\
\hline
\end{tabular}

Notes: Estimates of the effect of Facebook Speakers on the log of one plus protests with different targets. Country-level regressions with monthly data from January 2000 to December 2015. Protests are classified by target (when known). Establishment aggregates protests against armed forces, legislature, and government. Facebook Speakers is the proportion of people speaking (as a first language) a language available in Facebook in each country and month. For all variable definitions and sources, see Appendix Table A-1 In parentheses on each title: \% of total protests (col 2 of Panel A) and \% of protests with known target (Panel B and cols 3-9 of Panel A). In Panel B, Columns 2 to 4 and 6 to 8 break down the effect of Facebook Speakers by low, middle, and high levels of democracy as measured by Freedom House, Polity, and V-dem (See Figure 5 . Beta coefficient is the standardized effect, or implied effect on the dependent variable, in standard-deviation units, of a one-standard-deviation increase in Facebook Speakers. All regressions include country fixed effects, month fixed effects, initial population interacted with time fixed effects and country-specific quadratic trends. Two-way clustering of standard errors is at the month and country levels. 
Table 11: Effect of Facebook Speakers on Regime change, Democracy, Governance and Conflict

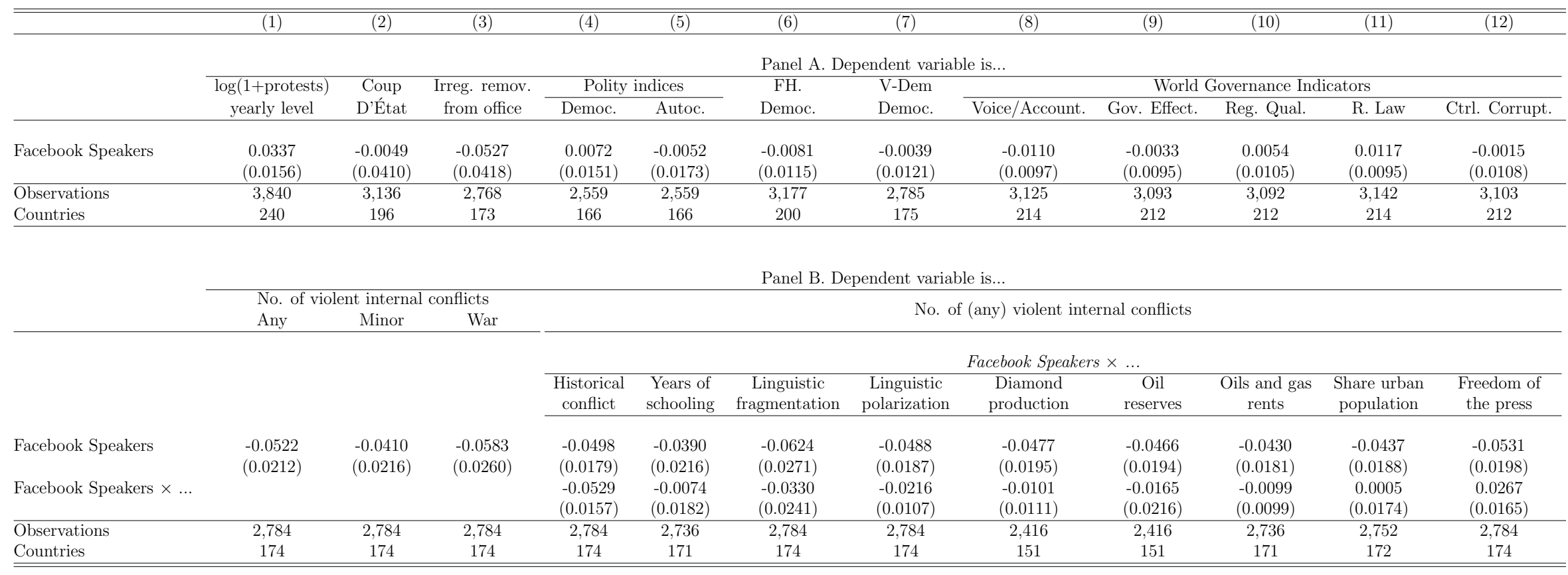

Notes: Estimates of the effect of Facebook Speakers on other political outcomes specified in the column titles. Country-level regressions with yearly data from 2000 to 2015 . Dependent variables in Panel A are: $\log$ of 1 plus protests (column 1), number of successful, attempted, plotted or alleged coup d'état events (a forceful seizure of executive authority and office that results in a change in the executive leadership and policies of the prior regime, column 2), number of irregular removals from office, when the executive leader was removed in contravention of explicit rules and established conventions (column 3), composite index of institutionalized democracy on a 0 (less democratic) to 10 (more democratic) scale (column 4), composite index of institutionalized autocracy on a 0 (less autocratic) to 10 (more autocratic) scale (column 5), combined freedom rating, average of Political Rights and Civil Liberties indices, on a 1 to 7 scale (column 6 ), continuous index of institutionalized democracy on a 0 (less democratic) to 1 (more democratic) scale (column 7), and the following World Bank governance indicators on a scale of 0 (lowest rank) to 100 (highest rank): voice and accountability (column 8), government effectiveness (column 9), regulatory quality (column 10), rule of law (column 11), and control of corruption (column 12). Dependent variables in Panel B are: number of violent internal conflicts of any intensity (columns 1 and 4 to 12), number of internal conflicts producing 25-1,000 battle-related deaths in a given year (column 2), number of internal conflicts producing over 1,000 battle-related death in a given year (column 3). Facebook Speakers is the proportion of people speaking (as a first language) a language available in Facebook in each country and year. For all variable definitions and sources, see Appendix Table A-1 Beta coefficients (standardized effect, or implied effect on the dependent variable, in standard-deviation units, of a one-standard-deviation increase in Facebook Speakers or its interaction with predetermined variables) are reported. All variables used in the interactions are standardized. All regressions include country fixed effects, year fixed effects, initial population interacted with time fixed effects and country-specific linear trends. Clustering of standard errors is at the country level. 
Figure 1: Facebook Language-Specific Versions and Facebook Speakers

Panel A. Number of Facebook versions (left axis) and Facebook Speakers (right axis)

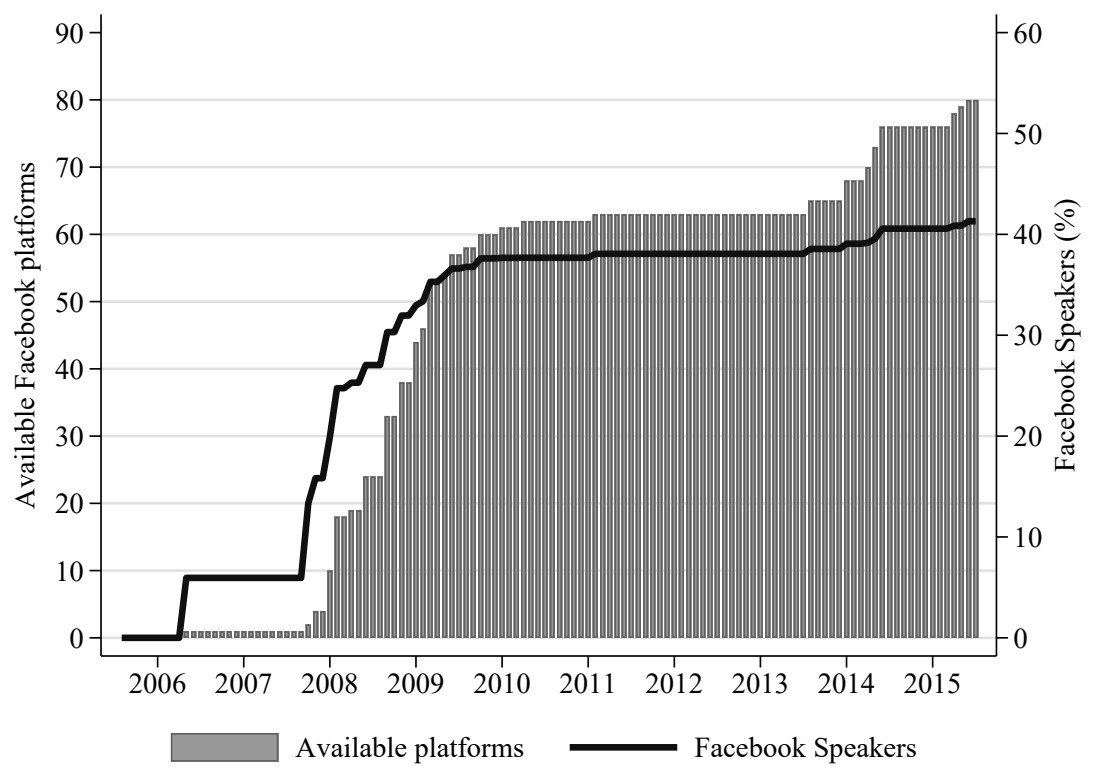

Panel B. Facebook Speakers in the survey data, by survey and wave

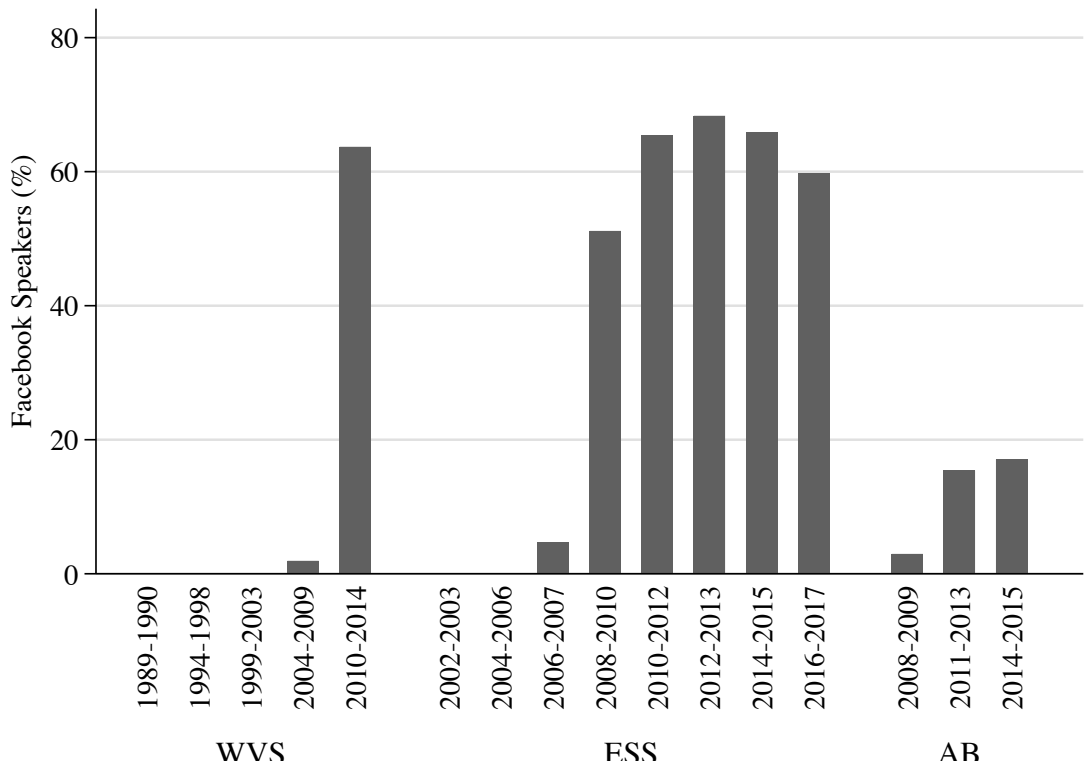

Notes: Facebook versions are language-specific platforms. Facebook Speakers is the average share of the population in each country (Panel A) or in each survey wave (Panel B) whose first language is available in a Facebook languagespecific platform. WVS is World Values Survey, ESS is European Social Survey and $\mathrm{AB}$ is Afrobarometer. For all variable definitions and sources, see Appendix Table A-1 


\section{Figure 2: Facebook Speakers, Facebook use and complier analysis}

A. Effect of Facebook Speakers on Facebook searches breaking the sample by countries' characteristics

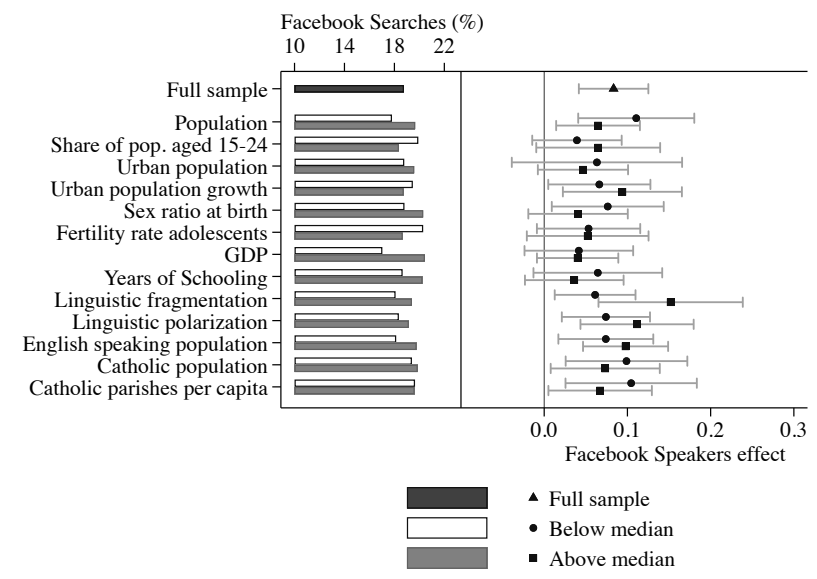

B. Effect of Facebook Speakers on Social media use breaking the sample by individuals' characteristics

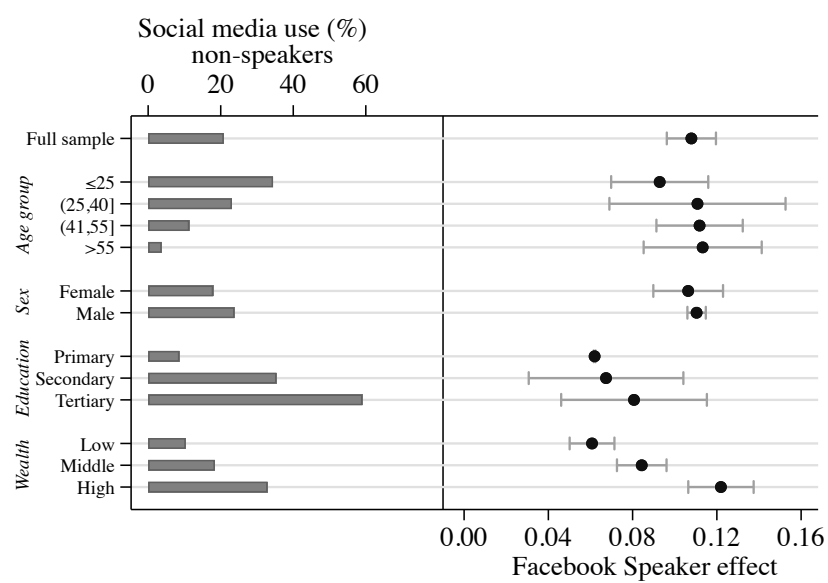

C. Distribution of characteristics of all respondents and compliers

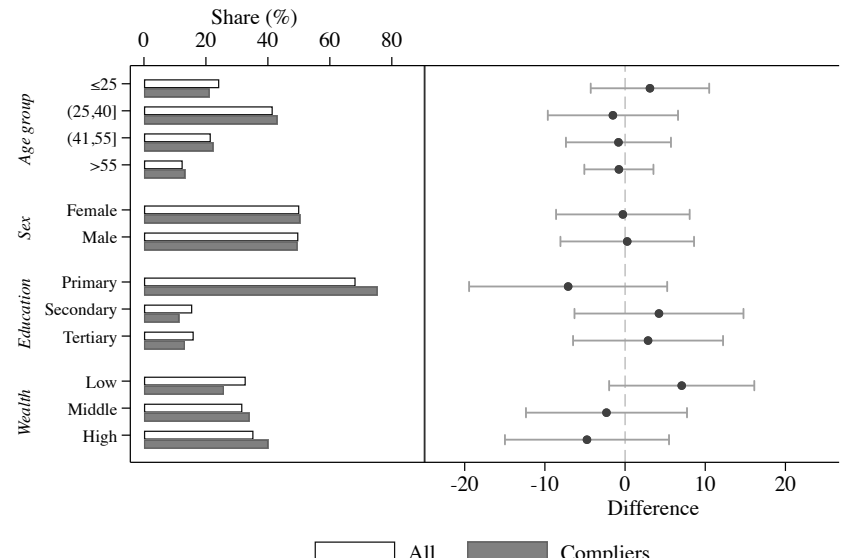

Notes: Estimates of the effect of Facebook Speakers on Facebook use using country-level data (Panel A) and individual level data (Panel B). For all variable definitions and sources, see Appendix Table A-1 Panel A reports the average of our main measure of Facebook use Facebook Searches (to the left) and the effect (and 95\% confidence intervals) of Facebook Speakers on Facebook Searches (to the right) breaking the sample in two equally-sized groups (below and above the median) according to several predetermined countries characteristics (as indicated in the vertical axis). Panel B reports, using individual-level data, the average Social media use among Facebook non-Speakers (to the right) and the effect (and 95\% confidence intervals) of being a Facebook Speaker on Social media use (to the right) breaking down the sample across different individual characteristics (as indicated in the vertical axis). Panel $\mathrm{C}$ reports, on the left, the fraction of respondents with certain characteristic (as indicated in the vertical axis), both among all respondents and among the subset of compliers, the latter estimated following Abadie (2003]. On the right, it reports the difference with 95\% confidence intervals. 


\section{Figure 3: Event-Study Estimates of the Impact of Facebook Speakers}

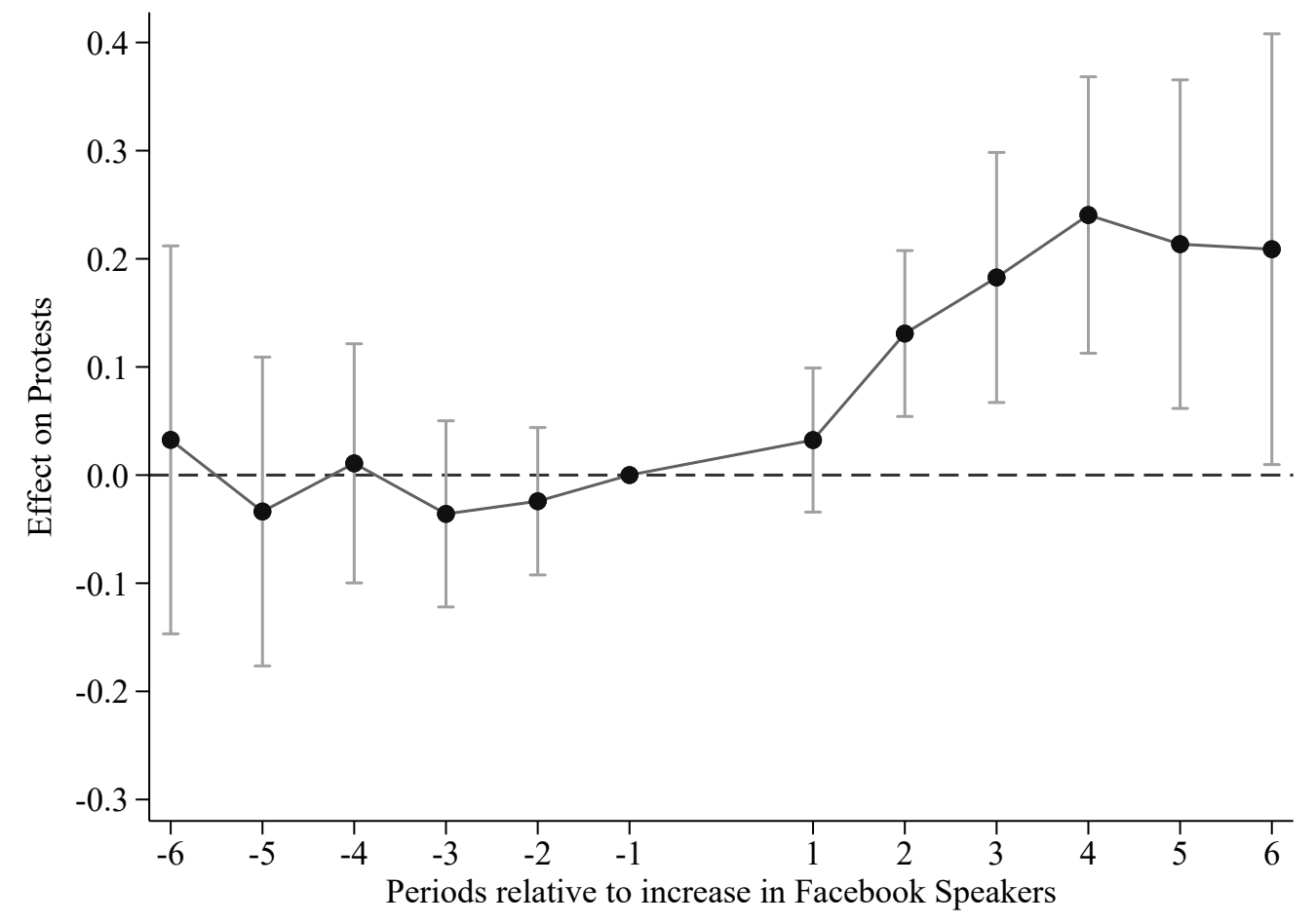

Notes: Event-Study Estimates of the Impact of Facebook Speakers on the log of one plus protests. Unit of analysis is a language polygon (region) within a country, with data from January 2000 to December 2015. Facebook Speakers is the share of the population in each region within a country speaking (as a first language) a language already available in Facebook. For all variable definitions and sources, see Appendix Table A-1. The vertical axis plots coefficients on 6-month intervals dummies from a regression for (the log of) protests that also includes unit (regions within a country) and time $\times$ country fixed effects. Negative numbers on the horizontal axis indicate periods before a discrete increase in Facebook Speakers, and positive numbers those following this event. The period just preceding the increase in Speakers is the omitted category. Confidence intervals at the $95 \%$ level with clustering at the country level are also shown. 
Figure 4: Implied Cumulative Effects of Facebook Speakers on Protests

Panel A: National-level regressions

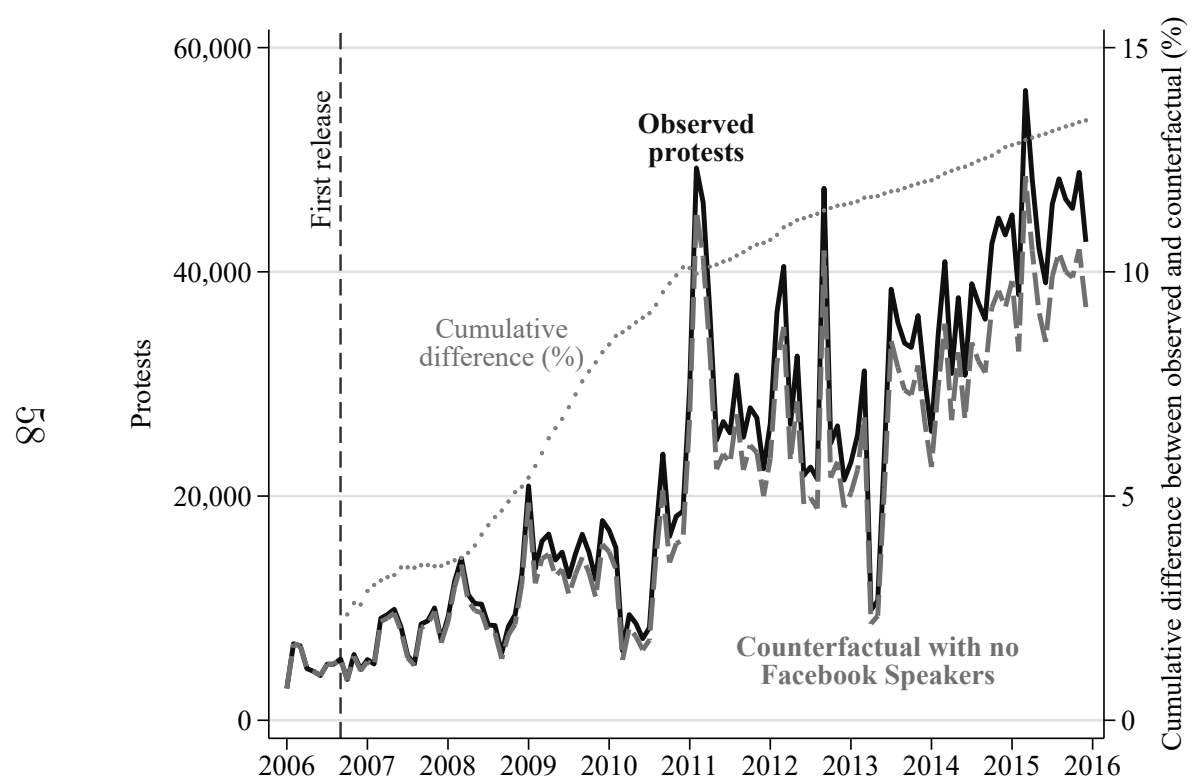

Panel B: Subnational-level regressions

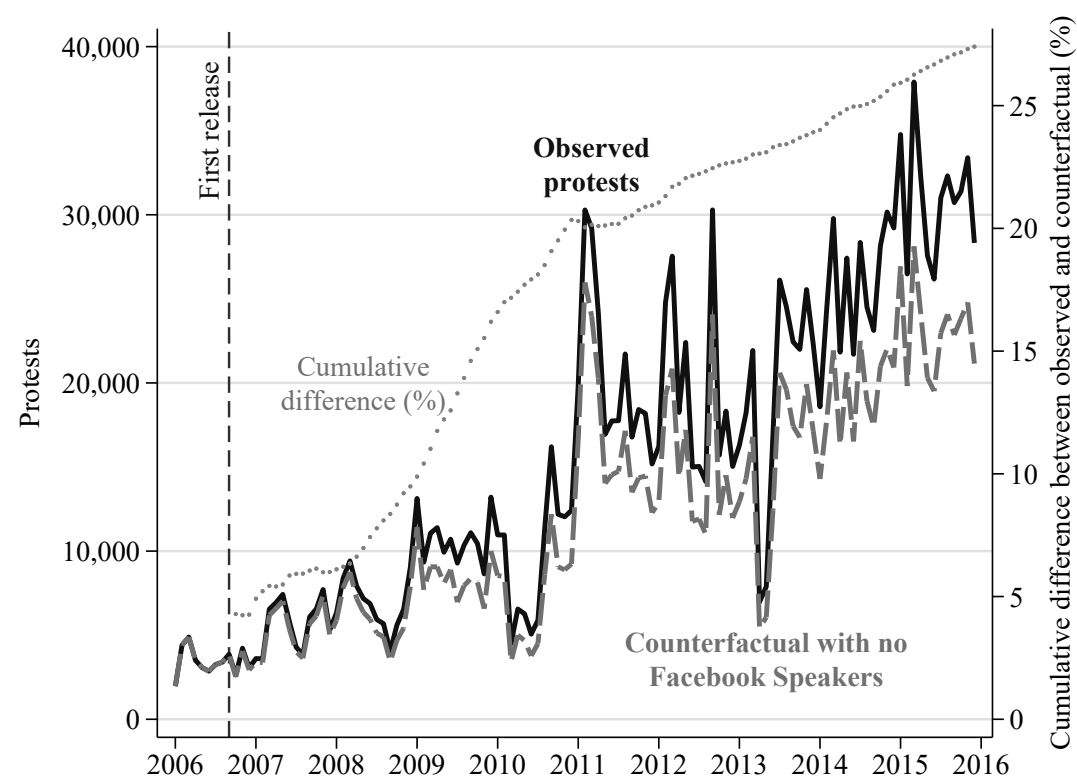

Notes: For all variable definitions and sources, see Appendix Table A-1 The solid line in each panel plots the total observed protests in each month, from 2006 to 2015. The dashed line is the corresponding number of protests that would have been observed without Facebook (if Facebook Speakers are held constant at zero throughout the period) as implied by our baseline national (Panel A) or subnational (Panel B) estimates. Finally, the dotted line is the cumulative difference since September 2006 (when Facebook first appeared) between protests with and without Facebook (expressed as a percent of total cumulative protests without Facebook up to each time period). 


\section{Figure 5: Facebook Speakers Impact by Features of the Political Regime}

A: Democracy (Freedom House)

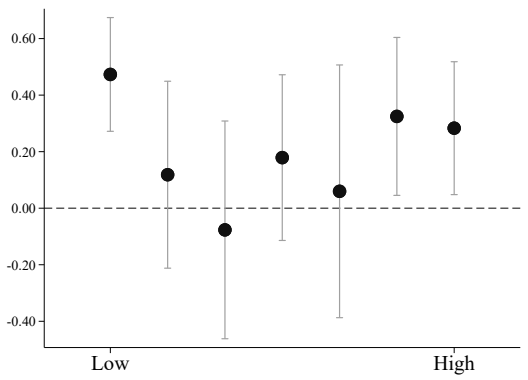

D: Voice and Accountability

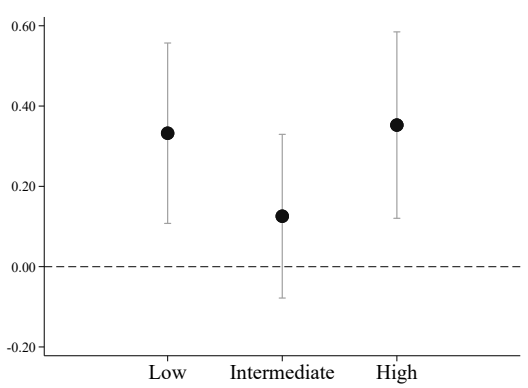

G: Control of Corruption

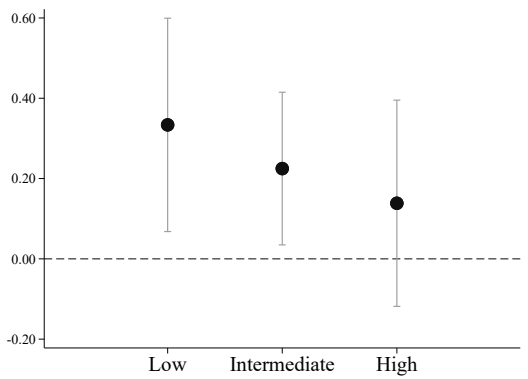

$\mathrm{J}$ : Freedom of Opposition

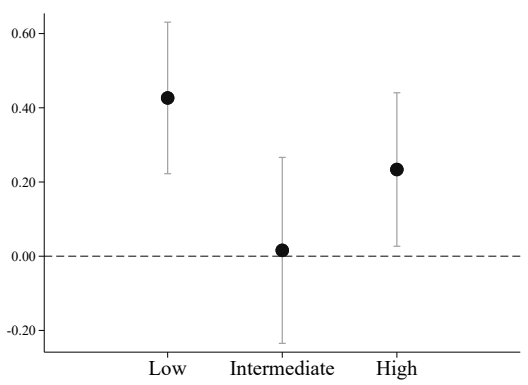

B: Democracy (Polity IV)

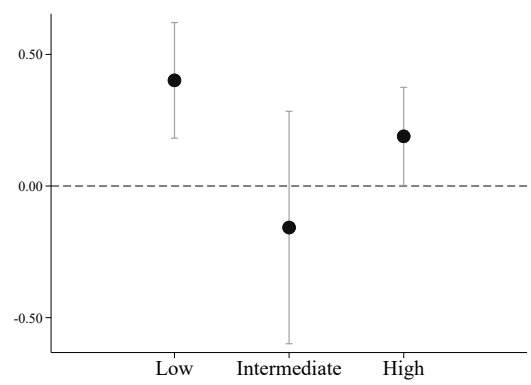

E: Regulatory Quality

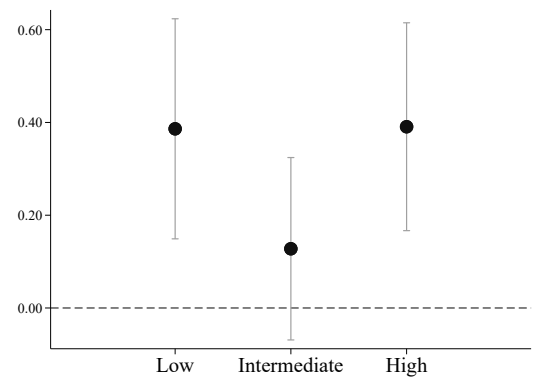

H: Political Rights

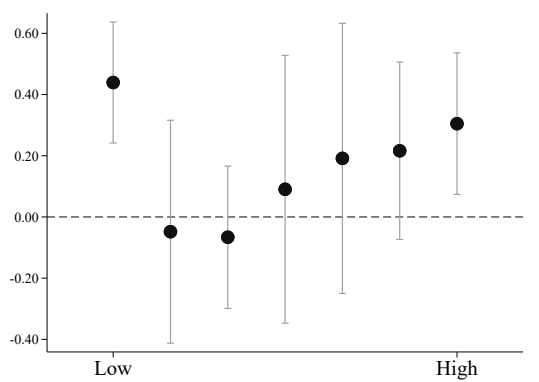

K: Freedom of Association

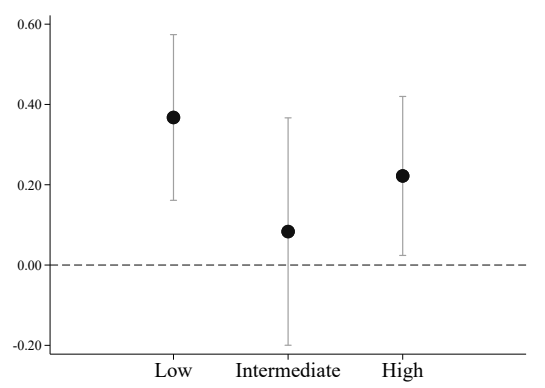

C: Democracy (V-Dem)

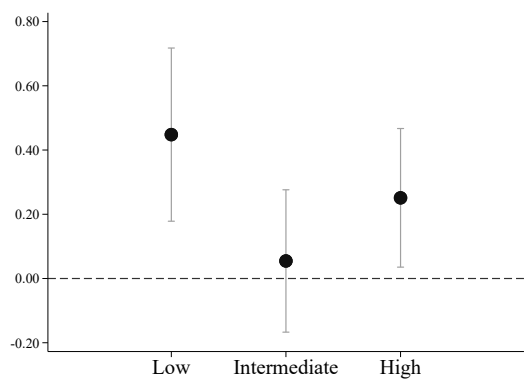

F: Rule of Law

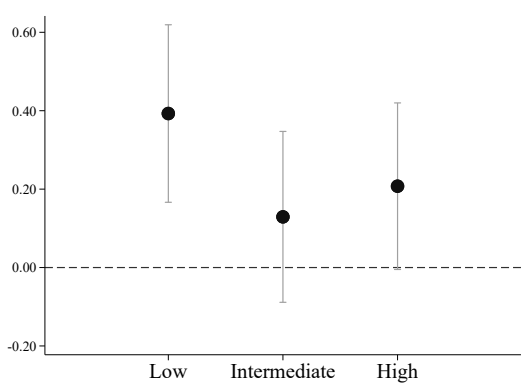

I: Civil Liberties

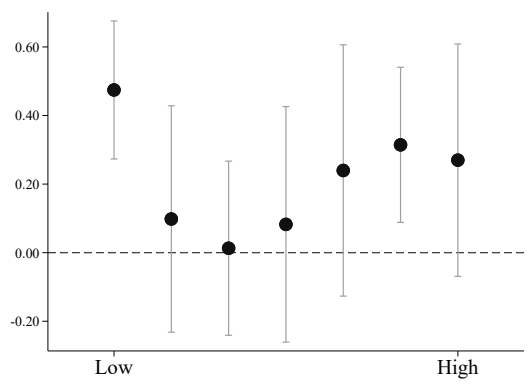

L: Freedom of the Press

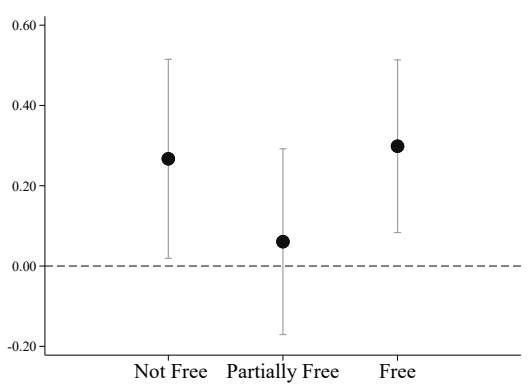

Notes: Estimates of the effect of Facebook Speakers, and its interaction with features of the political regime, on the log of one plus protests. Country-level regressions with monthly data from January 2000 to December 2015. Facebook Speakers is the proportion of people speaking (as a first language) a language available in Facebook in each country and month. For all variable definitions and sources, see Appendix Table A-1. This figure is based on regression (1), extended to include the interaction of Facebook Speakers with indicator variables built using the measures of democracy and governance indicated in each panel. We plot the effect (and 95\% confidence bands) of Facebook Speakers on protests at different levels of the indicators. Since the Freedom House indices are constructed on a 7-point scale, we interact Facebook Speakers with dummy variables for each level and plot the coefficients. For Press Freedom we use the three categories "not free," "partially free," and "free." With the Polity IV, V-Dem, World Bank indices, Opposition Freedom and Association Freedom, we divide the scales into three equal parts (low, intermediate, and high) and plot the coefficients for these interactions. 


\section{Figure 6: Facebook Speakers, Protests and Elections}

A. Protests around elections

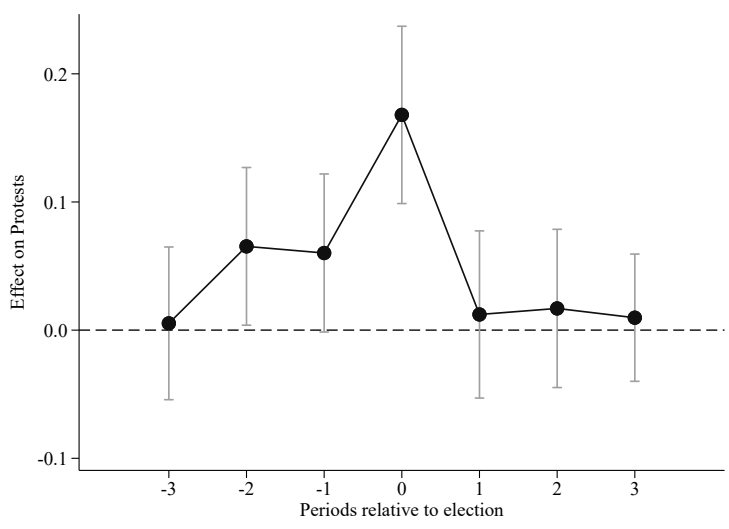

C. Facebook Speakers' effect on

Facebook Searches and other media use

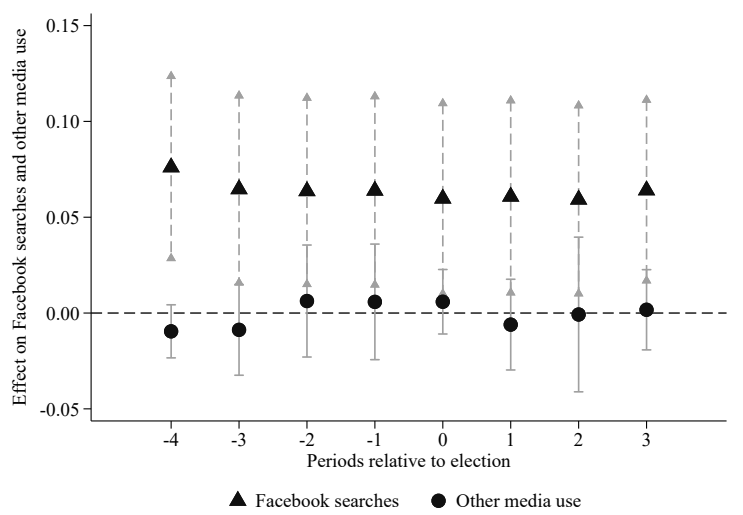

E. Facebook Speakers' effect

on satisfaction with government

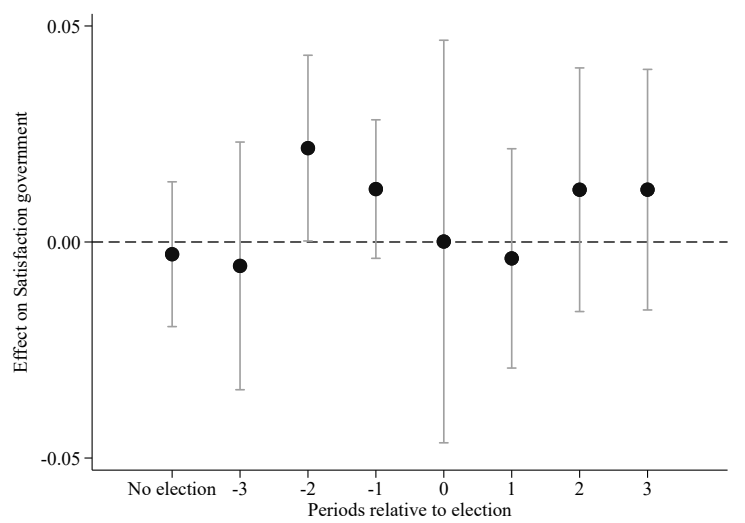

B. Facebook Speakers' effect on Protests

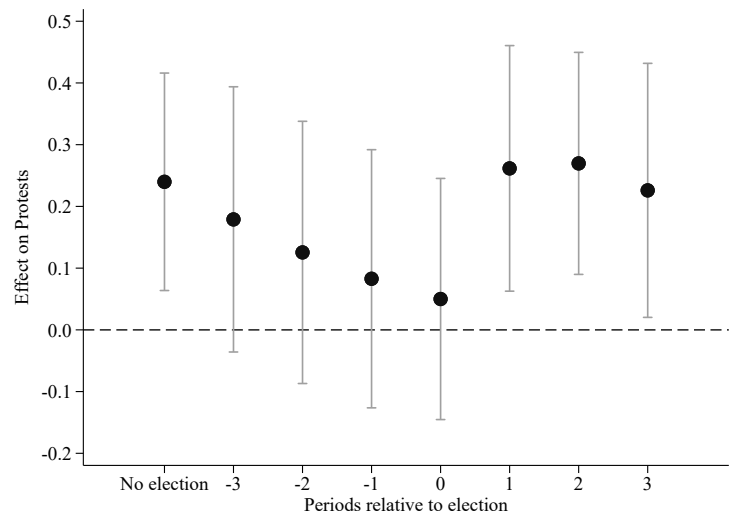

D. Facebook Speakers' effect on trust in institutions

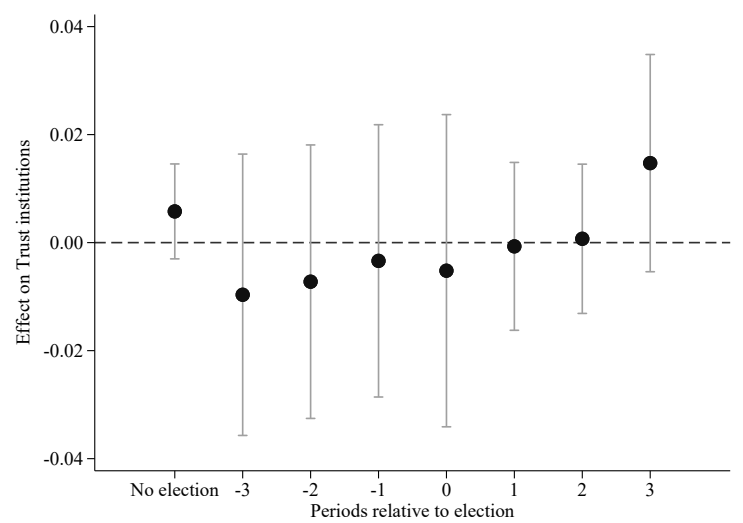

F. Facebook Speakers' effect

on satisfaction with democracy

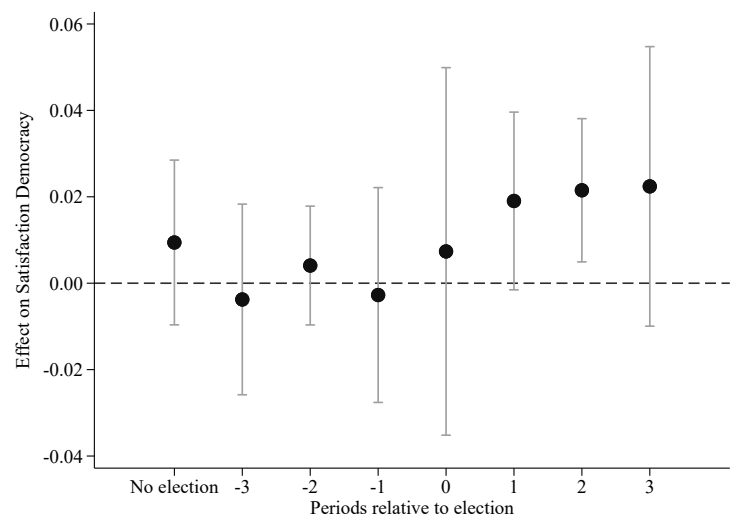

Notes: Estimates of the effect of Facebook Speakers on the different outcomes specified in the panel titles. For all variable definitions and sources, see Appendix Table A-1. We extend our baseline regressions to include dummies indicating if each observation took place in the quarters after, during or after an election took place as well as their interaction with Facebook Speakers. Panel A plots the coefficient of the uninteracted quarter dummies while Panels B to F plot the interactions of quarterly dummies with Facebook Speakers. The dependent variable is specified in each panel. Panels A to C (Facebook Searches) are based on country-level counts and Panels $\mathrm{C}$ (other media) to $\mathrm{F}$ on survey data. The omitted category are the periods outside the plus/minus three-quarter range around elections. Confidence intervals at the $95 \%$ level. 


\section{A Appendix - Variables and Sources}

\section{Table A-1: Variable Definition and Sources}

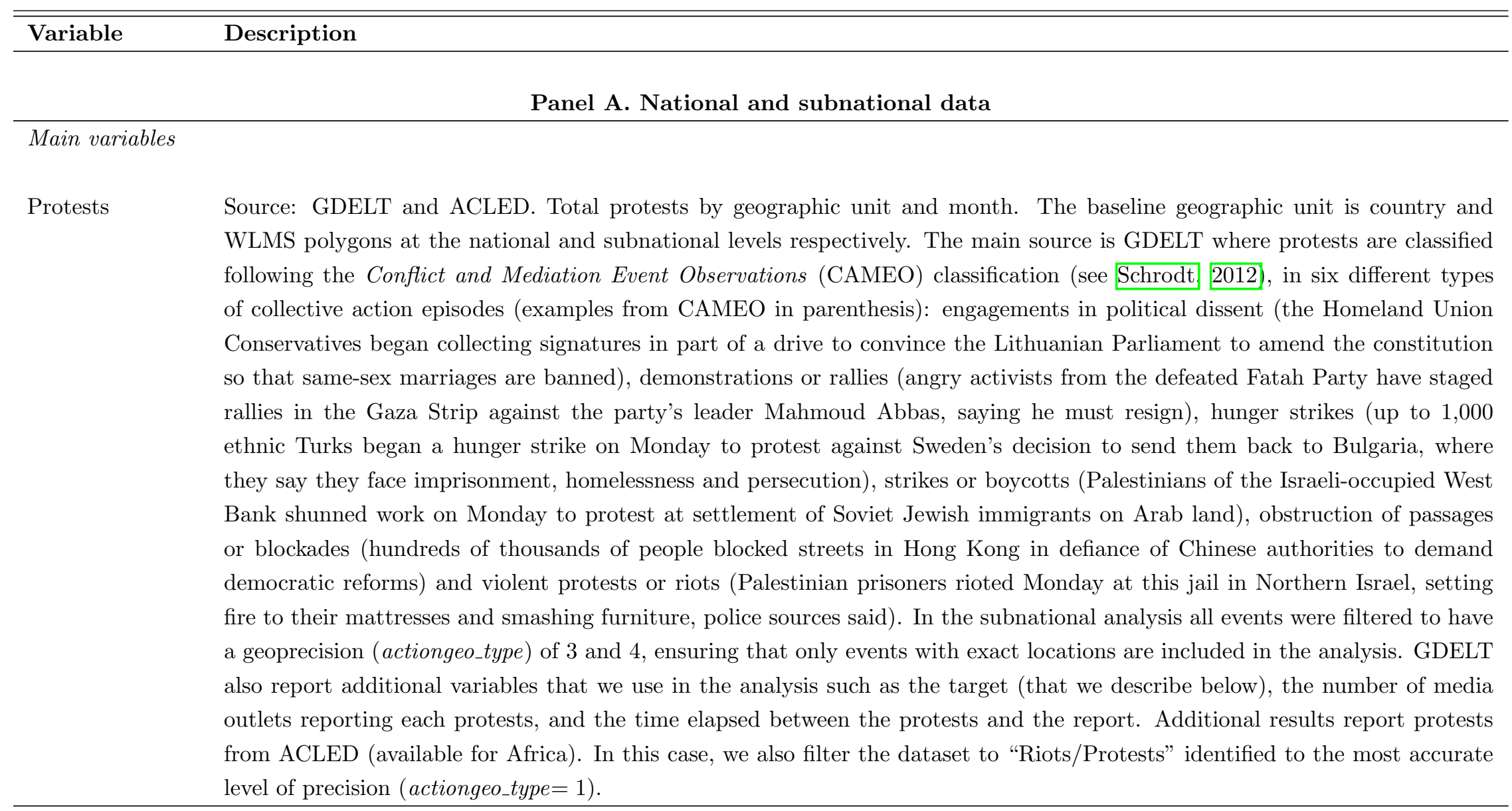

Continued on next page 
Facebook Source: World Language Mapping System (WLMS) and own coding from web searches and Internet Archive (https://archive Speakers $\quad . \circ \mathrm{rg} /$. Proportion of people who, in each country-month, speak (as their first language) a language available in Facebook. We use WLMS to identify languages spoken in countries or regions, and use our own coding of launch dates for language-specific Facebook platforms from internet queries of news, official announcements, specialized blogs and (if no other source is available) the earliest date with a web crawl at the Internet Archive's Way Back Machine tool. See Table A-2 for launch dates and source for date of entry of each platform. For 12 countries (British Indian Ocean Territory, Faroe Islands, Hong Kong, Isle of Man, Kosovo, Macau, Paracel Islands, Saitn Martin, Seychelles, South Sudan, Svalbard, Western Sahara), the information in WLMS is in-existent or extremely incomplete. In such cases we rely directly in Ethnologue.

Other variables (in alphabetical order)

Arab spring Source: Own coding. Equals one if country is Algeria, Egypt, Gaza Strip, Iran, Iraq, Jordan, Kuwait, Mauritania, Morocco, countries Lebanon, Libya, Oman, Saudi Arabia, Sudan, Syria, Tunisia, West Bank, Western Sahara or Yemen. between 2000 and 2015.

Catholic Source: The Hierarchy of the Catholic Church. Catholic parishes per capita per country 1996-2005.

parishes per

capita

Catholic popula- Source: The Hierarchy of the Catholic Church. Catholic population per country 1996-2005.

tion

Colony/Colonizer Source: ICOW Colonial History Data version 1.1. It represents the Primary Colonial Ruler defined as "the colonial or imperial power that was most responsible for shaping the development of the entity (or entities) that became this modern state."

Control of Source: The Worldwide Governance Indicators (WGI). It captures "perceptions of the extent to which public power is exercised Corruption for private gain, including both petty and grand forms of corruption, as well as 'capture' of the state by elites and private interests. Estimate gives the country's score on the aggregate indicator, in units of a standard normal distribution, i.e. ranging from approximately -2.5 to 2.5." We use the country average from 1996 to 2004. More details at https://datacatalog . worldbank.org/control-corruption-estimate-0.

Coup D'État

Source: Coup D'État Events Dataset, 1946-2018, Center for Systemic Peace. Number of successful, attempted, plotted or alleged coup d'état events (a forceful seizure of executive authority and office that results in a change in the executive leadership and policies of the prior regime. 
Crisis $\quad$ Source: World Bank. Dummy equals one if GDP growth for a country is 2 standard deviations below its mean.

Democracy Source: Freedom House. Index measuring the degree of democratic freedoms. Based on two indices, each assessing the state of (Freedom

House)

Democracy

(Polity IV) Civil Liberties and Political Rights on a scale from 1 (most free) to 7 (least free). In Figure 5 the index is the value in 2000.

Source: Systemic Peace. Polity score which ranges from -10 to +10 , where with -10 to -6 corresponding to autocracies, -5 to 5 corresponding to anocracies, and 6 to 10 to democracies. Based on an evaluation of elections for competitiveness and openness, the nature of political participation in general, and the extent of checks on executive authority. We use the country average from 1996 to 2004.

Democracy (V- Source: Varieties of Democracy https://www.v-dem.net/en/. V-Dem measures democracy distinguishing five aspects of Dem) democratic institutions: electoral, liberal, participatory, deliberative, and egalitarian. The level of democracy is given by the average of the five components. We use the value for 2000.

Diamond

production

population

Exports to US

Facebook Most

Spoken, $50 \%$ and

$20 \%$

Source: Constituency-Level Elections Archive (CLEA). Equals one for observations where constituency-level elections were carried out in each country.

Source: Ethnologue. Fraction of the population in the country speaking English as a first language.

Source: BACI. Share of exports from each country to the United States measured yearly between 2000 and 2015.

Source: Own coding from WLMS and Facebook language-specific platforms launch dates. Equals one if, in a country-month, a Facebook version had been released in: the most spoken language in the country (Facebook Most Spoken), a language spoken by more than $50 \%$ of the population (Facebook $50 \%$ ) or one spoken by more than $20 \%$ of the population (Facebook $20 \%$ ). See Table A-2 for launch dates and source for date of entry of each platform.

Facebook Source: Google Trends.We use the log of (one plus) the total number of google searches of the word "Facebook" for country $c$ Searches during month $m$ (as percentage of the highest number of searches in a month for the country $c$ ). Google reports this information weekly. We take the average over the month for each country. These series start in January, 2004. We assume that before 2004, the index equals zero. 
Facebook Sec- Source: Ethnologue. Ethnologue reports for each country and language the number of people who speak a language as a second ond Language language (L2 Users). We construct the share of each country's population that can access a Facebook interface in a second Speakers language as in equation (4) (in this case, Speakers ${ }_{c l}$ refers to the proportion of people in country $c$ who speak a language $l$ as a second language). Note that people may speak more than one second language, so this proportion may exceed 1.

Facebook Users Log of one plus number of Facebook users. Source: We combine figures from three sources: Frost and Strauss (2016), https:// www.internetworldstats.com/, https://www.nickburcher.com/ and information that Maria Petrova kindly shared with us for 47 countries from 2008 to 2012. We build an unbalanced panel for 115 countries.

Fertility rate Source: World Bank. Births per 1,000 women in ages 15-19, country average 1995-2005.

adolescents

Financial Crisis Source: NBER https://www.nber.org/cycles.html. Dummy variable equals one for any period between December 2007 and June 2009.

Freedom of Asso- Source: CIRI Human Rights Data Project. Equals one if freedoms of assembly and association in the period 2000-2005 was ciation reported as "severely restricted or denied completely to all citizens". Source: Systemic Peace. Equals one if oppositional activity is either repressed or suppressed outside the ranks of the regime Opposition and ruling party. Totalitarian party systems, authoritarian military dictatorships, and despotic monarchies are typically coded here. Coded from parcomp in polity IV. Average 2000-2004.

Freedom of Source: Freedom House. Index based on four elements "(A) Laws and regulations that influence media content, (B) political the Press pressures and controls on media content, (C) economic influences over media content and (D) repressive actions (killing of journalists, physical violence against journalists or facilities, censorship, self-censorship, harassment, expulsions, etc.)". Results in classification as Free, Partly Free or Not Free. We use this index for 2000.

GDP Source: World Bank. GDP in USD billion dollars (constant dollars of 2005). Average between 2000-2005. Where unavailable, we complemented the information for some countries by consulting national statistics offices.

GDP growth Source: World Bank. Annual gross domestic product per capita growth rate.

Historical Source: GDELT. Average of protests by country between January 2000 and August of 2006 (before Facebook was released).

protests Internet users

Source: International Telecommunication Union. Millions of internet users in 2002.

Irreg. remov. Source: Archigos Dataset on Leaders version 4.1. Number of irregular removals from office, when the executive leader was from office removed in contravention of explicit rules and established conventions. 
Linguistic

fragmentation

Linguistic polarization

No. of violent internal conflicts

Number of phrases translated

or number of translators

Oil reserves

Oil and gas rents

Protest targets
Source: Own coding using WLMP/Ethnologue. Fragmentation in country $c$ is defined as $F_{c}=1-\sum_{i=1}^{N} \pi_{i c}^{2}$, where $\pi_{i j}$ is the share of speakers of $i$ language in country $c$ before Facebook was launched.

Source: Own coding using using WLMP/Ethnologue. Polarization for country $c$ is defined as $P_{c}=1-\sum_{i=1}^{N} \pi_{i c}\left(\frac{1 / 2-\pi_{i c}}{1 / 2}\right)^{2}$, where $\pi_{i c}$ is the share of speakers of the $i$ language in country $c$ before Facebook was launched.

Source: UCDP/PRIO Armed Conflict Dataset version 19.1. Number of violent internal conflicts of either any intensity or broken down by intensity level: producing 25-1,000 (or over 1,000) battle-related deaths in a given year, .

Source: Own coding. Facebook publishes, for each language, a ranking of the top 100 users by number of published phrases and makes it available to users of that language. We use this feature to measure the frequency of translations by country and language. We created several user accounts for the 81 different languages in our sample. For the top 100 translators in each platform (8,100 users) we identify the name, profile link, ranking position, and number of published phrases. We next identify each user's country of residence. In $75 \%$ of the cases, this is directly identifiable in the user profile, either because the country of residence is listed (35\%) or because we can match the city or district to the country (30\%) using the Geonames dataset. In an additional $30 \%$ of the cases, we manually review the user's profiles and posts to infer the country from complementary information (e.g., the user attends a university or works in a firm that can be located). We are unable to match the country for only $5 \%$ of the users.

Source: Humphreys (2005). Oil reserves (thousand barrels per person), average 1961-2000.

Source: M. Ross (2008). Oil and gas rents per capita (per capita rents from oil and gas in constant 2000 dollars), average 1990-2000.

Source: GDELT. Armed forces: police forces, officers, criminal investigative units, protective agencies and troops, soldiers, all state/military personnel/equipment. Legislature: parliaments, assemblies, lawmakers, references to specific legislative entities or subentities such as committees. Government: the executive, governing parties, coalitions partners, executive divisions. Political opposition: opposition parties, individuals, anti-government activists. Education: educators, schools, students, or organizations dealing with education. Media: journalists, newspapers, television stations, providers of Internet services and other forms of mass information dissemination. Civilians: civilian individuals or groups sometimes used as a catch-all for individuals or groups for whom no other role or category is appropriate. Business: businessmen, companies, and enterprises. Labor: individuals in (or elements of) organized labor, organizations concerned with labor issues.

Continued on next page 
Population Source: United Nations, World Bank and WMLS. Number of inhabitants by country and year. When used as control in the national regressions, population is the average 1995-1999. In the subnational regressions, we use the population of the polygon.

Regulatory Quality

Rule of Law

Share of GDP in manufacturing Share of population aged $15-24$ Sex ratio at birth Urban population share Voice and Accountability

Years of schooling
Source: The Worldwide Governance Indicators (WGI) project. It captures "perceptions of the ability of the government to formulate and implement sound policies and regulations that permit and promote private sector development. Estimate gives the country's score on the aggregate indicator, in units of a standard normal distribution, i.e. ranging from approximately -2.5 to 2.5." We use the country average from 1996 to 2004. More details at https://datacatalog.worldbank.org/regulatory -quality-estimate-0

Source: The Worldwide Governance Indicators (WGI) project. It captures "perceptions of the extent to which agents have confidence in and abide by the rules of society, and in particular the quality of contract enforcement, property rights, the police, and the courts, as well as the likelihood of crime and violence. Estimate gives the country's score on the aggregate indicator, in units of a standard normal distribution, i.e. ranging from approximately -2.5 to 2.5." We use the country average from 1996 to 2004. More details at https://datacatalog.worldbank.org/rule-law-estimate-0

Source: United Nations. GDP in manufacturing as percentage of total GDP, average 1990-2005.

Source: United Nations. Share of inhabitants aged between 15 and 24 for 2000.

Source: World Bank. Male births per female births, country average 1995-2005.

Source: World Bank. Urban population as percentage of total population. Average 1990-2005.

Source: The Worldwide Governance Indicators (WGI) project . It captures "perceptions of the extent to which a country's citizens are able to participate in selecting their government, as well as freedom of expression, freedom of association, and a free media. Estimate gives the country's score on the aggregate indicator, in units of a standard normal distribution, i.e. ranging from approximately -2.5 to 2.5." We use the country average from 1996 to 2004 . More details at https:// datacatalog.worldbank.org/voice-and-accountability-estimate-0

Source: United Nations. Average schooling in inhabitants aged 15 and over in 1995.

Panels B-D. Individual-level data from surveys (source is the corresponding survey) Panel B. World Values Survey

Continued on next page 
Table A-1 - Variable Definition and Sources (Continues from Previous Page)

\begin{abstract}
Main variables
Protest Equals one if the respondent answers "Have done" or "Might do" (zero if "Would never do") to the question, "I'm going to read out some forms of political action that people can take, and I'd like you to tell me ... whether you have done any of these things, whether you might do it or would never under any circumstances do it ... Attending peaceful demonstrations". In Table B-10 we also explore alternative definitions. Effective protest equals one if the respondent answers "Have done", and zero if "Would never do". Intention to protest equals one if the respondent answers "Might do" and zero if "Would never do".

Facebook Equals one if Facebook is available in the respondent's home language, coded from the question "What language do you normally Speaker $\quad$ speak at home?"
\end{abstract}

Other variables (in alphabetical order)

Age group Respondent's age in years in the following groups: $\leq 25,(25,40],(41,55]$ and $\geq 55$.

Education We classify education in three levels: tertiary completed (Tertiary), secondary completed (Secondary) or less than secondary completed (Primary). Based on the question "What is the highest educational level that you have attained?" we classify this variable as (1) Primary if "No formal education", "Inadequately completed primary school", "Completed (compulsory) elementary education" or "Incomplete secondary school"; (2) Secondary if "Complete secondary school: technical/vocational type", "Incomplete secondary: university-preparatory type" or "Complete secondary: university-preparatory type" (3) Tertiary if "Some university without degree" or "University with degree/Higher education".

In favor of a Equals one if the respondent answers "Very good" or "Fairly good" (zero if "Fairly bad" or "Very bad") to the question "I'm democratic sys- going to describe various types of political systems and ask what you think about each as a way of governing this country. tem For each one, would you say it is a very good, fairly good, fairly bad or very bad way of governing this country?... Having a democratic political system".

Interested Equals one if the respondent answers "Very interested" (zero if "Not at all interested", "Not very interested" or "Somewhat in politics interested") to the question "How interested would you say you are in politics?" 
Member of Equals one if the respondent answers "Active member" (zero if always "Inactive member" or "Don't belong") to any of the association questions "Now I am going to read off a list of voluntary organizations. For each organization, could you tell me whether you are an active member, an inactive member or not a member of that type of organization?" (1) "sport or recreation", (2) "art, music, educational", (3) "labour unions", (4) "political party", (5) "environmental organization", (6) "professional organization", (7) "charitable/humanitarian organization" or (8) "any other organization".

Newspaper news Variable homogenized from slightly different questions. For Morocco and Spain in Wave 6 as well as any country in Wave 5 , the question is "People use different sources to learn what is going on in their country and the world. For each of the following sources, please indicate whether you used it last week or did not use it last week to obtain information: Daily newspaper". For the rest of the countries in Wave 6, the question is "People learn what is going on in this country and the world from various sources. For each of the following sources, please indicate whether you use it to obtain information daily, weekly, monthly, less than monthly or never: Daily newspaper". We define the variable as equals one if the respondent answers either "Used it last week" (zero if "Did not use it last week") or "Daily" or "Weekly" (zero if "Monthly", "Less than monthly" or "Never").

Party identity Equals one if the respondent answers "Active member" (zero if "Inactive member" or "Don't belong") to the question "Now I am going to read off a list of voluntary organizations. For each organization, could you tell me whether you are an active member, an inactive member or not a member of that type of organization? ...political party"

Radio or TV Variable homogenized from slightly different questions. For Morocco and Spain in Wave 6 the question is "People use different news $\quad$ sources to learn what is going on in their country and the world. For each of the following sources, please indicate whether you used it last week or did not use it last week to obtain information". For the rest of the countries in Wave 6, the question is "People learn what is going on in this country and the world from various sources. For each of the following sources, please indicate whether you use it to obtain information daily, weekly, monthly, less than monthly or never: Daily newspaper". In both questions, the survey includes independent questions for Radio and TV. In Wave 5, the question is "People use different sources to learn what is going on in their country and the world. For each of the following sources, please indicate whether you used it last week or did not use it last week to obtain information". Unlike the former question, they ask for "News broadcasts or In depth reports on radio or TV". We define the variable as equals one if the respondent answers either "Used it last week" (zero if "Did not use it last week") or "Daily" or "Weekly" (zero if "Monthly", "Less than monthly" or "Never"). 
Rejects... (1) experts making decisions, (2) military rule and (3) one-man rule equal one if the respondent answers "Fairly bad" or "Very bad" (zero if "Very good" or "Fairly good") to the question "I'm going to describe various types of political systems and ask what you think about each as a way of governing this country. For each one, would you say it is a very good, fairly good, fairly bad or very bad way of governing this country?..." (1) "...Having experts, not government, make decisions according to what they think is best for the country", (2) "...Having the army rule" and (3) "...Having a strong leader who does not have to bother with parliament and elections", respectively.

Satisfied Individuals are asked to rate in a card from 0 to 10 the question "And how democratically is this country being governed democracy today? Again using a scale from 1 to 10, where 1 means that it is "not at all democratic" and 10 means that it is "completely democratic," what position would you choose?". Variable is normalized to the [0,1] interval.

Sex Sex of respondent.

Signs petition Equals one if the respondent answers "Have done" or "Might do" (zero if "Would never do") to the question, "I'm going to read out some forms of political action that people can take, and I'd like you to tell me ... whether you have done any of these things, whether you might do it or would never under any circumstances do it ... Sign a petition"

(1) civil service, (2) courts, (3) military, (4) government, (5) parliament and (6) police equal one if the respondent answers "A great deal" or "Quite a lot" (zero if "Not very much" or "None at all") to the question "I am going to name a number of organizations. For each one, could you tell me how much confidence you have in them: is it a great deal of confidence, quite a lot of confidence, not very much confidence or none at all..." (1) "...The Civil service", (2) "...The courts", (3) "...The armed forces", (4) "...The government (in your nation's capital)", (5) "...Parliament" and (6) "...The police" respectively.

Votes in election Equals one if the respondent answers "Always" or "Usually" (zero if "Never") to any of the following to question "When elections take place, do you vote always, usually or never?" in (1) "Local level" or (2) "National level".

Wealth We categorize households by wealth using the question "On this card is an income scale on which 1 indicates the lowest income group and 10 the highest income group in your country. We would like to know in what group your household is." We classify households in three subgroups: 1-3, 4-7 and 8-10.

\section{Panel C. European Social Survey}


Protest Equals one if the respondent answers "Yes" (zero if "No") to the question, "There are different ways of trying to improve things in [country] or help prevent things from going wrong. During the last 12 months, have you ... taken part in lawful public demonstration last 12 months?".

Facebook Equals one if Facebook is available in the respondent's home language, coded from the question "What language or languages do Speaker $\quad$ you speak most often at home?" Respondents can choose up to two languages (47\% of the respondents report two languages). An individual is a Facebook Speaker at time $t$ if Facebook had been launched at $t$ in any of the (up to two) first languages reported.

Other variables (in alphabetical order)

Age group $\quad$ We categorize the respondent's age in years in the following groups: $\leq 25,(25,40],(41,55]$ and $\geq 55$.

Contacts Equals one if the respondent answers "Yes" (zero if "No") to the question "There are different ways of trying to improve things politician in [country] or help prevent things from going wrong. During the last 12 months, have you ... contacted a politician, government or local government official?"

Education We classify education in three levels: tertiary completed (Tertiary), secondary completed (Secondary) or less than secondary completed (Primary). When the International Standard Classification of Education (ISCED) variable (eisced) is available (mostly since wave 5), we classify this variable as (1) Primary if "None", "ISCED I (less than lower secondary)", "ISCED II, lower secondary" or "ES-ISCED IIIb"; (2) Secondary if "ES-ISCED IIIa (upper tier upper secondary)" or (3) Tertiary if "ISCED IV (advanced vocational)", "ISCED V1 (lower tertiary education)" or "ISCED V2 (higher tertiary education)". When ISCED is not available, we rely on the question "What is the highest level of education you have achieved?" (edulvla) and classify education as (1) Primary if "Less than lower secondary education" or "Lower secondary education completed"; (2) Secondary if "Upper secondary education completed" or (3) Tertiary if "Tertiary education completed".

Interested Equals one if the respondent answers "Very interested" (zero if "Not at all interested", "Hardly interested" or "Quite interested") in politics Member of $\quad$ Equals one if the respondent answers "Yes, currently" (zero if "Yes, previously" or "No") to the question "Are you or have you association ever been a member of a trade union or similar organisation? if yes, is that currently or previously?" 


\section{Table A-1 - Variable Definition and Sources (Continues from Previous Page)}

Newspaper Equals one if the respondent answers reading newspapers ("Less than 0.5 hour" 0.5 to 1 hour", "More than 1 hour, up to 1.5 hours", "More than 1.5 hours, up to 2 hours", "More than 2 hours, up to 2.5 hours", "More than 2.5 hours, up to 3 hours" or "More than 3 hours"); zero if "No time at all") to the question "On an average weekday, how much time, in total, do you spend reading the newspapers?"

Newspaper news Equals one if the respondent answers reading newspapers ("Less than 0.5 hour" 0.5 to 1 hour", "More than 1 hour, up to 1.5 hours", "More than 1.5 hours, up to 2 hours", "More than 2 hours, up to 2.5 hours", "More than 2.5 hours, up to 3 hours" or "More than 3 hours"); zero if "No time at all") to the question "how much of this time is spent reading about politics and current affairs?"

Party identity Equals one if the respondent answers "Yes" (zero if "No") to "Is there a particular political party you feel closer to than all the other parties?"

Radio Equals one if the respondent answers listening to radio ("Less than 0.5 hour" 0.5 to 1 hour", "More than 1 hour, up to 1.5 hours", "More than 1.5 hours, up to 2 hours", "More than 2 hours, up to 2.5 hours", "More than 2.5 hours, up to 3 hours" or "More than 3 hours"); zero if "No time at all") to the question "On an average weekday, how much time, in total, do you spend listening to the radio?"

Radio news

Equals one if the respondent answers listening to radio ("Less than 0.5 hour" 0.5 to 1 hour", "More than 1 hour, up to 1.5 hours", "More than 1.5 hours, up to 2 hours", "More than 2 hours, up to 2.5 hours", "More than 2.5 hours, up to 3 hours" or "More than 3 hours"); zero if "No time at all") to the question "on an average weekday, how much of your time listening to the radio is spent listening to news or programmes about politics and current affairs?"

Satisfied Individuals are asked to rate from 0 to 10 when responding the question "Now thinking about the [country] government, how government Satisfied satisfied are you with the way it is doing its job? Still use the card". We normalize to the $[0,1]$ interval using $\frac{x-x_{\min }}{x_{\max }-x_{\min }}$.

democracy

Sex Individuals are asked to rate from 0 to 10 when responding the question "And on the whole, how satisfied are you with the way democracy works in [country]? Still use this card". We normalize to the $[0,1]$ interval using $\frac{x-x_{\min }}{x_{\max }-x_{\min }}$.

Sex of respondent. 
Signs a petition Equals one if the respondent answers "Yes" (zero if "No") to the question "There are different ways of trying to improve things in [country] or help prevent16 things from going wrong. During the last 12 months, have you ... Signed a petition?"

Trust in...

(1) courts, (2) parliament, (3) police, (4) political parties and (5) politicians. Based on the question "Using this card, please tell me on a score of $0-10$ how much you personally trust each of the institutions I read out. 0 means you do not trust an institution at all, and 10 means you have complete trust:" (1) “...the legal system?", (2) “...[country]'s parliament?", (3) “...the police?", (4) “...political parties?" and (5) “...politicians?" respectively. Each variable is normalized to the [0,1] interval using $\frac{x-x_{\min }}{x_{\max }-x_{\min }}$.

TV

Equals one if the respondent answers watching TV ("Less than 0.5 hour" 0.5 to 1 hour", "More than 1 hour, up to 1.5 hours", "More than 1.5 hours, up to 2 hours", "More than 2 hours, up to 2.5 hours", "More than 2.5 hours, up to 3 hours" or "More than 3 hours"); zero if "No time at all") to the question "On an average weekday, how much time, in total, do you spend watching television?"

TV news $\quad$ Equals one if the respondent answers watching TV ("Less than 0.5 hour" 0.5 to 1 hour", "More than 1 hour, up to 1.5 hours", "More than 1.5 hours, up to 2 hours", "More than 2 hours, up to 2.5 hours", "More than 2.5 hours, up to 3 hours" or "More than 3 hours"); zero if "No time at all") to the question "on an average weekday, how much of your time watching television is spent watching news or programmes about politics and current affairs?"

Votes in Equals one if the respondent answers "Yes" (zero if "No") to the question "Some people don't vote nowadays for one reason or election another. Did you vote in the last [country] national election in [month/year]?"

Wealth We categorize households by wealth using the total net income classification in the survey. In waves 1-3, individuals are asked "Using this card, if you add up the income from all sources, which letter describes your household's total net income? If you don't know the exact figure, please give an estimate." In waves 4-8, individuals are asked "Using this card, please tell me which letter describes your household's total income, after tax and compulsory deductions, from all sources? If you don't know the exact figure, please give an estimate." In the former case the card goes from 1 to 12 and we group households in three subgroups: 1-4, 5-8 and 9-12. In the later case the card goes from 1 to 10 and we classify households in three subgroups: 1-3, 4-7 and 8-10.

Works in Equals one if the respondent answers "Yes" (zero if "No") to the question "There are different ways of trying to improve things political party in [country] or help prevent things from going wrong. During the last 12 months, have you ... worked in a political party or action group?" 
Worn campaign Equals one if the respondent answers "Yes" (zero if "No") to the question "There are different ways of trying to improve things badge in [country] or help prevent things from going wrong. During the last 12 months, have you ... worn or displayed a campaign badge/sticker?"

Panel D. Afrobarometer

Main variables

Protest

Equals one if the respondent answers "Yes, once or twice", "Yes, several times", "Yes, often" or "No, but would do if had the chance" (zero if "No, would never do this") to the question, "Here is a list of actions that people sometimes take as citizens. For each of these, please tell me whether you, personally, have done any of these things during the past year. If not, would you do this if you had the chance: Attended a demonstration or protest march?". In Table B-10 we explore alternative definitions. Effective protest equals one if the respondent answers "Yes, once or twice", "Yes, several times" or "Yes, often", and equals zero if "No, would never do this". Intention to protest equals one if the respondent answers "No, but would do if had the chance", and equals zero if "No, would never do this".

Facebook Equals one if Facebook is available in the respondent's home language, coded from the question "Which language is your home Speaker language?"

\section{Other variables (in alphabetical order)}

Age group

Attends

meeting
We categorize the respondent's age in years in the following groups: $\leq 25,(25,40],(41,55]$ and $\geq 55$.

Equals one if the respondent answers "Yes, once or twice", "Yes, several times", "Yes, often" or "No, but would do if had the chance" (zero if "No, would never do this") to the question "Here is a list of actions that people sometimes take as citizens. For each of these, please tell me whether you, personally, have done any of these things during the past year. If not, would you do this if you had the chance: Attended a community meeting?" 


\section{Table A-1 - Variable Definition and Sources (Continues from Previous Page)}

Checks Equals one if the respondent answers "Agree with Statement 2", "Agree very strongly with Statement 2" (zero if "Agree very court strongly with Statement 1" or "Agree with Statement 1" or "Agree with neither") to the question "Which of the following statements is closest to your view? Choose Statement 1 or Statement 2. Statement 1: Since the President was elected to lead the country, he/she should not be bound by laws or court decisions that he thinks are wrong. Statement 2: The President must always obey the laws and the courts, even if he/she thinks they are wrong".

Checks Equals one if the respondent answers "Agree very strongly with Statement 1" or "Agree with Statement 1" (zero if "Agree media with Statement 2", "Agree very strongly with Statement 2" or "Agree with neither") to the question "Which of the following statements is closest to your view? Choose Statement 1 or Statement 2. Statement 1: The news media should constantly investigate and report on corruption and the mistakes made by the government. Statement 2: Too much reporting on negative events, like corruption, only harms the country".

Checks Equals one if the respondent answers "Agree very strongly with Statement 1" or "Agree with Statement 1" (zero if "Agree parliament with Statement 2", "Agree very strongly with Statement 2" or "Agree with neither") to the question "Which of the following statements is closest to your view? Choose Statement 1 or Statement 2. Statement 1: Parliament should ensure that the President explains to it on a regular basis how his/her government spends taxpayers' money. Statement 2: The President should be able to devote his/her full attention to developing the country rather than wasting time justifying his actions".

Checks

opposition Equals one if the respondent answers "Agree very strongly with Statement 1" or "Agree with Statement 1" (zero if "Agree with Statement 2", "Agree very strongly with Statement 2" or "Agree with neither") to the question "Which of the following statements is closest to your view? Choose Statement 1 or Statement 2. Statement 1: Opposition parties should regularly examine and criticize government policies and actions. Statement 2: Opposition parties should concentrate on cooperating with government and helping it develop the country".

Choosing leaders Equals one if the respondent answers "Agree very strongly with Statement 1" or "Agree with Statement" (zero if "Agree in elections with Statement 2", "Agree very strongly with Statement 2" or "Agree with neither") to the question "Which of the following statements is closest to your view? Choose Statement 1 or Statement 2. Statement 1: We should choose our leaders in this country through regular, open and honest elections. Statement 2: Since elections sometimes produce bad results, we should adopt other methods for choosing this country's leaders."

Discusses $\quad$ Equals one if the respondent answers "Frequently" (zero if "Never" or "Occasionally") to the question "When you get together politics with your friends or family, would you say you discuss political matters?" 
Education We classify education in three levels: (Tertiary), secondary completed (Secondary) or less than secondary completed (Primary). Using the question "What is the highest level of education you have completed?" we classify this variable as (1) Primary if "No formal schooling", "Informal schooling only (including Koranic schooling)", "Some primary schooling", "Primary school completed" or "Some secondary school/ high school"; (2) Secondary if "Secondary school completed/high school completed"; (3) Tertiary if "Post-secondary qualifications", "Some university" or "University completed".

Fearless of polit- Equals one if the respondent answers "Not at all" (zero if "A lot", "Somewhat" or "little bit") to the question "During election ical intimidation Free to... campaigns in this country, how much do you personally fear becoming a victim of political intimidation or violence?"

(1) say what you think, (2) join political organization, (3) vote, (4) say political opinion equal one if the respondent answers "Completely free" (zero if "Not at all free", "Not very free" or "Somewhat free") to the question "In this country, how...' (1) “... free are you: To say what you think?”, (2) “... free are you: To join any political organization you want?”, (3) “... free are you: To choose who to vote for without feeling pressured?" and (4) "... often: do people have to be careful of what they say about politics?"

Interested Equals one if the respondent answers "Very interested" (zero if "Not at all interested", "Not very interested" or "Somewhat in politics

Newspaper news interested") to the question "How interested would you say you are in public affairs?"

Equals one if the respondent answers "A few times a week" or "Every day" (zero if the respondent answers "Less than once a month", "A few times a month" or "Never") to the question "How often do you get news from the following sources: Newspapers?"

Parliament Equals one if the respondent answers "Agree very strongly with Statement 1" or "Agree with Statement 1" (zero if "Agree law making with Statement 2", "Agree very strongly with Statement 2" or "Agree with neither") to the question "Which of the following statements is closest to your view? Choose Statement 1 or Statement 2. Statement 1: Members of Parliament represent the people; therefore they should make laws for this country, even if the President does not agree. Statement 2: Since the President represents all of us, he/she should pass laws without worrying about what Parliament thinks".

Party identity Equals one if response is "Yes" (zero if "No") to the question "Do you feel close to any particular political party?".

Performance of... (1) assembly, (2) local councilor and (3) president equal one if the respondent answers "Approve" or "Strongly approve" (zero if "Strongly disapprove" or "Disapprove") to the question "Do you approve or disapprove of the way the following people have performed their jobs over the past twelve months, or haven't you heard enough about them to say:..." (1) "...Your Member of Parliament", (2) "...Your Elected Assembly man/woman" and (3) "...The President", respectively. 
Political leader Equals one if the respondent answers "Official leader" (zero if "Not a Member", "Inactive member" or "Active member") to the question "Let's turn to your role in the community. Now I am going to read out a list of groups that people join or attend. For each one, could you tell me whether you are an official leader, an active member, an inactive member, or not a member: Some other voluntary association or community group?"

Radio news Equals one if the respondent answers "A few times a week" or "Every day" (zero if "Less than once a month", "A few times a month" or "Never") to the question "How often do you get news from the following sources: Radio?"

Rejects... (1) military rule, (2) one-man rule and (3) one-party rule equal one if the respondent answers "Strongly disapprove" or "Disapprove" (zero if "Neither approve nor disapprove", "Approve" or "Strongly approve") to the question "There are many ways to govern a country. Would you disapprove or approve of the following alternatives:..." (1) "...The army comes in to govern the country?", (2) “...Elections and Parliament/National Assembly are abolished so that the President/Prime Minister can decide everything?" and (3) "...Only one political party is allowed to stand for election and hold office?", respectively.

Satisfied Equals one if the respondent answers "Fairly satisfied" or "Very satisfied" (zero if "My country is not a democracy", "Not democracy at all satisfied" or "Not very satisfied") to the question "Overall, how satisfied are you with the way democracy works in [Ghana/Kenya/etc.]? Are you:"

Satisfied Average of performance of assembly, performance of local councilor and performance of president.

government

Sex

Sex of respondent.

Signs a petition Equals one if the respondent answers "Yes, once or twice", "Yes, several times", "Yes, often" or "No, but would do if had the chance" (zero if "No, would never do this") to the question "Here is a list of actions that people sometimes take as citizens. For each of these, please tell me whether you, personally, have done any of these things during the past year. If not, would you do this if you had the chance: Got together with others to raise an issue?"

Social media

usage

Equals one if the respondent answers "A few times a week" or "Every day" (zero if "Less than once a month", "A few times a month" or "Never") to the question "How often do you get news from the following sources: Social media such as Facebook or Twitter?" Only available in round 6.

Support for Equals one if the respondent answers "Statement 1" (zero if "Statement 2" or "Statement 3") to the question "Which of these democracy three statements is closest to your own opinion? Statement 1: Democracy is preferable to any other kind of government. Statement 2: In some circumstances, a non-democratic government can be preferable. Statement 3: For someone like me, it doesn't matter what kind of government we have." 
Trust in... (1) courts, (2) electoral commission, (3) opposition (4) parliament, (5) police, (6) president and (7) ruling party equal one if the respondent answers "Somewhat" or "A lot" (zero if "Not at all" or "Just a little") to the question "How much do you trust each of the following, or haven't you heard enough about them to say:..." (1) "...Courts of law", (2) "...The Electoral Commission of [Ghana, Kenya, etc.]", (3) "Opposition Political Parties", (4) "...Parliament", (5) “...The Police", (6) “...The President" and (7) "...The Ruling Party", respectively.

TV news $\quad$ Equals one if the respondent answers "A few times a week" or "Every day" (zero if "Less than once a month", "A few times a month" or "Never") to the question "How often do you get news from the following sources: Television?"

Votes in Equals one if the respondent answers "You voted in the elections" (zero if "You were not registered or you were too young to election vote", "You decided not to vote", "You could not find the polling station", "You were prevented from voting", "You did not have time to vote" "Did not vote for some other reason" or "You could not find your name in the voter's register") to the question "With regard to the most recent, national elections, which statement is true for you?"

Wealth We categorize households by wealth in three groups. First, we compute the first principal component of the following three questions (for each wave): "Over the past year, how often, if ever, have you or anyone in your family gone without:" (1) "Enough food to eat?" (2) "Enough clean water for home use?" and (3) "Medicines or medical treatment?" (classified as " $0=$ Never", " $1=$ Just once or twice", " $2=$ Several/Many times" and " $3=$ Always"). Next, using this component, we divide the households into terciles. 


\section{Table A-2: Languages available in Facebook by January 2016 and source for date of entry}

\begin{tabular}{|c|c|c|c|}
\hline$\underline{\overline{\text { Platform }}}$ & Source & Platform & Source \\
\hline Afrikaans & Internet Archive, New Sudan Vision & Kazakh & Facebook Translation Team \\
\hline Albanian & Wikipedia, Internet Archive & Khmer & Open Equal Free, Chamnan Muon \\
\hline Arabic & The Daily Telegraph, The Guardian & Kinyarwanda & PC Tech Magazine \\
\hline Armenian & Internet Archive, Panarmenian & Korean & Blog Nick Burcher, Internet Archive \\
\hline Assamese & Facebook Translation Team & Kurdish & Facebook Translation Team \\
\hline Azerbaijani & Adweek, Wikipedia & Latvian & Internet Archive \\
\hline Basque & Internet Archive & Lithuanian & Internet Archive \\
\hline Belarusian & Internet Archive & Macedonian & Internet Archive \\
\hline Bengali & Medianama, Anshprat Wordpress & Malay & Internet Archive \\
\hline Bosnian & Internet Archive & Malayalam & Medianama, Anshprat Wordpress \\
\hline Breton & Facebook Translation Team & Marathi & Facebook Translation Team \\
\hline Bulgarian & Internet Archive & Mongolian & Facebook Translation Team \\
\hline Burmese & Facebook Translation Team & Nepali & Adweek \\
\hline Catalan & Blog Nick Burcher, Internet Archive & Norwegian & Adweek, Wikipedia \\
\hline Cebuano & Internet Archive & Oriya & Facebook Translation Team \\
\hline Chinese & The Daily Telegraph, The Guardian & Pashto & Internet Archive, Pashtunforums \\
\hline Croatian & Internet Archive & Persian & Facebook Translation Team \\
\hline Czech & Blog Nick Burcher, Internet Archive & Polish & Adweek \\
\hline Danish & Blog Nick Burcher, Internet Archive & Portuguese & Google Discovery, Blog Nick Burcher \\
\hline Dutch & Blog Nick Burcher, Internet Archive & Punjabi & Medianama, Anshprat Wordpress \\
\hline English & Wikipedia, Internet Archive & Romanian & Wikipedia, Internet Archive \\
\hline Estonian & Internet Archive & Russian & Blog Nick Burcher, Internet Archive \\
\hline Filipino & Internet Archive & Serbian & Internet Archive, Ukratko Turanjanin \\
\hline Finnish & Blog Nick Burcher, Internet Archive & Sinhala & Facebook Translation Team \\
\hline France & The Age, Blog Nick Burcher & Slovak & Internet Archive \\
\hline Frisian & Internet Archive, Facebook Translation Team & Slovenian & Wikipedia, Internet Archive \\
\hline Galician & Wikipedia, Internet Archive & Sorani Kurdish & Facebook Translation Team \\
\hline Georgian & Adweek & Spanish & El Pais \\
\hline German & TechCrunch, Adweek & Swahili & Bet News, New Sudan Vision \\
\hline Greek & Internet Archive, Facebook Translation Team & Swedish & Blog Nick Burcher, Internet Archive \\
\hline Guarani & Ultima hora & Tajik & Facebook Translation Team \\
\hline Gujarati & Facebook Translation Team & Tamil & Medianama, Anshprat Wordpress \\
\hline Hebrew & The Daily Telegraph, The Guardian & Telugu & Medianama, Anshprat Wordpress \\
\hline Hindi & ReadWrite & Thai & Wikipedia, Internet Archive \\
\hline Hungarian & Wikipedia, Internet Archive & Turkish & Haberturk \\
\hline Icelandic & Internet Archive & Ukrainian & Internet Archive \\
\hline Indonesian & Internet Archive & Urdu & Askmohsin \\
\hline Italian & Blog Nick Burcher, Internet Archive & Uzbek & Facebook Translation Team \\
\hline Japanese & Adweek & Vietnamese & Internet Archive, Radio Free Asia \\
\hline Javanese & Facebook Translation Team & Welsh & Internet Archive, WalesOnline \\
\hline Kar & book Translation Team & & \\
\hline
\end{tabular}




\section{Table A-3: Countries and non-sovereign territories}

Countries in the main sample

Afghanistan, Albania, Algeria, Andorra, Angola, Antigua and Barbuda, Argentina, Armenia, Australia, Austria, Azerbaijan, Bahamas, Bahrain, Bangladesh, Barbados, Belarus, Belgium, Belize, Benin, Bhutan, Bolivia, Bosnia and Herzegovina, Botswana, Brazil, Brunei Darussalam, Bulgaria, Burkina Faso, Burundi, Cambodia, Cameroon, Canada, Cape Verde, Central African Republic, Chad, Chile, China, Colombia, Comoros, Congo (Republic), Congo D.R. (Zaire), Costa Rica, Cote Divoire, Croatia, Cuba, Cyprus, Czech Republic, Denmark, Djibouti, Dominica, Dominican Republic, Ecuador, Egypt, El Salvador, Equatorial Guinea, Eritrea, Estonia, Ethiopia, Fiji, Finland, France, Gabon, Gambia, Georgia, Germany, Ghana, Greece, Grenada, Guatemala, Guinea, Guinea-Bissau, Guyana, Haiti, Honduras, Hungary, Iceland, India, Indonesia, Iran, Iraq, Ireland, Israel, Italy, Jamaica, Japan, Jordan, Kazakhstan, Kenya, Kiribati, Kuwait, Kyrgyzstan, Laos, Latvia, Lebanon, Lesotho, Liberia, Libya, Liechtenstein, Lithuania, Luxembourg, Macedonia, Madagascar, Malawi, Malaysia, Maldives, Mali, Malta, Marshall Islands, Mauritania, Mauritius, Mexico, Micronesia, Moldova, Monaco, Mongolia, Montenegro, Morocco, Mozambique, Myanmar, Namibia, Nauru, Nepal, Netherlands, New Zealand, Nicaragua, Niger, Nigeria, North Korea, Norway, Oman, Pakistan, Palau, Panama, Papua New Guinea, Paraguay, Peru, Philippines, Poland, Portugal, Qatar, Romania, Russia, Rwanda, Saint Kitts and Nevis, Saint Lucia, Saint Vincent and The Grenadines, Samoa, San Marino, Sao Tome and Principe, Saudi Arabia, Senegal, Serbia, Seychelles, Sierra Leone, Singapore, Slovakia, Slovenia, Solomon Islands, Somalia, South Africa, South Korea, South Sudan, Spain, Sri Lanka, Sudan, Suriname, Swaziland, Sweden, Switzerland, Syria, Tajikistan, Tanzania, Thailand, Timor Leste, Togo, Tonga, Trinidad and Tobago, Tunisia, Turkey, Turkmenistan, Tuvalu, Uganda, Ukraine, United Arab Emirates, United Kingdom, United States, Uruguay, Uzbekistan, Vanuatu, Venezuela, Vietnam, Yemen, Zambia, Zimbabwe.

Non sovereign territories in the main sample

American Samoa, Anguilla, Aruba, Bermuda, British Indian Ocean Territory, British Virgin Islands, Cayman Islands, Christmas Island, Cook Islands, Falkland Islands, Faroe Islands, French Guiana, French Polynesia, Gaza Strip, Gibraltar, Greenland, Guadeloupe, Guam, Guernsey, Holy See, Hong Kong, Isle Of Man, Jersey, Kosovo, Macau, Martinique, Mayotte, Montserrat, Netherlands Antilles, New Caledonia, Niue, Norfolk Island, Northern Mariana Islands, Paracel Islands, Puerto Rico, Reunion, Saint Helena, Saint Martin, Saint Pierre and Miquelon, Svalbard, Taiwan, Tokelau, Turks and Caicos Islands, US Virgin Islands, Wallis and Futuna, West Bank, Western Sahara. 


\section{B Appendix - Additional Results}

\section{B.1 Administrative divisions within countries and month $\times$ state fixed effects}

For the subnational analysis we rely on WLMS's polygons within countries where each language is spoken. Some of these polygons intersect, creating areas where more than one language is spoken. For simplicity our baseline analysis assigned protests in these "overlapping zones" to all the corresponding polygons. While this double-counts protests, only $5 \%$ of protests fall in these zones. Moreover, Appendix Table B-2 shows that our results are virtually the same if we exclude these areas (column 2) or if we include them and infer language shares using national totals and grid-level population figures from the Socioeconomic Data and Applications Center (SEDAC) (column 3). In columns 4 and 5, we further confirm that the choice of the relevant subnational areas is not important for the findings by using administrative divisions and not just language polygons. These divisions are also appealing since they may be a relevant unit of analysis for political collective action. In column 4 we use the intersection of administrative divisions (the first level of administrative division, equivalent to US states) with language polygons as the unit of analysis. In column 5 , we exploit this specification by incorporating month $\times$ state fixed effects, thus flexibly controlling even for subnational trends in collective action. In every specification we find that Facebook Speakers has a positive and significant impact on protests. The magnitude of the impacts, once we recognize the changing scales of our variables, is similar across most specifications (we report the beta coefficients in the lower row of the table).

\section{B.2 Threats to identification}

Endogeneity First, we test for the presence of pre-trends. If our assumptions hold, we should not observe differential trends in collective action in countries with and without increased Facebook access in their languages before these language-specific platforms are launched. Panel A of Appendix Figure B-2 confirms that this is indeed the case. This figure extends our baseline regression (1) to include anticipation effects (leads) of our treatment variable (Facebook Speakers $_{c, t+n}$, for $n$ ranging from 1-18 months). While the treatment effect (lead zero) is positive and significant, other leads are not significantly different from zero, are typically smaller than the treatment, and follow no discernible pattern. This evidence is consistent with the lack of any substantial change in protests before a hike in 
Facebook Speakers observed in the event study analysis of Figure 3, which excluded neveradopters from the control group. Moreover, the conclusions are similar when we use Facebook search intensity in Google (Facebook Searches) as the dependent variable in Panel B: there is no increase in Facebook interest before Facebook Speakers increase ${ }^{38}$

Demand effects: endogenous translators Second, by exploiting the way in which Facebook platforms are launched, we show complementary evidence suggesting that the "demand" for Facebook is unlikely to be driven by the incidence of predetermined social unrest. Facebook translations are partly carried out by Facebook users who voluntarily translate phrases on the website. Others then vote on the preferred translations, and a platform is launched when sufficient phrases have been translated and approved. It could therefore be the case that users from certain "protest-prone" countries are more likely to contribute to the translations, hoping that a local platform will be launched sooner (perhaps precisely to organize protests). If this were the case, it would invalidate our identification assumption. Our parallel-trends results already suggest this is unlikely, since one would expect at least some anticipated action in protests (and certainly in Facebook search interest). But to further test this hypothesis, we collect data on each translator's location and use the frequency of both translations and translators from each country and language as proxies of the "eagerness" to have Facebook 39 Panel A in Appendix Table B-3 finds no evidence that collective action events in a given country speed up translations to promote the Facebook language-specific platforms 40

\footnotetext{
${ }^{38}$ In Appendix Figure B-3 we follow a slightly different approach and include, in regression (1), quarter dummies for the periods leading up to the adoption of the first Facebook version in any of the country's languages. We also interact Facebook Speakers with quarterly dummies for each quarter after the first adoption of a Facebook platform in a language spoken in the territory. Again, there is no increase in protests (Panel A) or Facebook Searches (Panel B) before local languages are available. Point estimates are statistically insignificant and close to zero. Instead, as soon as a local language becomes available, we see a sizable increase in protests and searches, and though there is naturally noise when estimating this high-frequency effect, even the quarterly effects become individually significant after just a few periods.

${ }^{39}$ To conduct this exercise, we created Facebook profiles in each of the languages in our sample to access information on top translators by language. Details on the data construction are in Appendix Table A-1.

${ }^{40}$ The unit of observation is a country-language (for languages spoken by more than $10 \%$ of the population) and the dependent variable is the total number of phrases translated (columns 1 and 2) or the total number of translators (columns 3 and 4 ) in each country and language. To measure protest activity before a language is launched we look at the protest growth in the 12-month period before Facebook's launch (columns 1 and 3 ) or at an indicator variable for whether this growth is above two standard deviations of the mean (columns 2 and 4). Whether we are looking at published phrases or the number of translators, collective action trends before Facebook appears do not predict translation efforts. Coefficients are not significant and the lower row of each panel reports the beta coefficients to gauge the magnitude of the correlations, which are all smaller than $4 \%$.
} 
Demand effects: big players Third, even though the parallel-trend analysis and the lack of association between collective action events and translation activity by Facebook users suggest that reverse causality is unlikely to be driving our results, we further explore the concern that social changes, turmoil, modernization, increased openness, and other trends can drive a society to "demand" Facebook local platforms and simultaneously be more prone to protesting. In Appendix Figure B-4, we show the baseline specification for subsamples that exclude territories that could plausibly influence the pace of adopting Facebook in a particular language. We drop countries with the largest number of people, GDP, Internet users, protests and speakers for each language, and similarly for the same variables measured in per capita terms. We also use the World Bank governance indicators to drop those performing worst in the rule of law, control of corruption, voice and accountability, political stability, government effectiveness, and regulatory quality. The left panel excludes countries speaking any language and the right panel only drops countries speaking languages available in the platform (since these drive the variation in Facebook Speakers).

The exercise is motivated by the idea that, for instance, Facebook may be launched in Portuguese to meet Brazil's or Portugal's demands, but it is less likely to respond to the political and social situation in a smaller Portuguese-speaking country (by population, income, and Internet users) like Cape Verde. Also, even small but very conflict-prone countries may drive the introduction of Facebook. Nevertheless, the results are maintained and the key coefficient is remarkably stable, suggesting that our estimates of Facebook's effect on protests is not driven by a rise in demand for social networks in large countries or those with increasing protest activity or political turmoil ${ }^{41}$

The financial crisis and economic turmoil Finally, we explore the potential role that the 2008 crisis plays in our analysis given that, as Panel A of Figure 1 shows, a considerable number of platforms were launched around this period. This could be a concern if the crisis

\footnotetext{
${ }^{41}$ Appendix Figure B-5 verifies that our results are robust to dropping: one country at a time and the set of Arab Spring countries (Panel A), countries in a given region (Panel B), countries in a given continent (Panel C), countries from a given former colonizer (Panel D), and countries having a given main language (Panel E). Panel F excludes countries according to how widespread worldwide each language is: the first bar excludes all countries whose main language is only spoken (as the most popular language) in that country, the second removes all countries whose main language is the most popular language in two countries, and so on. This last exercise addresses the concern that single-country languages are driving our effects. Indeed, if a Facebook platform will benefit just one (or very few) countries, then it is more likely that circumstances in that country or groups of countries drive the arrival of Facebook. On the x-axis, we exclude the set of languages "spoken" (as the main, most-spoken language) in 1, 2, 3, 4 countries and so on. Generally, the effect of Facebook Speakers varies only slightly and is always statistically significant.
} 
raised demand for Facebook in local platforms to coordinate protests. The exercises above suggest this is unlikely since we do not observe differential trends in collective action before these language-specific platforms are launched and the subnational-level regressions absorb any national-level trends in protests caused by the crisis.

Still, we explore this issue directly in five additional ways. First, in Appendix Figure B-6, we interact Facebook Speakers with a full set of year fixed effects to explore whether its influence has decreased or increased over time. The resulting coefficients show the effects are not limited to crisis years but also, and even more, much later on ${ }^{42}$

Second, we rely on our data on translators and find no evidence that periods of recession predict increased interest of users for translating Facebook platforms (Panel B of Appendix Table B-3). Third, we rely on the literature on the correlates of the spread of the crisis (e.g. Rose \& Spiegel, 2011) to verify whether they are in turn correlated with changes in Facebook Speakers. Panel A of Appendix Table B-4 finds that GDP growth, GDP per capita, bilateral trade and exports to the US are not correlated with subsequent changes in Facebook Speakers. Fourth, we examine the robustness of our baseline regression to allowing for differential trends capturing the potential influence of the crisis. Panel B of Appendix Table B-4 shows that our results are robust to controlling for characteristics potentially associated with the crisis (columns 1 to 7 ) or the global financial crisis years (column 8).

Fifth and finally, we explore the broader relationship between the economic cycle and the magnitude of the main effect of Facebook Speakers. In Panel A of Appendix Figure B-7, we extend our baseline regression (1) by interacting Facebook Speakers with indicator variables for 40 equally-spaced intervals in the distribution of GDP growth and plotting the resulting coefficients. The effects are stronger for low GDP growth levels (these differences arise for contractions of under $2 \%$ ). This finding is in line with the evidence of the effects of mobile phones in Manacorda and Tesei (2020), and consistent with poor economic conditions likely triggering discontent and reducing the opportunity cost of protesting. At the same time and unlike Manacorda and Tesei (2020), we find that protests respond not only during times of economic hardship. Indeed, the effects of Facebook Speakers remain relatively constant for annual GDP growth levels ranging from -2 to +8 (estimates are noisy for the few observations with faster rates of growth). This also suggests an effect not confined to the crisis years ${ }^{43}$

\footnotetext{
${ }^{42}$ This is relevant for two additional reasons. First, it suggests that the effect of Facebook on collective mobilization has been persistent over time. Second, it shows that even though marginal languages entering late in the sample represent a small fraction of the world's population, their appearance on Facebook is nonetheless important for collective mobilization in regions where they are spoken.

${ }^{43}$ Panel B uses Facebook Searches as the dependent variable, revealing a constant effect across all growth
} 


\section{B.3 Reporting biases}

We now investigate the possibility of reporting bias because Facebook makes protests more visible (e.g., by creating spillovers on protest reporting), and therefore that Facebook increases not actual protests, but reported protests in GDELT (Weidmann, 2016, Cagé et al. 2020). GDELT does not use Facebook data, but such an effect may still be present indirectly through Facebook's impact on news production. However, our finding of a generalized effect on very different types of protests also suggests that the observed effects cannot be fully accounted for by reporting spillovers when Facebook gains notoriety. Indeed, some types of protest events are likely to be relatively less visible and newsworthy, and these should be more influenced by increased reporting than others. Moreover, notice that violent protests, which one should expect to be highly visible regardless of social media and in fact are most likely to be reported by more than one source, have a similar effect as the average (Table 4).

We can also examine whether more media outlets report on a protest when a country has more Facebook Speakers. The logic is that if media outlets with limited resources can now use Facebook as a primary source, this might increase the number of outlets reporting protests. In Panel A of Appendix Table B-5 we run our baseline specification using different features of the distribution of the number of outlets reporting protests as the dependent variables. Columns 1 to 4 report, respectively, the mean, median, 25th percentile, and 75th percentile of the number of news sources reporting each protest, and column 5 examines the probability that just one outlet reports the protest. Another approach to investigate a possible change in reporting behavior is to verify whether there is a change in the time elapsed between the protest and the report (as in Bhuller, Havnes, Leuven, \& Mogstad, 2013). Panel B of Appendix Table B-5 therefore uses different features of the distribution of this temporal distance as the dependent variable (the mean, median, 25th percentile, 75 th percentile and the probability that the protest is reported in the same month it occurs). There is no evidence that Facebook Speakers change the distribution of the number of outlets reporting protests or the time elapsed between the event and the report. This suggests that our effects are not simply capturing a change in reporting behavior without any real impact on actual collective action episodes.

We also examine a related source of reporting error in Panel C of Appendix Table B5 that the results are influenced by GDELT failing to successfully de-duplicate protests that are reported on more than once. This would affect our estimates if Facebook directly

levels. Thus, the larger effects around recessions reflect a more substantial effect of a given level of social media use, rather than a stronger impact of Facebook Speakers on social media use during contractions. 
influences this success rate (for instance, by increasing the number of reports or the different stories around them because reporters can now more easily write about them). Following Manacorda and Tesei (2020), in Panel C-1 we construct an alternative measure of protests that treats events in the same location (but that are classified as different events in the data) as a single event. Column 1 is the baseline, column 2 aggregates all columns on the same day in a single location, column 3 takes a larger location grid with a resolution of $5 \mathrm{~km} \times 5 \mathrm{~km}$, and in column 4 one location represents an entire country. Even in the most conservative regression to avoid double counting, we find similar qualitative results. Panel C-2 combines geographic and temporal aggregation by counting as one all protests that occur in a week and landmark (column 1), week and $5 \mathrm{~km} \times 5 \mathrm{~km}$ grid (column 2), month and landmark (column 3 ), and month and $5 \mathrm{~km} \times 5 \mathrm{~km}$ grid (column 4). Again, our results are not sensitive to these changes. While this does not rule out the possibility that the well-known de-duplication challenges associated with the GDELT data (Strezhnev, 2014; Caren, 2014; Wang, Kennedy, Lazer, \& Ramakrishnan, 2016) are affecting the reported protest levels, ${ }^{44}$ it suggests that our results do not mechanically result from these biases correlating with increased Facebook access.

To further explore the possibility that reporting errors may be driving our findings, we use data from the Armed Conflict Location \& Event Data Project (ACLED). This is a public collection of political violence and protest data for Africa since 1997. Like GDELT, this database is daily and georeferenced. But it has been more widely used and, while also mediabased, its information is complemented with reports from nongovernmental organizations and "hand checked." Panel A in Appendix Figure B-8 shows the total number of protests reported in GDELT and ACLED for Africa since Facebook was originally released. While GDELT reports more protests, there is a strong correlation (88.12\%) between the measures.

Also, consistent with our findings so far, column 8 in Table 4 shows that Facebook Speakers increase (coefficient 0.24, standard error 0.14) ACLED protests. For comparison, column 9 uses GDELT just for Africa, and the coefficient is smaller (0.18). In Panel B of Appendix Figure B-8, we further compare the implied sizes by again conducting the counterfactual analysis assuming no Facebook Speakers and plotting the cumulative difference with observed protests. While GDELT predicts that Facebook explains just over 1\% additional protests in our sample period, ACLED's estimates imply just over a $3 \%$ increase. Our finding that the implied effect is larger for ACLED reassures us that GDELT is not overestimating the effects due to reporting errors.

\footnotetext{
${ }^{44}$ Our log transformation also helps minimize the impact of level differences.
} 


\section{B.4 Additional robustness checks}

Appendix Table B-6 verifies that our results are not driven by outliers (column 1), and explores alternative transformations of the dependent variable (columns 2-6). Our estimates are very similar when we remove outliers (defined as observations with residuals in the upper or lower $2.5 \%$ of the distribution for our baseline specifications) ${ }^{45}$ Column 2 shows that the inverse hyperbolic sine transformation produces results that are close to our baseline choice of $\log (1+$ protests $)$, as expected given the average incidence of protests (see footnote 15). Column 3 examines the results for the extensive margin, running a simple linear probability model for the binary indicator of protests. The coefficient is positive in both the national- and subnational-level specifications (Panels A and B, respectively), though it is only statistically significant in the latter. Instead, examining indicators for high protest incidence (more than the median incidence, in column 4, or than the average, in column 5) reveals a positive and very significant relationship with Facebook Speakers in both panels. Finally, column 6 excludes information on the number of protests each month and finds that Facebook Speakers also increase a different measure of intensity that is less prone to errors in double-counting protests by the media: the number of days in the month in which protests occur.

Panel A of Appendix Table B-7 shows that our results are also robust to estimating nonlinear models, including quantile regressions for impacts at the median (column 1), a negative binomial regression (column 2), a zero-inflated negative binomial regression (column 3 ), and logit and probit models for the probability of having at least one protest (columns 4 and 5). We also estimated dynamic panel data models (Panel B of Appendix Table B-7) that incorporate lagged protests on the right-hand side of the equation and instrument these with longer lags (Arellano \& Bond, 1991). The effect of Facebook Speakers remains robust to acknowledging persistence in the dependent variable ${ }^{46}$ Also, while we prefer the continuous Facebook Speakers measure, which takes advantage of all the variation in potential access to Facebook, the results are also similar if we use simple binary variables indicating whether there is a Facebook version in the most spoken language or in a language spoken by more than $50 \%$ (or 20\%) of the country's inhabitants (Appendix Table B-8).

\footnotetext{
${ }^{45}$ Also, if we use Cook's D criteria (Cook, 1977) to detect influential observations, common rules of thumb such as using $D>0.5$ to identify outliers suggest that our regressions contain no such unusually influential data points.

${ }^{46}$ We also carried out several tests to check stationarity and reject the presence of unit root in the protest process. The null hypothesis in the Levin-Lin-Chu is strongly rejected (the adjusted $t$-statistic is -90.8727). Since this test assumes that protest persistence is the same for all countries, we checked Dickey-Fuller tests for each country independently and always rejected the null hypothesis at the $95 \%$ confidence level.
} 


\section{B.5 Examining the language barrier}

Some individuals may overcome the language barrier with a second language. Columns 1 to 3 of Appendix Table B-9 use data on second languages from Ethnologue to construct a variable for Facebook Second-Language Speakers, which captures the share of each country's population that can access a Facebook interface in any second language (it is constructed exactly the same as Facebook Speakers in equation (2), except Speakers ${ }_{c l}$ refers to the proportion of people in country $c$ who speak language $l$ as a second language).

We find that while positive, the impact of speaking a second language available in Facebook is small and not significant (column 1) and does not change the significance or magnitude of the main Facebook Speakers effect (column 2). The interaction term is positive, but not significant at conventional levels (column 3).

In columns 4 to 6 we use Facebook searches as the dependent variable. Interestingly, availability in a second language increases access (column 4), but the coefficient for Facebook Speakers (0.08) is more than twice the size (0.03) of the coefficient on Facebook SecondLanguage Speakers (column 5). One plausible reason is that people who are fluent in English and other major languages available in Facebook are not "marginal" Internet and social media users, and factors other than the language barrier determine their participation. Perhaps more interestingly, as noted before, even individuals who are fluent in a second language that enables them to access Facebook may still respond to a local language arriving on Facebook since this enriches their network of interactions (with friends, politicians, businesses, etc. that enter the platform then). Confirming this intuition that access in the first language complements rather than displaces Facebook use for those who can access in a second language, the interaction term is positive, significant and large in column 6 . The stronger effects on Facebook use for availability in the first language and its interaction with the second language is consistent with the corresponding positive impacts of these variables on protests in column 3.

There could also be spillover effects on protests by people speaking languages that are close enough to a language already in a Facebook platform (for instance, the Facebook English platform is more likely to be understood by Welsh-speaking than Spanish-speaking people). If so, our baseline effects could underestimate Facebook's effects since some "nontreated" speakers could use this linguistically akin Facebook version and increase their protest participation.

To explore this hypothesis, we construct a similarity index for each pair of languages using

the Automated Similarity Judgment Program. The index compares a list of 40 words and 
assesses their similarity across pairs of languages (Wichmann, Holman, \& Brown, 2016) ${ }^{47}$ In Panel A of Appendix Figure B-9 we redefine Facebook Speakers as not simply those who have a Facebook version in their first language, but in any language that is at least $x \%$ as similar according to the index (measured in the horizontal axis). The vertical axis on the left measures the resulting coefficient for Facebook Speakers, and the vertical axis on the right the number of languages that are considered "treated" under each threshold. As expected, Facebook's impact is slightly larger when similar languages are considered treated, but the change is very small and the effect of Facebook Speakers is very stable regardless of the threshold used. Therefore, these potential spillovers do not appear to significantly bias our baseline estimates downwards.

Another possibility is that if language is a barrier to accessing Facebook, the writing system might also keep some people away from the platform. To explore this idea, in Panel B of Appendix Figure B-9 we break down the total effect of Facebook Speakers based on whether the language in question is also the first in the corresponding writing system. Thus, for instance, English was the first language in Latin, Arabic the first in Arabic, and Russian the first in Cyrillic (Spanish, Panjabi and Serbian came second in each of the writing systems, respectively). Though the coefficients are measured with considerable noise, the pattern does reveal that the impact of Facebook Speakers is larger for the first language in the writing system, followed by the second, third and so on.

\section{B.6 Individuals' intended versus effective participation}

The ESS identifies whether respondents have participated or not in a lawful public demonstration during the last 12 months. Instead, the response options for the AB and the WVS include hypothetical participation: "No, but would do if had the chance" in the AB and "Might do" in the WVS 48 For our baseline results in Table 5, we code the protest indicator as 1 if the respondent selects any of the straight yes categories ("Yes, once or twice," "Yes,

\footnotetext{
${ }^{47}$ We follow Holman (2014), who points out that the best way to compute a similarity index for languages $k$ and $i$ involves three steps. First, computing the Levenshtein Distance (LD) for each word between both languages $i$ and $k$ (where $L D$ is the minimum number of characters that must be replaced for one of them to be identical to the other). Second, normalizing $L D$ for the maximum length of the word in both languages $(L D N)$. Finally, the pairwise similarity index is one minus the ratio between the average $L D N$ between words with the same meaning and the average $L D N$ between words with different meanings.

${ }^{48}$ The questions read as follows. AB: "Please tell me whether you, personally, have [participated in a demonstration or protest march] during the past year. If not, would you do this if you had the chance?" WVS: "I'm going to read out some forms of political action that people can take, and I'd like you to tell me... whether you have ... attended peaceful demonstrations."
} 
several times," or "Yes, often" in the AB, or "Yes" in the WVS) or the hypothetical involvement options. This increases incidence, but survey-wave fixed effects absorb any level effects of these different designs. However, the slope of the effects will vary under the two designs. In the $\mathrm{AB}$ and WVS samples, they reflect the combined impact on actual participation and on the willingness to participate. While not all individuals who report a willingness to participate end up doing so, it is reasonable to assume that they are more likely to join in than those who report otherwise. Therefore, our coding choice allows us to capture Facebook's full effect on collective action.

It might be argued that stated willingness does not reflect a higher likelihood of actual participation when the opportunity arises or a trigger event occurs. However, notice that if these reports are entirely uninformative and the resulting measurement error is random (classical), it reduces precision without influencing the consistency of our estimates. In short, the differences between the survey questions are only an issue if Facebook Speakers are more or less willing to lie about intended participation. This appears unlikely and second-order relative to the real effects of Facebook on attitudes toward collective action. But since we cannot rule it out, we verify that our effects are not driven by "hypothetical" participation.

Appendix Table B-10 breaks down the effects for the AB and WVS samples on protest intention and effective participation. In panel $\mathrm{A}$, we first estimate a multinomial logistic model finding that, compared to the baseline category of no protest, both willingness to participate and effective participation increase among Facebook Speakers. The multinomial model avoids potential sample selection biases from dropping observations based on endogenous outcomes. Still, for comparison Panel B estimates linear models comparing either willingness to participate or effective participation to the baseline category. As expected, we find positive coefficients for both, with larger effects for intention; the magnitudes for participation are closer to those reported in the ESS, and not larger than in previous research. Indeed, in the most demanding models for effective protest participation, the multinomial estimation implies that the odds of participation increase by $19 \%$ when Facebook Speaker goes from zero to one, and the Facebook Speaker coefficient in the linear model specification is close to 4.6 percentage points (resulting in a $24.5 \%$ increase in the mean incidence).49 These findings, together with the regressions for the EES sample, reveal that effective and not just intended protest participation reacts to Facebook.

\footnotetext{
${ }^{49}$ The standardized effects in these estimations are roughly $3.5 \%$ for the AB sample. This is similar to the effects we find in the cross-country data and smaller than those reported in Enikolopov et al. (2020).
} 


\section{Table B-1: IV Estimates of the Effect of Facebook Speakers on Protests}

\begin{tabular}{lcc}
\hline \hline \multicolumn{2}{l}{$(1)$} & $(2)$ \\
\hline \multicolumn{2}{l}{ Dependent variable is $l o g(1+$ protests $)$} & \\
Estimator: & OLS & IV \\
& & \\
Facebook Searches & 0.5346 & 2.6541 \\
& $(0.1370)$ & $(1.0810)$ \\
First-stage F-statistic & & \\
\hline Observations & 45,120 & 45.525 \\
Countries & 235 & 235 \\
\hline \hline
\end{tabular}

Notes: IV estimates of the effect of Facebook Speakers on the $\log$ of one plus protests. Country-level regressions with monthly data from January 2000 to December 2015. Facebook Searches is the log of an index of search interest for the term "Facebook" from Google Trends. Facebook Speakers is the proportion of people speaking (as a first language) a language available in Facebook in each country and month. For all variable definitions and sources, see Appendix Table A-1 All regressions include country fixed effects, month fixed effects, initial population interacted with time fixed effects, and country-specific quadratic trends. Two-way clustering of standard errors at the month and country levels. 


\section{Table B-2: Robustness of Subnational Estimates of the Effect of Facebook Speakers on Protests}

\begin{tabular}{|c|c|c|c|c|c|}
\hline & $(1)$ & $(2)$ & $(3)$ & $(4)$ & $(5)$ \\
\hline \multicolumn{6}{|c|}{ Dependent variable is $\log (1+$ protests $)$} \\
\hline Unit of analysis: & Baseline & $\begin{array}{l}\text { Language } \\
\text { Polygons }\end{array}$ & $\begin{array}{l}\text { Language } \\
\text { Polygons }\end{array}$ & State-Lang & State-Lang \\
\hline Facebook Speakers & $\begin{array}{c}0.5106 \\
(0.0846)\end{array}$ & $\begin{array}{c}0.4484 \\
(0.0791)\end{array}$ & $\begin{array}{c}0.3606 \\
(0.0503)\end{array}$ & $\begin{array}{c}0.1054 \\
(0.0377)\end{array}$ & $\begin{array}{c}0.0851 \\
(0.0346)\end{array}$ \\
\hline Observations & $1,441,728$ & $1,441,728$ & $1,483,776$ & $3,751,680$ & $3,751,680$ \\
\hline Polygons & 7,509 & 7,509 & 7,728 & 19,540 & 19,540 \\
\hline Beta-coefficient & {$[0.110]$} & {$[0.107]$} & {$[0.091]$} & {$[0.074]$} & {$[0.060]$} \\
\hline Month $\times$ State fixed effect & & & & & $\checkmark$ \\
\hline Overlapping zones & Yes & No & Yes & Yes & Yes \\
\hline
\end{tabular}

Notes: Estimates of the effect of Facebook Speakers on the log of one plus protests considering alternative specifications for the subnational analysis. Monthly data from January 2000 to December 2015. For the subnational analysis, we rely on WLMS's polygons within countries where each language is spoken. Some of these polygons intersect, creating areas where more than one language is spoken. Our baseline analysis (column 1) assign protests in these "overlapping zones" to all the corresponding polygons. Column 2 excludes overlapped zones. Column 3 infer language shares using national totals and grid-level population figures from the Socioeconomic Data and Applications Center (SEDAC). Columns 4 and 5 use as unit of analysis the intersection of WLMS's polygons and the first level of administrative division (equivalent to the US states). Facebook Speakers is the share of the population in each region within a country speaking (as a first language) a language already available in Facebook. For all variable definitions and sources, see Appendix Table A-1. The beta coefficient is the implied effect on the dependent variable, in standard-deviation units, of a one-standard-deviation increase in Facebook Speakers. Overlapping zones refer to polygons in Ethnologue where more than one language is spoken by the population. All regressions include fixed effects for each country and month, region fixed effects, and initial regional population interacted with month fixed effects. Two-way clustering of standard errors is at the month and country levels. 


\section{Table B-3: Determinants of Facebook Translation Activity}

\begin{tabular}{|c|c|c|c|c|}
\hline & $(1)$ & $(2)$ & $(3)$ & $(4)$ \\
\hline \multicolumn{5}{|c|}{ Dependent variable is published phrases or translators in each language and country } \\
\hline & \multicolumn{4}{|c|}{ Panel A. Protest activity and Facebook translations } \\
\hline & \multicolumn{2}{|c|}{ Published phrases } & \multicolumn{2}{|c|}{ Translators } \\
\hline Growth of Protests & $\begin{array}{c}0.0028 \\
(0.0335)\end{array}$ & & $\begin{array}{l}-0.0300 \\
(0.0358)\end{array}$ & \\
\hline Growth of Protests above two s.d. & & $\begin{array}{l}-2.8657 \\
(2.0690)\end{array}$ & & $\begin{array}{l}-2.9495 \\
(2.0685)\end{array}$ \\
\hline Observations & 1,473 & 1,529 & 1,473 & 1,529 \\
\hline Countries & 202 & 225 & 202 & 225 \\
\hline Beta-coefficient & {$[0.001]$} & {$[-0.027]$} & {$[-0.009]$} & {$[-0.039]$} \\
\hline
\end{tabular}

Panel B. Crisis and Facebook translations

Published phrases Translators

Growth of GDP

0.0625

$(0.6909)$

Growth of GDP below two s.d.

Observations

Countries

Beta-coefficient

\begin{tabular}{cccc} 
& -1.7940 & & -0.4997 \\
& $(2.8945)$ & & $(3.2822)$ \\
1,461 & 1,461 & 1,461 & 1,461 \\
194 & 194 & 194 & 194 \\
{$[0.003]$} & {$[-0.014]$} & {$[-0.014]$} & {$[-0.005]$} \\
\hline
\end{tabular}

$-0.2444$

$(0.6995)$

$-1.7940$

$(2.8945)$

194

$-0.014$

Notes: Estimates of the effect of predetermined growth of protests (Panel A) or GDP (Panel B) on Facebook translation activities. The unit of observation is a country-language (for languages spoken by more than $10 \%$ of the population). The dependent variable is the total number of phrases translated by users of each country in each language (columns 1 to 2) or the total number of translators of each country and language (columns 3 to 4 ). We define the growth of $x_{t}$ as $\frac{x_{t}-x_{t-1}}{x_{t-1}}$ and use as independent variable in Panel A (B) either the growth of Protests (GDP) measured in the year previous to the release of Facebook in each local platform or a dummy equals one if such growth rate is above (below) two standard deviations of its average. For all variable definitions and sources, see Appendix Table A-1 All regressions include fixed effects for each country. Clustering of standard errors is at the country level. 


\section{Table B-4: Protests and Facebook Speakers Exploring the role of the Financial Crisis}

\begin{tabular}{|c|c|c|c|c|c|c|c|c|}
\hline & $(1)$ & $(2)$ & $(3)$ & $(4)$ & $(5)$ & $(6)$ & $(7)$ & $(8)$ \\
\hline & \multicolumn{8}{|c|}{ Panel A. Testing pre-trends in determinants of the Financial Crisis } \\
\hline & \multirow{2}{*}{\multicolumn{2}{|c|}{ GDP growth }} & \multicolumn{4}{|c|}{ Dependent variable is... } & \multirow{2}{*}{\multicolumn{2}{|c|}{ Exports to US }} \\
\hline & & & G & & Bilate & l trade & & \\
\hline Facebook Speakers $_{t+1}$ & $\begin{array}{l}-1.9924 \\
(1.7005)\end{array}$ & $\begin{array}{l}-2.0459 \\
(1.8068)\end{array}$ & $\begin{array}{c}0.0029 \\
(0.0155)\end{array}$ & $\begin{array}{l}-0.0032 \\
(0.0112)\end{array}$ & $\begin{array}{l}-0.0040 \\
(0.0086)\end{array}$ & $\begin{array}{c}0.0011 \\
(0.0096)\end{array}$ & $\begin{array}{l}-0.0140 \\
(0.0095)\end{array}$ & $\begin{array}{l}-0.0123 \\
(0.0087)\end{array}$ \\
\hline Observations & 3,011 & 2,423 & 2,844 & 2,281 & 3,269 & 2,612 & 3,269 & 2,612 \\
\hline Countries & 207 & 207 & 191 & 191 & 220 & 219 & 220 & 219 \\
\hline \multirow[t]{2}{*}{$\underline{\text { P-value leads } 1-4}$} & & 0.25 & & 0.13 & & 0.18 & & 0.24 \\
\hline & \multicolumn{8}{|c|}{$\frac{\text { Panel B. Exploring the role of the crisis' determinants in the baseline regression }}{\text { Dependent variable is } \log (1+\text { protests })}$} \\
\hline Facebook Speakers & $\begin{array}{c}0.2170 \\
(0.0809)\end{array}$ & $\begin{array}{c}0.2123 \\
(0.0807)\end{array}$ & $\begin{array}{c}0.2228 \\
(0.0810)\end{array}$ & $\begin{array}{c}0.2236 \\
(0.0813)\end{array}$ & $\begin{array}{c}0.2211 \\
(0.0803)\end{array}$ & $\begin{array}{c}0.2274 \\
(0.0807)\end{array}$ & $\begin{array}{c}0.2305 \\
(0.0849)\end{array}$ & $\begin{array}{c}0.3115 \\
(0.1009)\end{array}$ \\
\hline Observations & 41,736 & 41,736 & 41,736 & 41,736 & 41,856 & 41,856 & 38,424 & 41,520 \\
\hline Countries & 218 & 218 & 218 & 218 & 220 & 220 & 209 & 240 \\
\hline Financial Crisis ${ }_{t} \times$ Exports to $\mathrm{US}_{i}$ & $\checkmark$ & & & & & & & \\
\hline 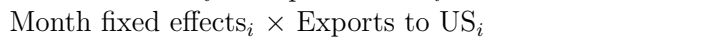 & & $\checkmark$ & & & & & & \\
\hline Financial Crisis $_{t} \times$ Bilateral trade $_{i}$ & & & $\checkmark$ & & & & & \\
\hline Month fixed effects $\times{\text { Bilateral } \text { trade }_{i}}$ & & & & $\checkmark$ & & & & \\
\hline 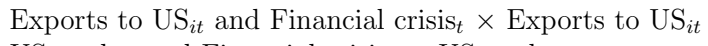 & & & & & $\checkmark$ & & & \\
\hline US trade $i t$ and Financial crisis $_{t} \times$ US trade $i t$ & & & & & & $\checkmark$ & & \\
\hline Crisis $_{i t}$ & & & & & & & $\checkmark$ & \\
\hline Exclude Financial Crisis ${ }_{t}$ sample & & & & & & & & $\checkmark$ \\
\hline
\end{tabular}

Notes: Panel A reports estimates of anticipation effects (leads) of Facebook Speakers on GDP growth, GDP, Bilateral trade and Exports to the US from country-level regressions with yearly data from 2000 to 2015. Panel B reports estimates of the effect of Facebook Speakers on the log of one plus protests when additionally controlling for crisis' determinants from country-level regressions with monthly data from January 2000 to December 2015. Facebook Speakers is the proportion of people speaking (as a first language) a language available in Facebook in each country and time. Financial Crisis ${ }_{t}$ is a dummy variable equals one for any period between December 2007 and June 2009. Exports to US ${ }_{i}$ is the share of exports from country $i$ to the United States. Bilateral trade ${ }_{i}$ is analogous, but substitutes two-way trade -the sum of bilateral exports and imports -in place of exports. Both variables are averages from 2000 to 2005. Exports to US $i t$ and US trade $i t$ follows the same definition but are computed for each year. Crisis $i t$ is a dummy equals one if GDP growth is less than two standard deviations. In column 9, we estimate the baseline regression excluding the period during the financial crisis. For all variable definitions and sources, see Appendix Table A-1 Yearly-level regressions from Panel A include country fixed effects, year fixed effects, initial population interacted with time fixed effects, and country-specific quadratic trends. Additionally, even columns include leads 1 to 4 of Facebook Speakers (p-values for joint significance are reported at the bottom of the panel). Clustering of standard errors is at the country level. Monthly-level regressions from Panel B include country fixed effects, month fixed effects, initial population interacted with time fixed effects, and country-specific quadratic trends. Two-way clustering of standard errors is at the month and country levels. 


\section{Table B-5: Facebook Speakers and Reporting Biases}

\begin{tabular}{|c|c|c|c|c|c|}
\hline & $(1)$ & $(2)$ & $(3)$ & $(4)$ & $(5)$ \\
\hline & \multicolumn{5}{|c|}{$\begin{array}{c}\text { Panel A. Number of media outlets reporting protests } \\
\text { Dependent variable is statistic in column for number of outlets reporting }\end{array}$} \\
\hline & Mean & Median & Percentile 25 & Percentile 75 & $P$ (one outlet) \\
\hline Facebook Speakers & $\begin{array}{c}0.0044 \\
(0.0351)\end{array}$ & $\begin{array}{l}-0.0079 \\
(0.0112)\end{array}$ & $\begin{array}{c}0.0004 \\
(0.0064)\end{array}$ & $\begin{array}{l}-0.0179 \\
(0.0331)\end{array}$ & $\begin{array}{c}0.0033 \\
(0.0077)\end{array}$ \\
\hline Observations & 32,121 & 32,121 & 32,121 & 32,121 & 32,121 \\
\hline Countries & 237 & 237 & 237 & 237 & 237 \\
\hline
\end{tabular}

Panel B. Time elapsed between the protest and the report

Dependent variable is statistic in column for months between the event and the report

\begin{tabular}{lccccc} 
& Mean & Median & Percentile 25 & Percentile 75 & $P($ same month) \\
\cline { 2 - 6 } Facebook Speakers & & & & & \\
& 0.0303 & 0.0282 & 0.0225 & 0.0347 & -0.0025 \\
& $(0.0250)$ & $(0.0235)$ & $(0.0174)$ & $(0.0341)$ & $(0.0015)$ \\
Observations & 32,121 & 32,121 & 32,121 & 32,121 & 32,121 \\
Countries & 237 & 237 & 237 & 237 & 237 \\
\hline
\end{tabular}

Panel C: Treating events in the same location or period as single events

Dependent variable is log of one plus protests, aggregation by...

\begin{tabular}{lcccc} 
Panel C-1 (location) & None (Baseline) & Day-landmark & Day-Grid & Day-Country \\
\hline & & & & \\
Facebook Speakers & 0.2210 & 0.2195 & 0.2191 & 0.1726 \\
& $(0.0777)$ & $(0.0622)$ & $(0.0621)$ & $(0.0505)$ \\
& & & \\
Panel C-2 (period) & Week-Landmark & Week-Grid & Month-Landmark & Month-Grid \\
\hline Facebook Speakers & 0.2067 & 0.2069 & 0.1859 & 0.1870 \\
& $(0.0520)$ & $(0.0517)$ & $(0.0441)$ & $(0.0437)$ \\
Observations & 46,080 & 46,080 & 46,080 & 46,080 \\
Countries & 240 & 240 & 240 & 240 \\
\hline \hline
\end{tabular}

Notes: Estimates of the effect of Facebook Speakers on media outlets reporting protests (Panel A), time elapsed between the protest and the report (Panel B) and the log of one plus protests (Panel C). Country-level regressions with monthly data from January 2000 to December 2015. Panel A (B) runs the baseline specification using different features of the distribution of the number of outlets reporting protests (time elapsed between the protest and the report) as the dependent variable, with the statistic used indicated in each column. In Panel C-1, instead of counting the total reported occurrences of protests by country-month as in the baseline (column 1), we construct alternative measures of protests, treating protests that occur in the same location, but are classified in GDELT as different protests, as a single event. In column 2, the location is the specific geographic coordinates provided in GDELT. In column 3 we use grids with a resolution of $5 \mathrm{~km} \times 5 \mathrm{~km}$, and in column 4 one location represents an entire country. Panel C-2 combines geographic and temporal aggregation by counting as one all protests that occur in a week and landmark (column 1), week and $5 \mathrm{~km} \times 5 \mathrm{~km}$ grid (column 2), month and landmark (column 3), month and $5 \mathrm{~km} \times 5 \mathrm{~km}$ grid $($ column 4 ) . Facebook Speakers is the proportion of people speaking (as a first language) a language available in Facebook in each country and month. For all variable definitions and sources, see Appendix Table A-1. All regressions include country fixed effects, month fixed effects, initial population interacted with time fixed effects and country-specific quadratic trends. Two-way clustering of standard errors is at the month and country levels. 
Table B-6: Effect of Facebook Speakers on Protests Robustness to Outliers and Dependent Variable Transformation

\begin{tabular}{|c|c|c|c|c|c|c|}
\hline & $\overline{(1)}$ & $\overline{(2)}$ & $\overline{(3)}$ & $(4)$ & $(5)$ & $(6)$ \\
\hline Dependent variable is... & $\begin{array}{c}\log (1+\text { protests }) \\
\text { without outliers }\end{array}$ & $\operatorname{arcsinh}$ (protests) & Protests $>0$ & Protests $>$ median & Protests $>$ mean & days in month \\
\hline $\begin{array}{l}\text { A. National } \\
\text { Facebook Speakers }\end{array}$ & $\begin{array}{c}0.2789 \\
(0.0618)\end{array}$ & $\begin{array}{c}0.2452 \\
(0.0861)\end{array}$ & $\begin{array}{c}0.0191 \\
(0.0179)\end{array}$ & $\begin{array}{c}0.0449 \\
(0.0248)\end{array}$ & $\begin{array}{c}0.0536 \\
(0.0251)\end{array}$ & $\begin{array}{c}1.5366 \\
(0.4727)\end{array}$ \\
\hline $\begin{array}{l}\text { Observations } \\
\text { Countries }\end{array}$ & $\begin{array}{c}44,006 \\
240\end{array}$ & $\begin{array}{c}46,080 \\
240\end{array}$ & $\begin{array}{c}46,080 \\
240\end{array}$ & $\begin{array}{c}46,080 \\
240 \\
\end{array}$ & $\begin{array}{c}46,080 \\
240 \\
\end{array}$ & $\begin{array}{c}46,080 \\
240 \\
\end{array}$ \\
\hline $\begin{array}{l}\text { B. Subnational } \\
\text { Facebook Speakers }\end{array}$ & $\begin{array}{c}0.2745 \\
(0.0289)\end{array}$ & $\begin{array}{c}0.5652 \\
(0.0942)\end{array}$ & $\begin{array}{c}0.0411 \\
(0.0156)\end{array}$ & $\begin{array}{c}0.0411 \\
(0.0156)\end{array}$ & $\begin{array}{c}0.0676 \\
(0.0175)\end{array}$ & $\begin{array}{c}3.0135 \\
(0.4910)\end{array}$ \\
\hline $\begin{array}{l}\text { Observations } \\
\text { Polygons }\end{array}$ & $\begin{array}{c}1,365,141 \\
7,110\end{array}$ & $\begin{array}{c}1,430,400 \\
7,450\end{array}$ & $\begin{array}{c}1,430,400 \\
7,450\end{array}$ & $\begin{array}{c}1,430,400 \\
7,450\end{array}$ & $\begin{array}{c}1,430,400 \\
7,450\end{array}$ & $\begin{array}{c}1,430,400 \\
7,450\end{array}$ \\
\hline
\end{tabular}

Notes: Estimates of the effect of Facebook Speakers on protests. Country-level regressions with monthly data from January 2000 to December 2015. Monthly data from January 2000 to December 2015. In Panel A the unit of observation is a country, and in Panel B a language polygon (region) within a country. Facebook Speakers is the proportion of people speaking (as a first language) a language available in Facebook. Outliers, removed in column 1, are observations with residuals in the upper or lower $2.5 \%$ of the distribution in the corresponding baseline regression. arcsinh (protests) is the inverse hyperbolic sine transformation on the number of protests. For all variable definitions and sources, see Appendix Table A-1 In Panel A, all regressions include country fixed effects, month fixed effects, initial population interacted with time fixed effects, and country-specific quadratic trends. In Panel B, all regressions include fixed effects for each country and month, region fixed effects and initial population interacted with month fixed effects. Two-way clustering of standard errors is at the month and country levels. 


\section{Table B-7: Non-linear and Dynamic Estimates of the Effect of Facebook Speakers on Protests}

\begin{tabular}{|c|c|c|c|c|c|}
\hline & $(1)$ & $(2)$ & $\overline{(3)}$ & (4) & $(5)$ \\
\hline \multirow[b]{3}{*}{ Estimation } & \multicolumn{5}{|c|}{$\begin{array}{c}\text { Panel A. Non-linear Estimators } \\
\text { Dependent variable is... }\end{array}$} \\
\hline & \multicolumn{3}{|c|}{ Number of protests } & \multicolumn{2}{|c|}{ Protests $>0$} \\
\hline & $\begin{array}{l}\text { Quantile } \\
\text { median }\end{array}$ & $\begin{array}{l}\text { Negative } \\
\text { binomial }\end{array}$ & $\begin{array}{c}\text { Zero- } \\
\text { inflated }\end{array}$ & Logit & Probit \\
\hline Facebook Speakers & $\begin{array}{l}12.1162 \\
(1.5070)\end{array}$ & $\begin{array}{c}0.4451 \\
(0.0730)\end{array}$ & $\begin{array}{c}0.2637 \\
(0.1051)\end{array}$ & $\begin{array}{c}0.2071 \\
(0.0490)\end{array}$ & $\begin{array}{c}0.1074 \\
(0.03045)\end{array}$ \\
\hline Observations & 46,080 & 46,080 & 46,080 & 46,080 & 46,080 \\
\hline \multirow[t]{2}{*}{ Countries } & 240 & 240 & 240 & 240 & 240 \\
\hline & \multicolumn{5}{|c|}{$\begin{array}{l}\text { Panel B. Dynamic Panel Data Estimators } \\
\text { Dependent variable is } \log (1+\text { protests })\end{array}$} \\
\hline Estimation & Baseline & & & lano-Bon & \\
\hline Facebook Speakers & $\begin{array}{c}0.2210 \\
(0.0777)\end{array}$ & $\begin{array}{l}0.2598 \\
(2.72)\end{array}$ & $\begin{array}{c}0.2651 \\
(3.12)\end{array}$ & $\begin{array}{l}0.1888 \\
(2.34)\end{array}$ & $\begin{array}{c}0.2011 \\
(2.27)\end{array}$ \\
\hline Lag 1 & & $\begin{array}{l}0.2392 \\
(25.76)\end{array}$ & $\begin{array}{l}0.2361 \\
(26.60)\end{array}$ & $\begin{array}{l}0.2505 \\
(26.75)\end{array}$ & $\begin{array}{l}0.2396 \\
(22.55)\end{array}$ \\
\hline Lag 2 & & & $\begin{array}{c}0.0535 \\
(8.72)\end{array}$ & $\begin{array}{c}0.0576 \\
(9.33)\end{array}$ & $\begin{array}{c}0.0485 \\
(6.38)\end{array}$ \\
\hline Lag 3 & & & & $\begin{array}{l}0.0286 \\
(4.52)\end{array}$ & $\begin{array}{l}0.0202 \\
(2.70)\end{array}$ \\
\hline Lag 4 & & & & $\begin{array}{c}0.0264 \\
(4.58)\end{array}$ & $\begin{array}{c}0.0181 \\
(2.46)\end{array}$ \\
\hline Lag 5 & & & & $\begin{array}{c}0.0068 \\
(1.12)\end{array}$ & $\begin{array}{c}-0.0015 \\
(0.20)\end{array}$ \\
\hline Observations & 46,080 & 45,600 & 45,360 & 44,640 & 43,440 \\
\hline Countries & 240 & 240 & 240 & 240 & 240 \\
\hline pvalue $\operatorname{AR}(2)$ & & 0.00 & 0.00 & 0.49 & 0.78 \\
\hline P-value lags 6-10 & & & & & 0.17 \\
\hline
\end{tabular}

Notes: Non-linear and dynamic estimates of the effect of Facebook Speakers on protests. Countrylevel regressions with monthly data from January 2000 to December 2015. Facebook Speakers is the proportion of people speaking (as a first language) a language available in Facebook in each country and month. For all variable definitions and sources, see Appendix Table A-1 P-value $\mathrm{AR}(2)$ is the p-value for a test of serial correlation in the residuals of the log protests series. In column 5, ten lags of log protests are included (but not reported) as controls. P-value lags 6-10 is the p-value of a test for the joint significance of these lags. Quantile regression (at the median) includes country and month fixed effects and reports standard errors clustered at the country level. Negative binomial regression reports the fixed-effects estimator and includes quadratic time trends. Zero-inflated negative binomial regression includes country fixed effects and a quadratic time trend and reports standard errors clustered at the country level. Logit regression reports the fixed-effects estimator; Probit regression reports the random-effects estimator. Negative binomial regression, Logit regression, and Probit regression include quadratic trends and report bootstrapped standard errors. Average marginal effects are reported for the Logit and Probit regressions. In Panel B, all regressions include country fixed, month fixed effects, country-specific quadratic trends, and initial population interacted with time fixed effects. In the Arellano-Bond estimation, we restrict the maximum lags for use as instruments to ten. Two-way clustering of standard errors is at the month and country levels in column 1 and Arellano-Bond robust standard errors in columns 2-5. 


\section{Table B-8: Effect of Facebook Speakers on Protests Robustness to Speakers Definition}

\begin{tabular}{lcccc}
\hline \hline & $\begin{array}{c}(1) \\
\text { Definition A } \\
\text { (Baseline) }\end{array}$ & $\begin{array}{c}(2) \\
\text { Definition B } \\
\text { (Most spoken) }\end{array}$ & $\begin{array}{c}(3) \\
\text { Definition C } \\
(50 \%)\end{array}$ & $\begin{array}{c}(4) \\
\text { Definition D } \\
(20 \%)\end{array}$ \\
\hline Dependent variable is log $(1+$ protests) & & & \\
Facebook Speakers & 0.2210 & 0.1244 & 0.1803 & 0.1733 \\
& $(0.0777)$ & $(0.0625)$ & $(0.0647)$ & $(0.0625)$ \\
Observations & 46,080 & 46,080 & 46,080 & 46,080 \\
Countries & 240 & 240 & 240 & 240 \\
\hline \hline
\end{tabular}

Notes: Estimates of the effect of Facebook Speakers ${ }^{\star}$ on the log of one plus protests. Country-level regressions with monthly data from January 2000 to December 2015. Facebook Speakers ${ }^{\star}$ under Definition $\mathbf{A}$ is the proportion of people speaking (as a first language) a language available in Facebook in each country and month. In columns 2 to 4, Facebook Speakers indicates whether, in a given country-month, a Facebook version had been released in: the most-spoken language (Definition B), a language spoken by more than $50 \%$ of the population (Definition C), or by more than $20 \%$ of population (Definition D). For all variable definitions and sources, see Appendix Table A-1 All regressions include country fixed effects, month fixed effects, country-specific quadratic trends, and initial population interacted with time fixed effects. Two-way clustering of standard errors is at the month and country levels. 


\section{Table B-9: Effect of Facebook Speakers on Protests and Facebook Use Exploring the Role of Bilingualism}

\begin{tabular}{|c|c|c|c|c|c|c|}
\hline & $(1)$ & $\overline{(2)}$ & 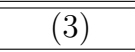 & $(4)$ & 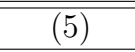 & 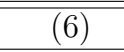 \\
\hline & \multicolumn{6}{|c|}{ Dependent variable is... } \\
\hline & \multicolumn{3}{|c|}{$\log (1+$ protests $)$} & \multicolumn{3}{|c|}{ Facebook searches } \\
\hline Facebook Second-Language Speakers & 0.0070 & 0.0006 & -0.0011 & 0.0367 & 0.0343 & 0.0303 \\
\hline & & & $(0.1741)$ & & & $(0.0522)$ \\
\hline Observations & 45,120 & 45,120 & 45,120 & 45,120 & 45,120 & 45,120 \\
\hline Countries & 235 & 235 & 235 & 235 & 235 & 235 \\
\hline
\end{tabular}

Notes: Estimates of the effect of Facebook Speakers and Facebook Second-Language Speakers on the log of one plus protests (Panel A) and Facebook Searches (Panel B). Country-level regressions with monthly data from January 2000 to December 2015. Facebook Searches is the $\log$ of an index of search interest for the term "Facebook" from Google Trends. Facebook Speakers is the proportion of people speaking (as a first language) a language available in Facebook in each country and month. Facebook Second-Language Speakers is the proportion of people speaking (as a second language) a language available in Facebook in each country and month. For all variable definitions and sources, see Appendix Table A-1 All regressions include country fixed effects, month fixed effects, country-specific quadratic trends, and initial population interacted with time fixed effects. Two-way clustering of standard errors is at the month and country levels. 
Table B-10: Individual-level Estimates of the Effect of Facebook Speaker on Protest

\section{Robustness to Discriminating Participation and Intention to Participate}

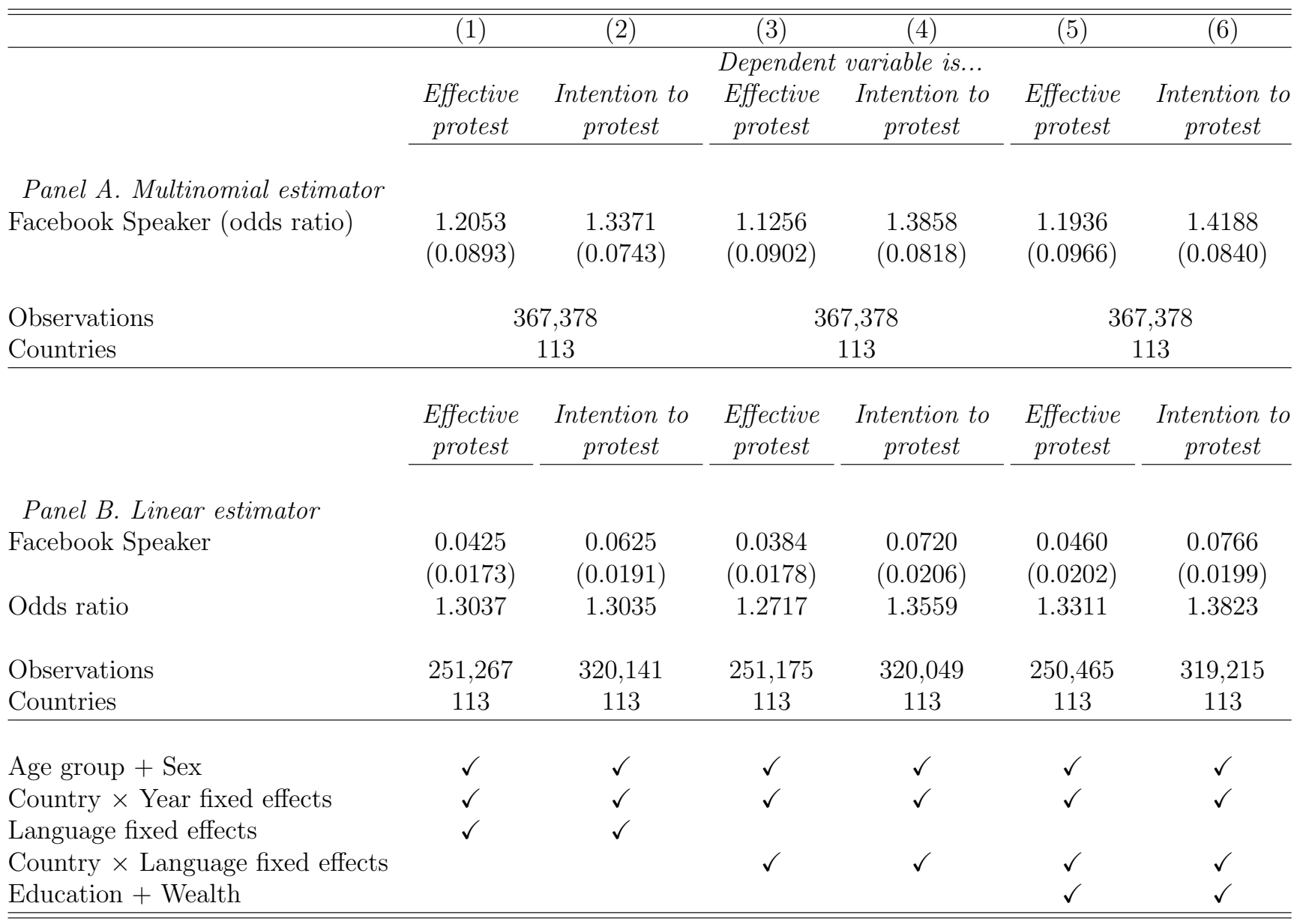

Notes: Individual-level estimates of the effect of Facebook Speaker on protests participation. Data from several rounds of the World Value Survey and Afrobarometer, see list in Figure 1. Each pair of columns in Panel A presents odds ratios (and corresponding standard errors) for a multinomial logit model with three possible outcomes: no protest (baseline), effective protest (if a respondent has participated in a demonstration) and intention to protests (if a respondent is planning to participate). In Panel B each column shows the coefficient (and corresponding standard error) of separate regressions where the dependent variable is a dummy variable of either effective protest (equals 1 if a respondent has participated in a demonstration and 0 if he has never participated, those planning to participate are excluded) or Intention to protest (equals 1 if the respondent is planning to participate and 0 if he has never participated, those who report participation are excluded). See Appendix Table B for more details. Facebook Speaker is a dummy that equals 1 if Facebook has been released in the respondent's language. In Panel B, two-way clustering of standard errors is at the year and country levels. 
Figure B-1: Randomization Inference Placebo coefficients randomly drawing the timing of Facebook's expansion

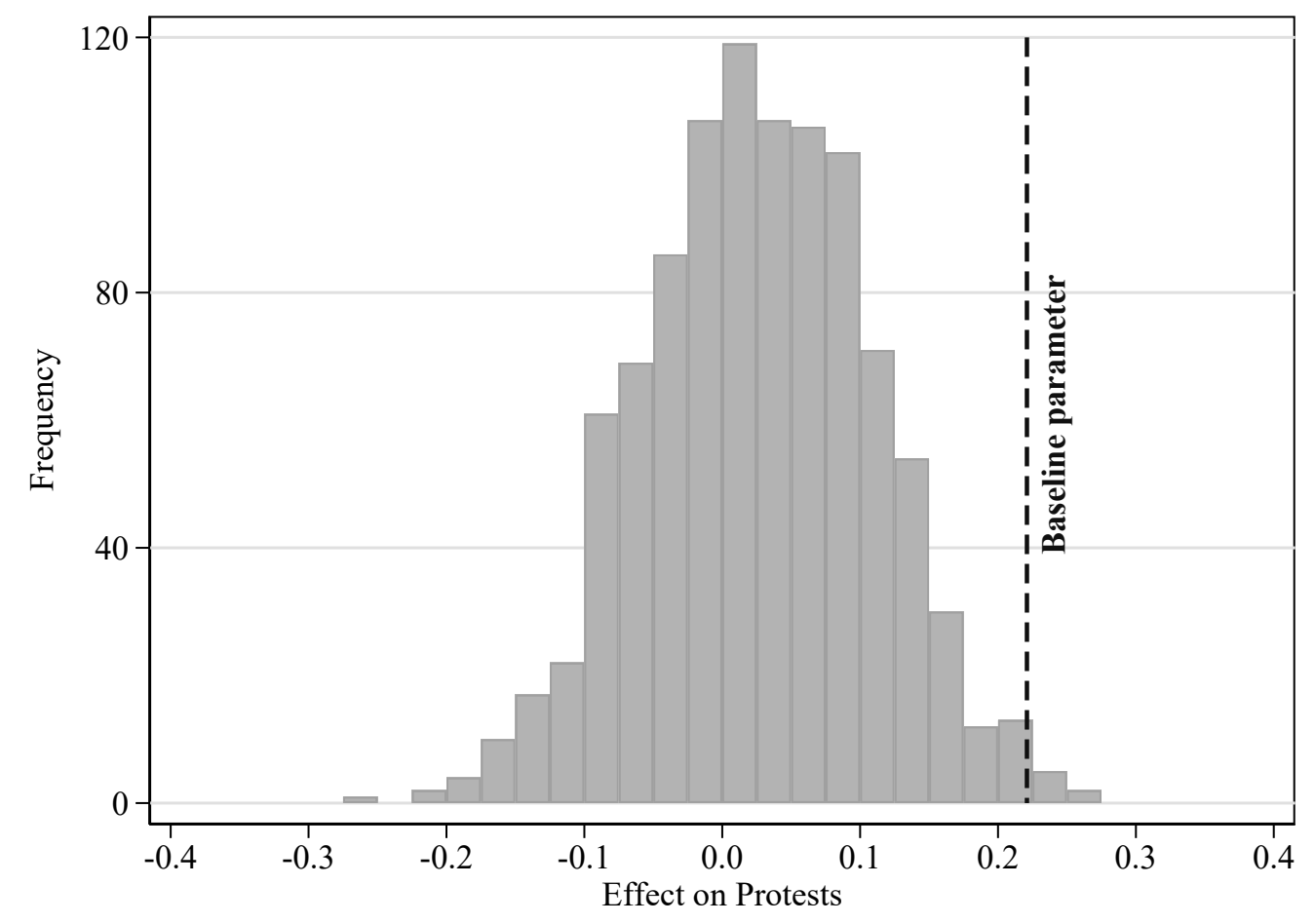

Notes: Distribution of randomization-inference coefficients of the effect of Facebook Speakers on the log of one plus protests in the baseline regression (1), drawing the timing of Facebook expansion across languages. Country-level regressions with monthly data from January 2000 to December 2015. Facebook Speakers is the proportion of people speaking (as a first language) a language available in Facebook in each country and year. For all variable definitions and sources, see Appendix Table A-1. All regressions include country fixed effects, month fixed effects, initial population interacted with time fixed effects, and country-specific quadratic trends. Two-way clustering of standard errors is at the month and country levels. 
Figure B-2: Parallel Trends in Protests Before Facebook

Exploring Anticipated Effects of Facebook Speakers

A. Protests

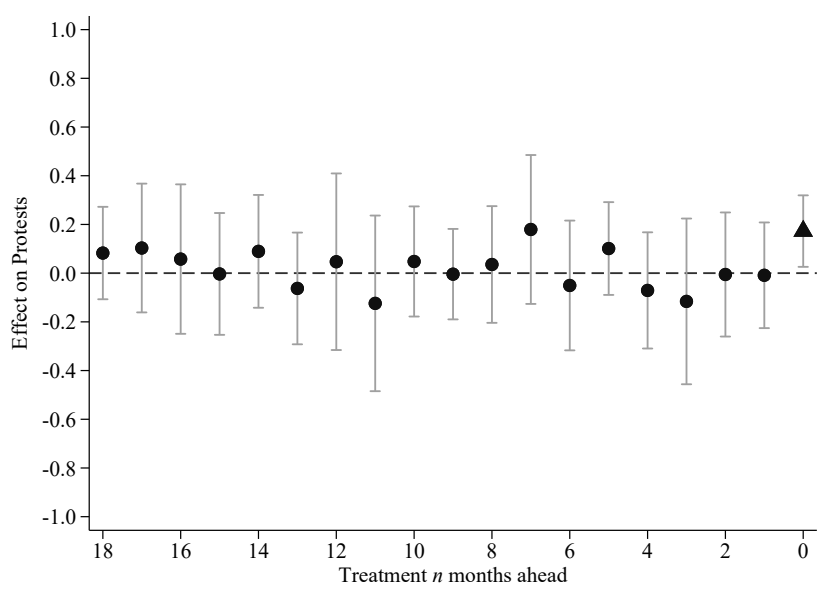

B. Facebook Searches

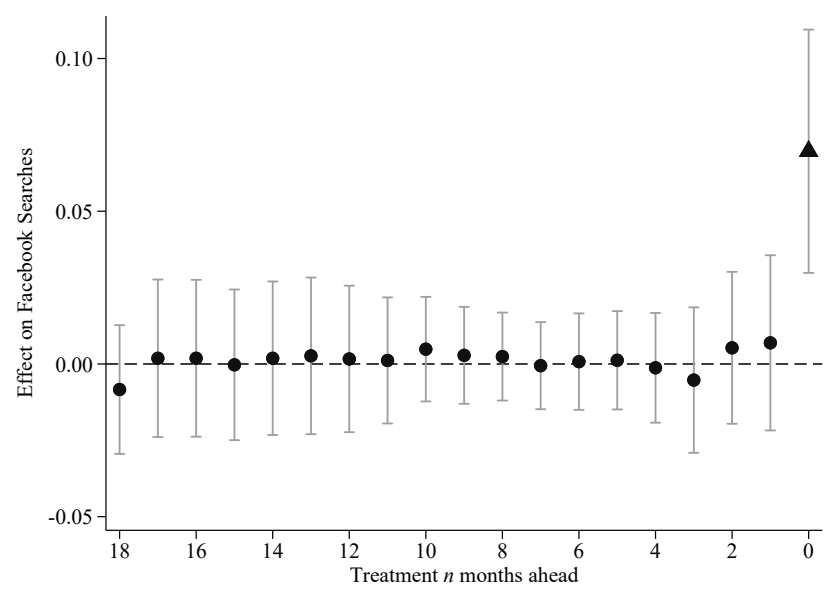

C. Individual protest participation

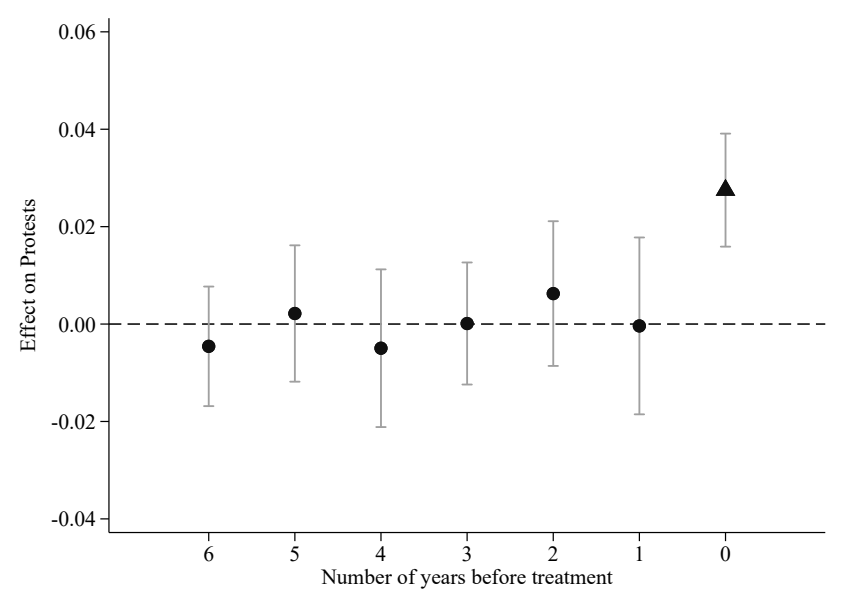

Notes: Estimates of the effect of Facebook Speakers, and its leads, on protests (Panels A and C) and Facebook Searches (Panel B). For all variable definitions and sources, see Appendix Table A-1 Panels A and B extend regression equation (1) to include anticipation effects (leads) of Facebook Speakers ${ }_{c t+n}$, for $n$ ranging from 1-18 months, and Panel C extends equation 5 to include leads of Facebook Speaker $_{c i t+n}$ for $n$ ranging from 1-6 years. Each panel plots the coefficients and $95 \%$ confidence bands for each lead (as marked in the x-axis, and where lead zero is the treatment effect of Facebook Speaker(s)). 


\section{Figure B-3: Parallel Trends in Protests Before Facebook Alternative Approach to Exploring Anticipated Effects of Facebook Speakers}

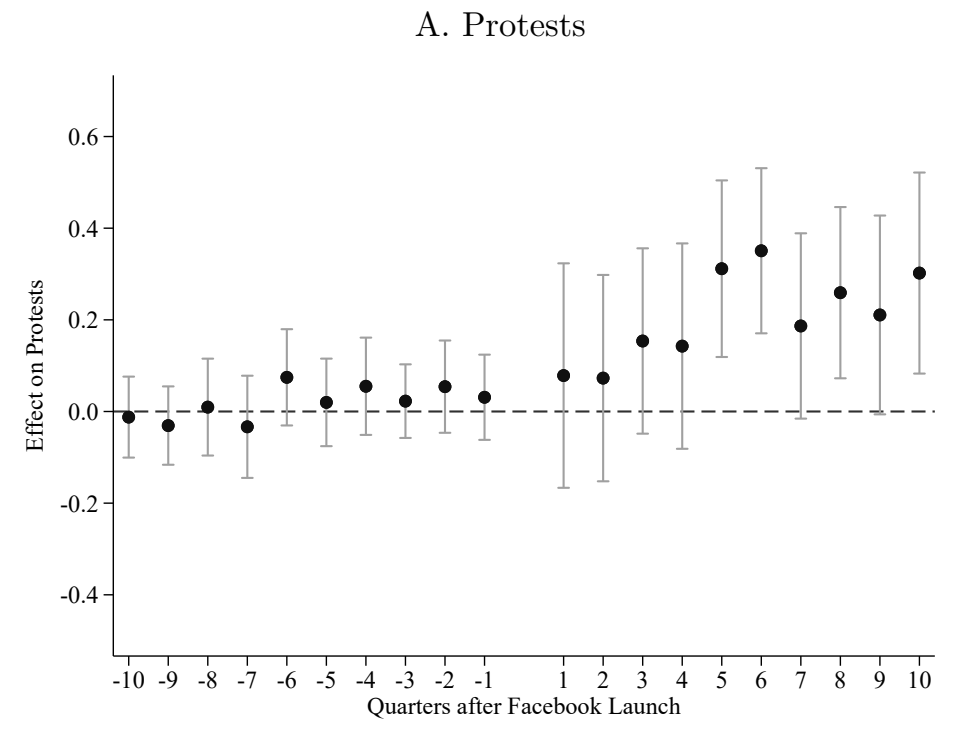

B. Facebook Searches

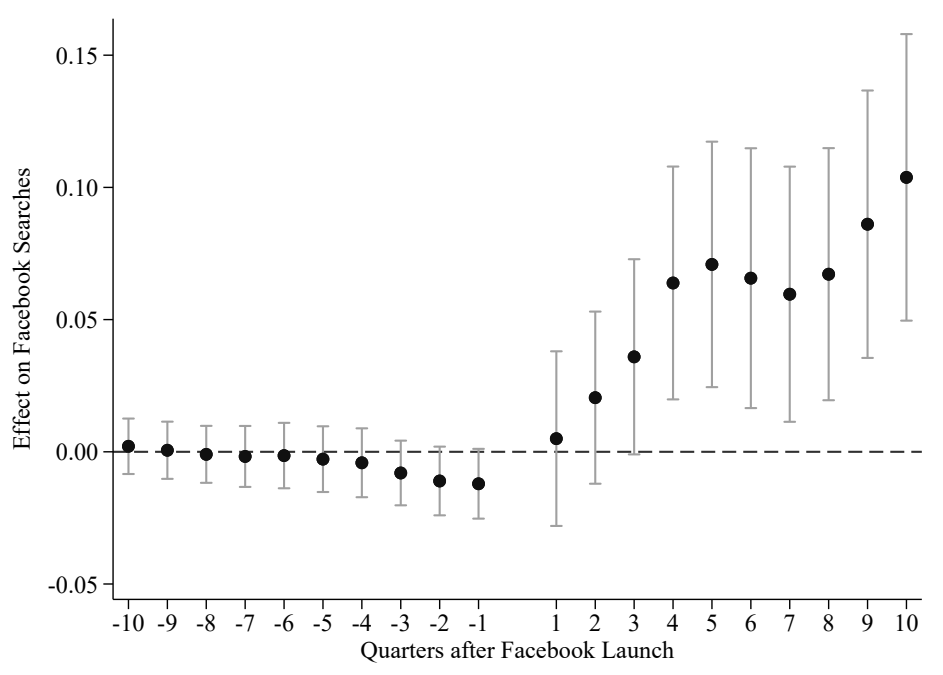

Notes: Each panel presents estimates from a modified version of the baseline regression in equation (1) with the log of one plus protests (Panel A) or Facebook Searches (Panel B) as the dependent variable. For all variable definitions and sources, see Appendix Table A-1 In addition to country and time fixed effects, quadratic country-specific trends, and initial population $\times$ time fixed effects, we include and plot the coefficients for: (a) quarter dummies for the periods leading up to the availability of Facebook in the country's main language (marked with negative integers in the horizontal axis) and (b) quarter dummies after this first adoption interacted with Facebook Speakers (positive integers in the horizontal axis). Coefficients are reported with $95 \%$ confidence bands, allowing for two-way clustered standard errors at the country and month levels. 


\section{Figure B-4: Protests and Facebook Speakers Reverse Causality: Excluding Major Countries}

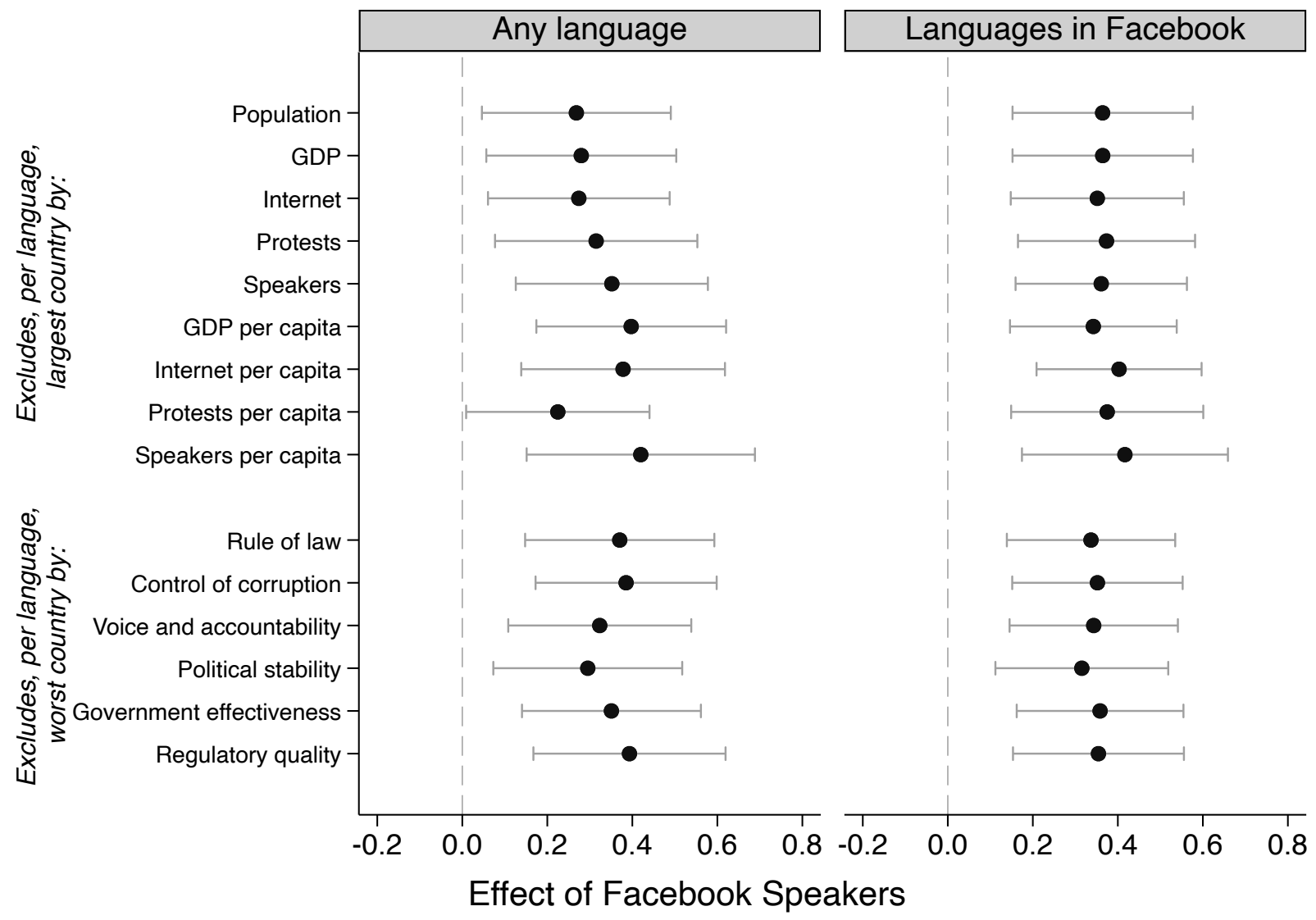

Notes: Estimates of the effect of Facebook Speakers on the log of one plus protests excluding major players. Country-level regressions with monthly data from January 2000 to December 2015. Facebook Speakers is the proportion of people speaking (as a first language) a language available in Facebook in each country and year. For all variable definitions and sources, see Appendix Table A-1. Different dots represent regression in which a different groups of countries is excluded as follows. Per each language, we exclude the largest (or worst) country in terms of the characteristic indicated in the vertical axis (e.g. Population). The figure reports the exercise excluding countries from any language (to the left) and from the subset of languages available in Facebook platforms (to the right). All regressions include country fixed effects, month fixed effects, initial population interacted with time fixed effects, and country-specific quadratic trends. Two-way clustering of standard errors is at the month and country levels. Coefficients are reported with $95 \%$ confidence bands, allowing for two-way clustered standard errors at the country and month levels. 


\section{Figure B-5: The Effect of Facebook Speakers on Protests}

\section{Robustness to Excluding Country Clusters}

Panel A: Excluding each country

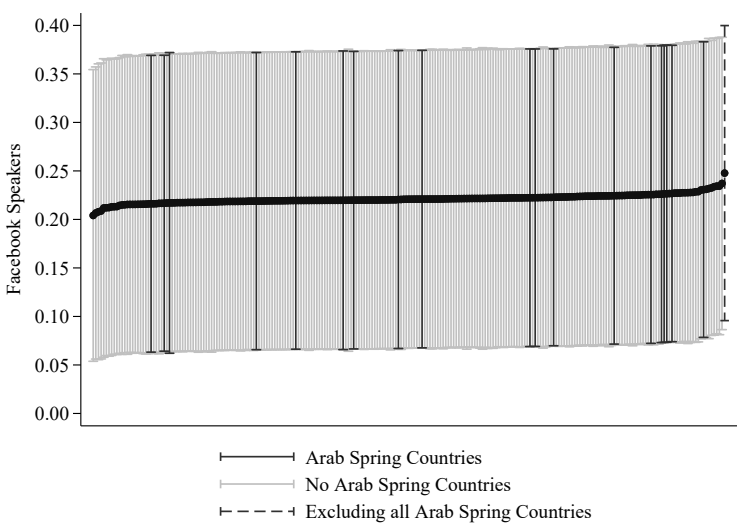

Panel D: Excluding countries by colonizer

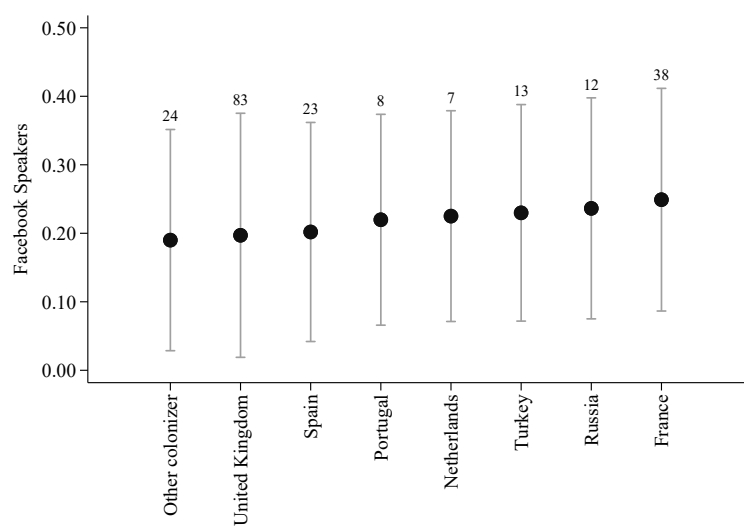

Panel B: Excluding countries by region

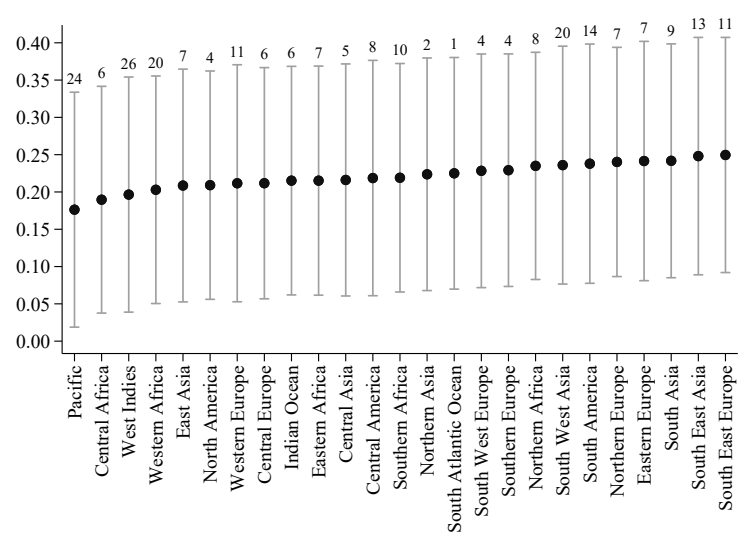

Panel E: Excluding countries by main language

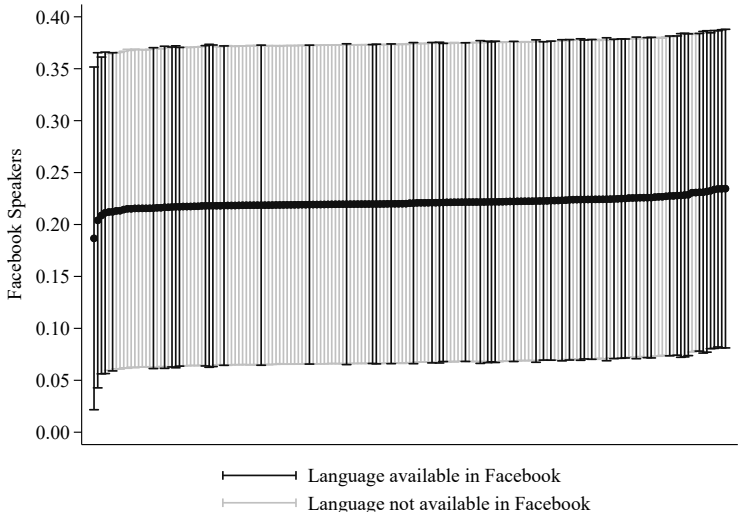

Panel C: Excluding countries by continent

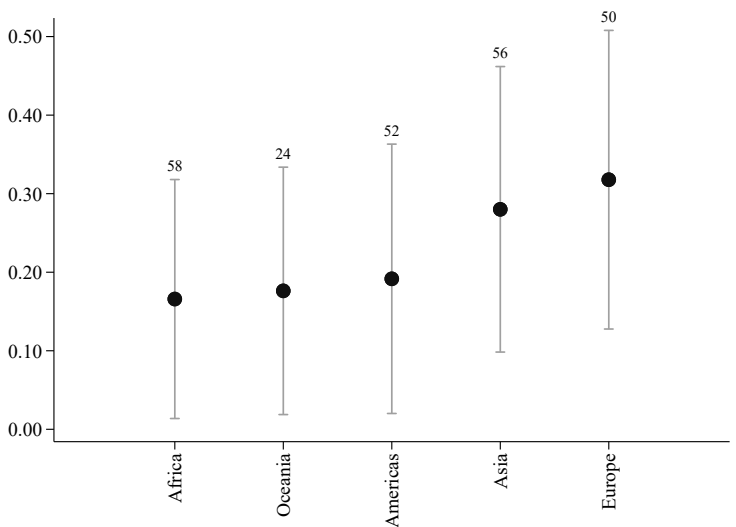

Panel F: Excluding countries by prevalence of their main language

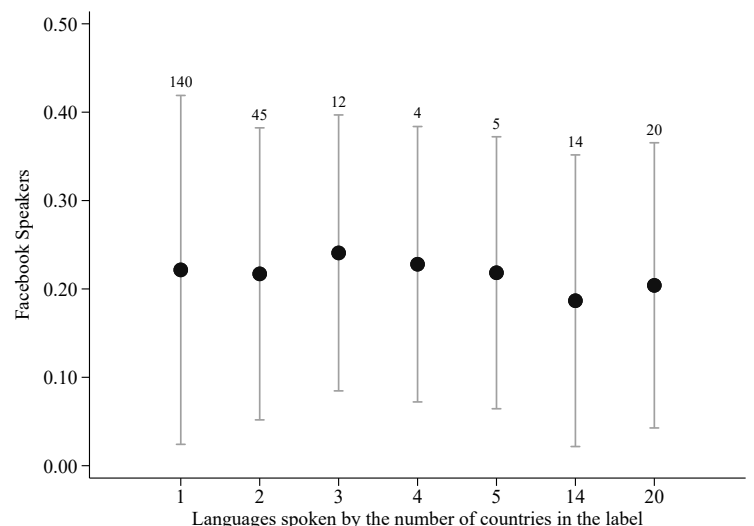

Notes: Estimates of the effect of Facebook Speakers on the log of one plus protests excluding country clusters. Country-level regressions with monthly data from January 2000 to December 2015. Facebook Speakers is the proportion of people speaking (as a first language) a language available in Facebook in each country and year. For all variable definitions and sources, see Appendix Table A-1 Different groups of countries are excluded in each panel as follows: countries (Panel A), regions (Panel B), continents (Panel C), former colonies by colonizer (Panel D), countries having a given main language (Panel E). Panel F excludes countries according to how widespread worldwide each language is: the first bar excludes all countries whose main language is only spoken (as the most popular language) in that country, the second removes all countries whose main language is the most popular language in two countries, and so on. When specified, the number of excluded countries is over each bar. All regressions include country fixed effects, month fixed effects, initial population interacted with time fixed effects, and country-specific quadratic trends. Two-way clustering of standard errors is at the month and country levels. Coefficients are reported with $95 \%$ confidence bands, allowing for two-way clustered standard errors at the country and month levels. 


\section{Figure B-6: The Effect of Facebook Speakers on Protests Heterogenous Effects by Year}

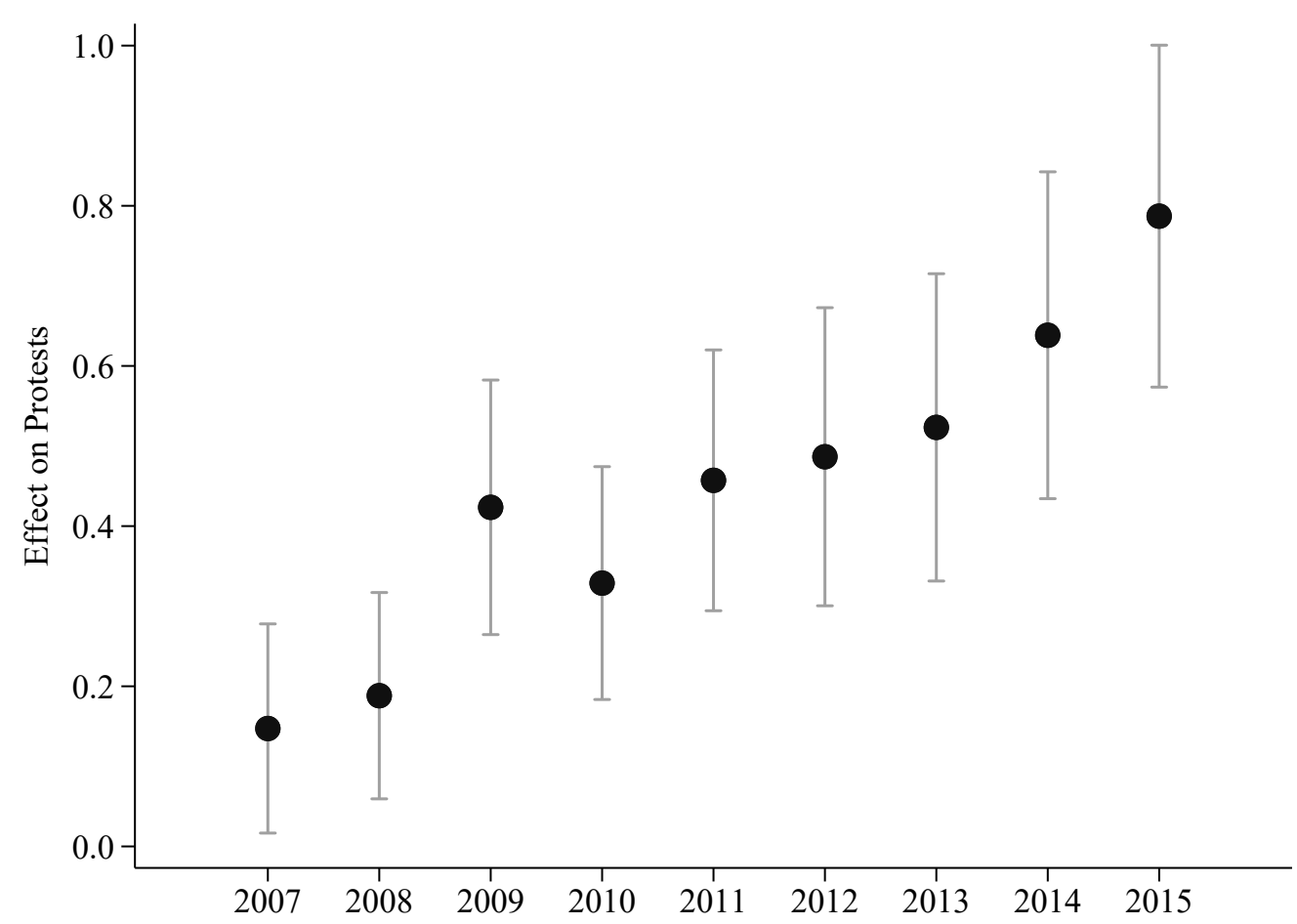

Notes: Estimates of the effect of Facebook Speakers on the log of one plus protests by year. Unit of analysis is a language polygon (region) within a country, with data from January 2000 to December 2015. Facebook Speakers is the share of the population in each region within a country speaking (as a first language) a language already available in Facebook. For all variable definitions and sources, see Appendix Table A-1. The regression includes fixed effects for each country and month, region fixed effects, and initial regional population interacted with month fixed effects. Coefficients are reported with $95 \%$ confidence bands, allowing for two-way clustered standard errors at the country and month levels. 


\section{Figure B-7: Facebook Speakers and Protests by levels of GDP growth}

A. $\log (1+$ protests $)$

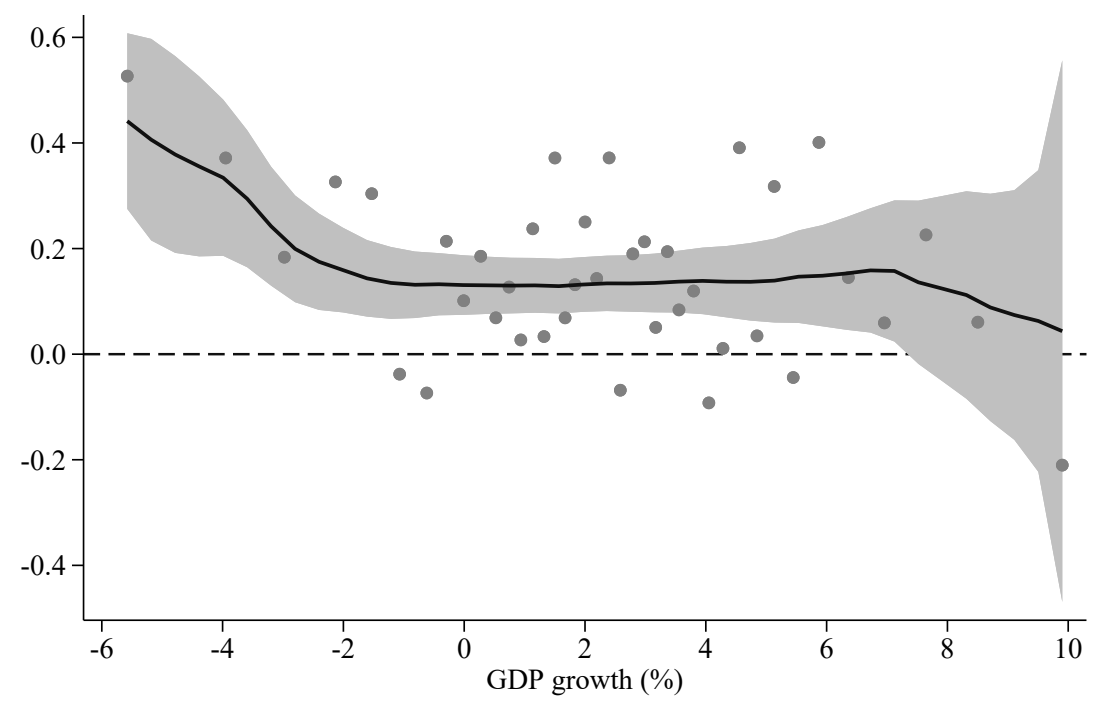

B. Facebook Searches

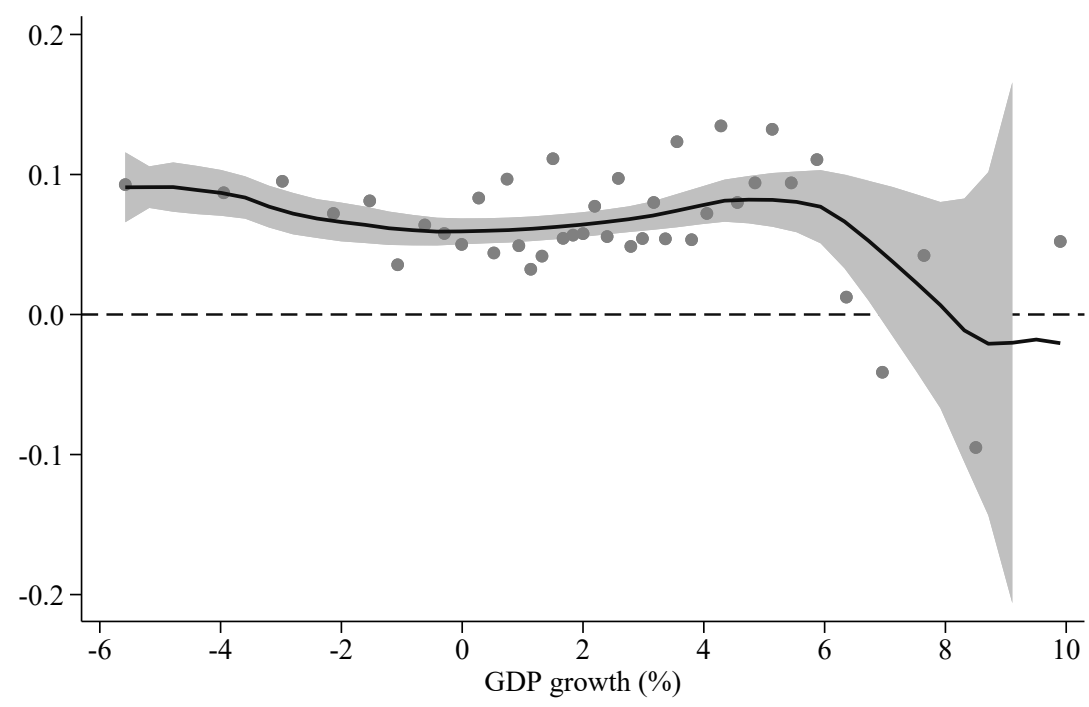

Notes: Estimates of the effect of Facebook Speakers on the log of one plus protests (Panel A) and Facebook Searches (Panel B), at different levels of GDP growth. For all variable definitions and sources, see Appendix Table A-1. We estimate an extended version of regression 1 including interactions of Facebook Speakers with dummies for 40 equally spaced dummies in the distribution of GDP. Point estimates for these interactions are reported as dots. We superimpose a kernel-weighted local polynomial regression where each observation is weighted by the inverse of the square of the standard error of the associated estimate. We use a polynomial of degree zero and an Epanechnikov kernel function, with a "rule-of-thumb" bandwidth for comparability to (Manacorda \& Tesei, 2020). The gray area represents 95\% confidence bands, allowing for two-way clustered standard errors at the country and month levels. 27 
Figure B-8: GDELT vs ACLED:

Differences in Protests and Cumulative Effects of Facebook Speakers

Panel A: Evolution of the number of protests in Africa

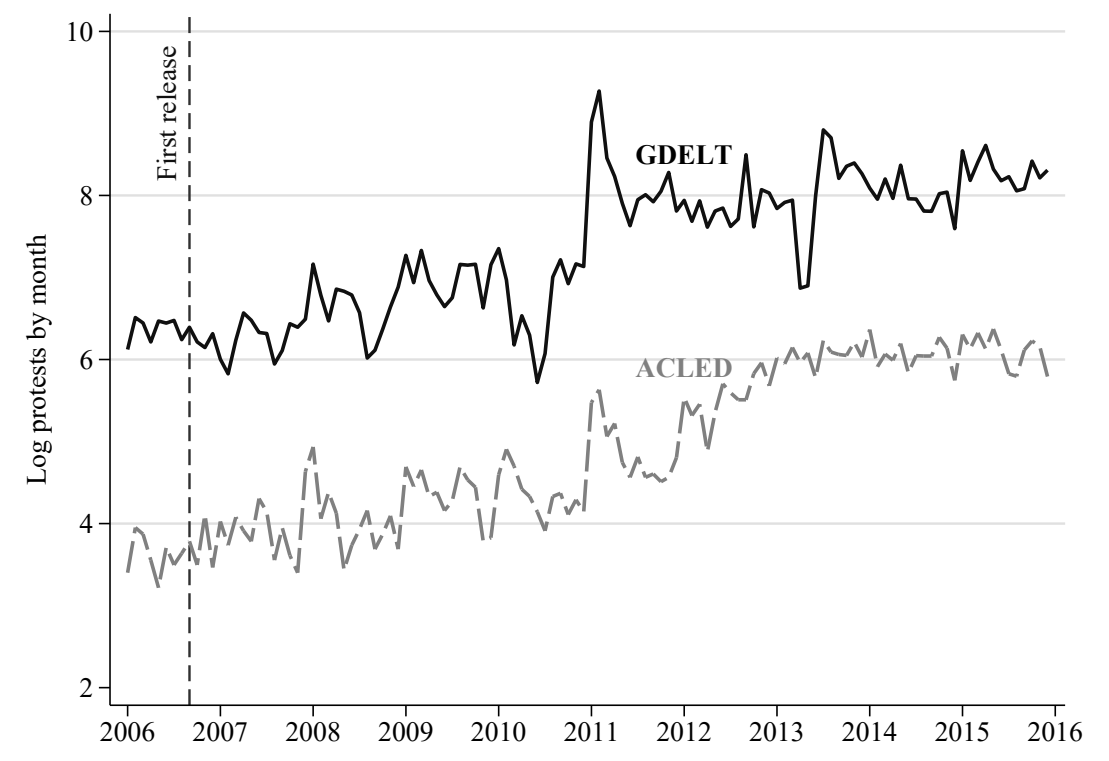

Panel B: Cumulative effect of Facebook Speakers in Africa, GDELT versus ACLED

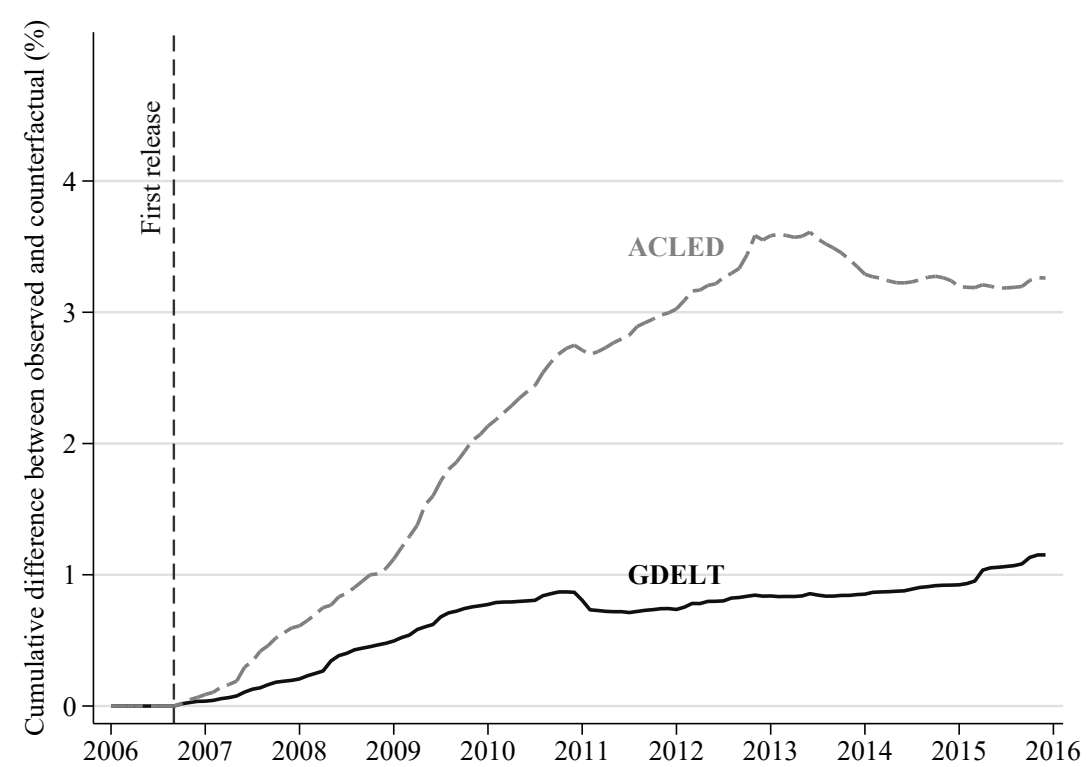

Notes: To construct the counterfactual in Panel B, we estimate the number of protests that would have been observed without Facebook (if Facebook Speakers are held constant at zero throughout the period) as implied by our baseline subnational estimates using each protest database (restricted to Africa where both sources are available). We then depict the cumulative difference since September 2006 (when Facebook first appeared) between protests with and without Facebook (expressed as a percent of total cumulative protests without Facebook up to each time period). For all variable definitions and sources, see Appendix Table A-1. 


\title{
Figure B-9: The Effect of Facebook Speakers on Protests
}

\author{
Panel A. Addressing Spillovers Between Similar Languages
}

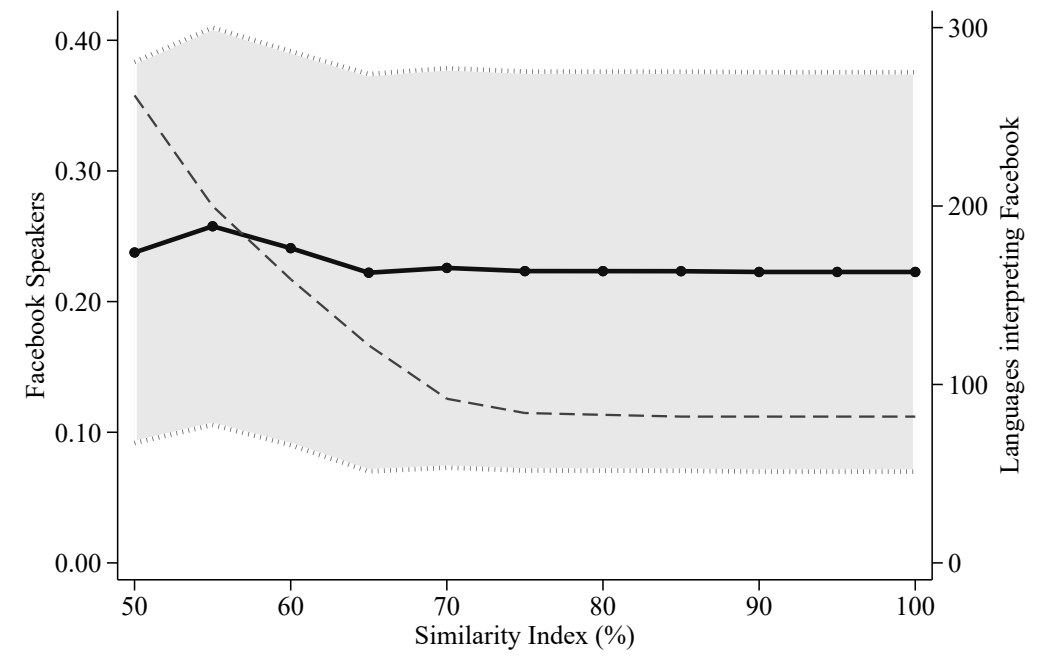

Facebook Speakers ---- Languages interpreting Facebook

Panel B. Differential Effects by Order of Appearance of Corresponding Writing System

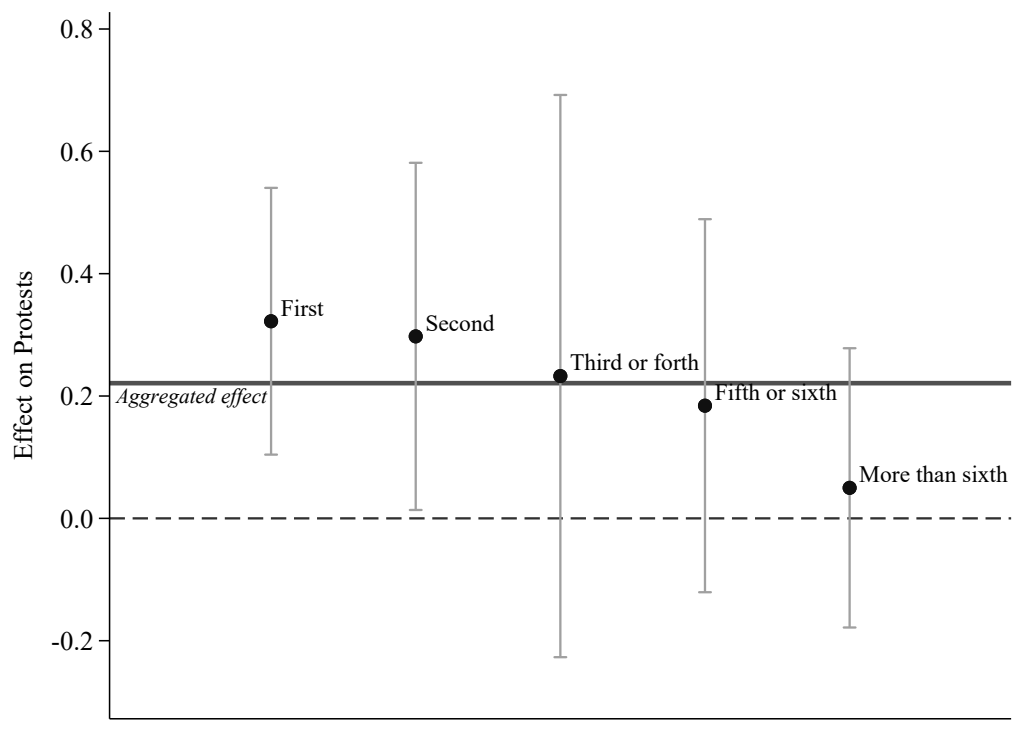

Note: Estimates from regression in equation (1) with country and time fixed effects, quadratic countryspecific trends, and initial population $\times$ time fixed effects. In Panel A, the figure plots the coefficient of Facebook Speakers, modified to assume that when a language version is launched, people who speak similar languages (with a similarity index at least as large as indicated in the horizontal axis) can understand this version. The figure in Panel B breaks down the effect of Facebook Speakers according to the order in which the platforms were launched in each writing system. Let $R_{l}$ be such order/rank. For example, $R_{l}=2$ for platforms/languages such as Spanish, Panjabi or Serbian that were launched second in their corresponding writing system (Latin, Arabic and Cyrillic respectively). They were launched after English, Arabic and Russian for which $R_{l}=1$. Then Facebook Speakers at writing system order "r" can be calculated as Facebook Speakers $_{c, t}^{r}=\left(\sum_{l}\right.$ Facebook $_{t, l} \times$ Speakers $\left._{c, l} \times \mathbb{1}\left\{R_{l}=r\right\}\right)$. The figure reports the coefficient of five subgroups $r$ (1 to 5 and greater than or equal to 6). Since Facebook Speakers ${ }_{c, t}=\sum_{r}$ Facebook Speakers $_{c, t}^{r}$, the total effect of Speakers is a weighted average of the subgroups. For all variable definitions and sources, see Appendix Table A-1. Coefficients are reported with 95\% confidence bands, allowing for two-way clustered standard errors at the country and month levels. 